AN EXPLORATORY STUDY OF

CULTURALLY RESPONSIVE TEACHING PRACTICES

FOR STUDENTS WHO ARE ELLS

\begin{tabular}{c} 
A Dissertation \\
Presented to \\
The Faculty of the Graduate School \\
At the University of Missouri \\
In Partial Fulfillment \\
Of the Requirements for the Degree \\
Doctor of Philosophy \\
\hline SUSHAMA NAGARKAR \\
Brica Lembke, Dissertation Supervisor \\
Dr. Ey
\end{tabular}

JULY, 2011 
(C) Copyright by Sushama Nagarkar 2011

All Rights Reserved 
The undersigned, appointed by the Dean of the Graduate School, have examined the dissertation entitled

AN EXPLORATORY STUDY OF

CULTURALLY RESPONSIVE TEACHING PRACTICES

FOR STUDENTS WHO ARE ELLS

Presented by Sushama Nagarkar

A candidate for the degree of Doctor of Philosophy

And hereby certify that in their opinion it is worthy of acceptance

Associate Professor Erica Lembke

Associate Professor Melissa Stormont

Associate Professor Rebecca McCathren

Assistant Professor Delinda Van Garderen

Assistant Teaching Professor Cheryl Offutt 


\section{DEDICATION}

With humility and gratitude, I dedicate this dissertation to my family. To Yashavant and Shailaja Mahajan, my parents, who with their unquestioning faith, always wholeheartedly supported my every endeavor, however out of the ordinary it may have been. To Aarti and Divya, my lovely and talented daughters; constant reminders that love is truly unconditional. To Anand, my brother, whose dogged determination is inspirational, and Vera, his wife, a staunch advocate for social justice. To Jay, my sister; Asoo, her husband, and Ajit, their son, whose courage and compassion in the face of adversity are incomparable. To Pushpa, my aunt, who has provided support every step of the way. To Ashaita, and Aakil, my niece and nephew whose talents and spirit I admire. To Rohan, whose journey ended too soon to fathom, yet whose footprint is eternal. 


\section{ACKNOWLEDGEMENTS}

As a non-traditional, part-time student, a journey such as this becomes particularly challenging and seemingly monumental. It certainly cannot be undertaken alone. Dr. Erica Lembke, with your skillful guidance and unmatched enthusiasm, you have been my constant support and to you I am indebted.

To Dr. Rebecca McCathren, Dr. Delinda Van Garderen and Dr. Cheryl Offutt, I simply say thank you. You have challenged me to think hard and deep and pushed me to grow as a professional. I am very grateful to Dr. Melissa Stormont for providing me the thoughtful discussions I have needed to develop clarity and a vision of what I wanted to achieve.

To Dr. Janette Klingner, Dr. Cara Richards-Tutor, Dr. Lisa Spanierman, Dr. Russell Gersten and Dr. Robert Rueda. Thank you for taking the time out of your busy schedules to provide me with thoughtful and invaluable feedback.

To Kiero Guerra of the Social Sciences Statistics Center, thank you for your patience. To Janice, thank you for all that you do.

To David, and my fellow doctoral students, I salute you. This would not have been possible without your constant smiles, and encouragement. 


\section{TABLE OF CONTENTS}

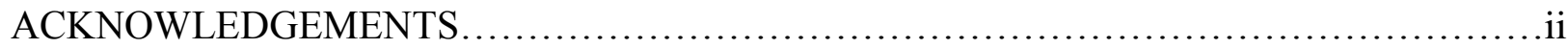

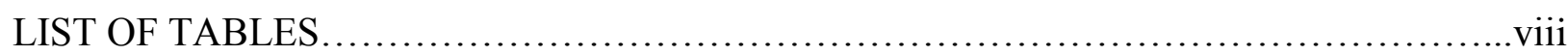

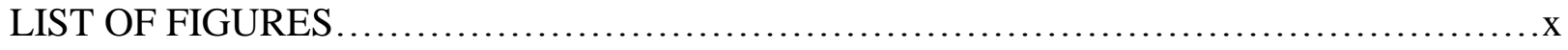

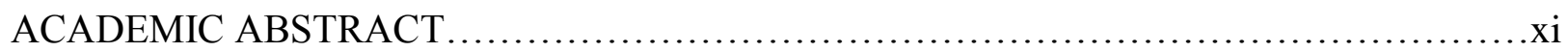

Chapter $\quad$ Page

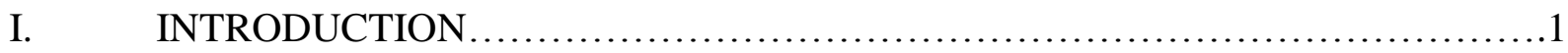

Statement of the problem............................................4

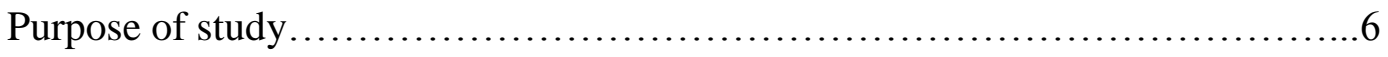

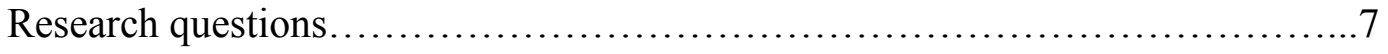

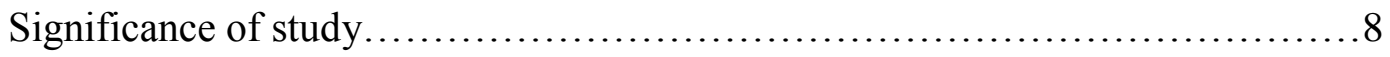

Rationale for study...............................................

Definition of terms.....................................................

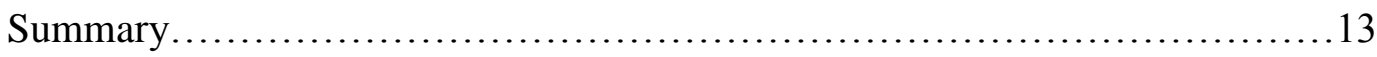

II. $\quad$ LITERATURE REVIEW ............................................... 15

Cultural responsiveness............................................16

Culturally responsive pedagogy................................ 17

Caring................................................ 17

Communication............................................. 18

Curriculum..............................................18

Instruction............................................ 18

Culturally responsive teaching................................... 19 
Teacher characteristics .22

Teacher quality. .26

NCLB.................................................26

Highly qualified..........................................28

Knowledge of second language acquisition processes................ 31

Stages of second language acquisition.......................32

Preproduction stage............................... 32

Early production stage................................32

Speech emergence stage...........................32

Intermediate fluency stage $\ldots \ldots \ldots \ldots \ldots \ldots \ldots \ldots \ldots . \ldots 32$

Advanced fluency stage.............................33

Second language proficiency...................................

Oral language development................................34

Vocabulary development..................................34

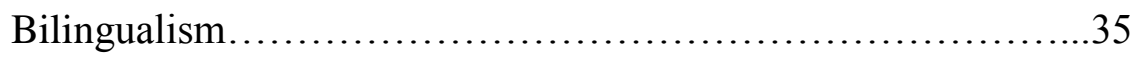

Implications for teachers................................ 37

Professional development in teaching ELLs...........................39

Critical need............................................... 39

Qualities of effective PD...............................41

Attitudes towards and perception of ELLs.......................43

Deficit beliefs........................................44

Orientations towards language diversity....................45

Difference orientation..................................46 
Tapping into funds of knowledge..........................47

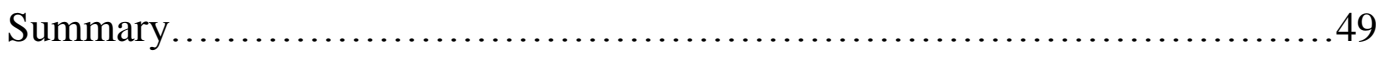

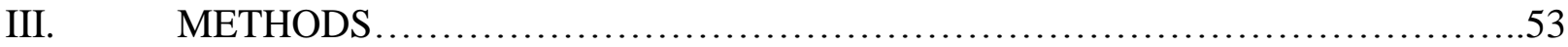

Research questions...............................................53

Research design...................................................57

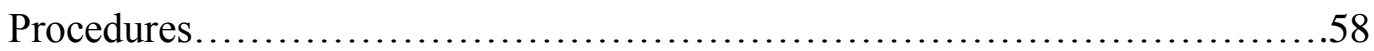

Phase 1: Development of questionnaire............................58

Phase 2: Expert review...................................... 59

Validity..............................................63

Phase 3: Pilot study.........................................63

Knowledge of SLA section..............................66

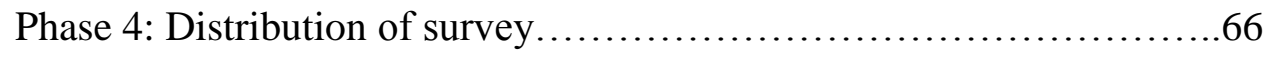

Sampling..............................................66

Coverage..........................................67

Invitation and contact with respondents..............67

Nonresponse........................................69

Measurement.........................................70

Participants........................................... 70

Data Analyses................................................... 74

Dependent variables.......................................... 74

Independent variables....................................... 75

Teacher quality...................................... 75 
Knowledge of second language acquisition..................76

Professional development..................................76

Attitudes towards ELLs................................... 77

Specific Analyses..............................................78

Supplementary research questions.......................80

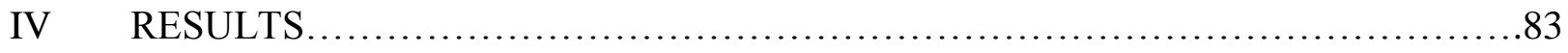

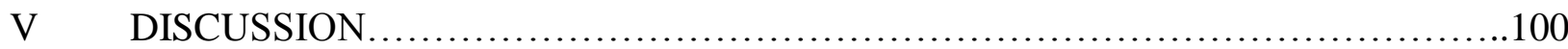

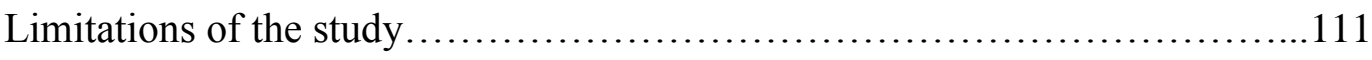

Implications for practice........................................... 112

Implications for future research.................................... 113

Conclusion............................................................. 115

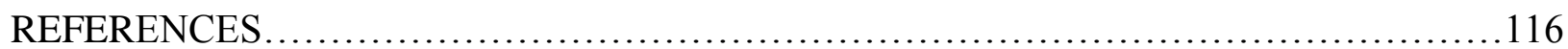

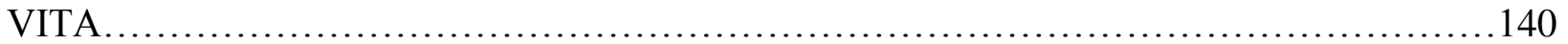




\section{APPENDICES}

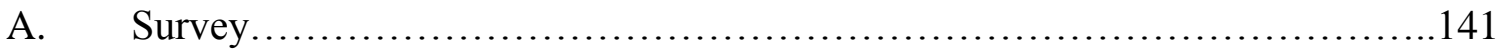

B. Pilot survey................................................... 160

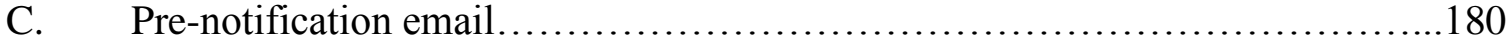

D. Survey link...................................................... 182

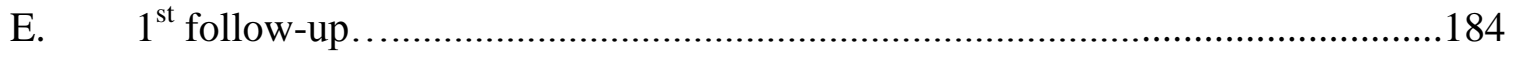

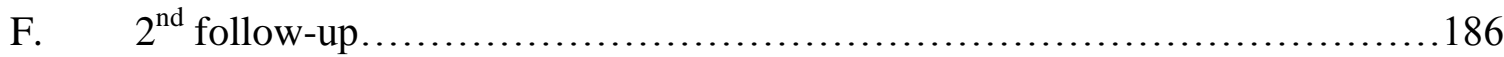

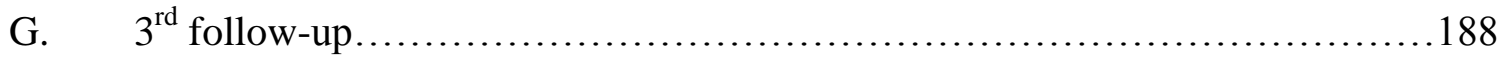

H. Internal consistency of subscale items tables............................ 190

I Verification of the assumptions of the linear regression model................ 194 


\section{LIST OF TABLES}

Table

Page

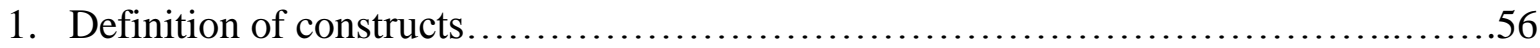

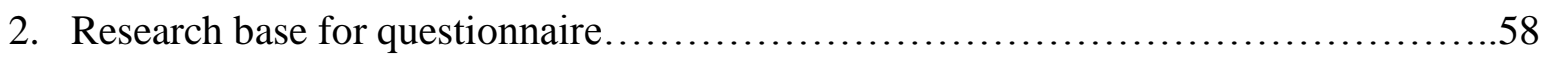

3. Demographics of pilot study participants.................................... 64

4. Comparison of questions between pilot study and final survey $\ldots \ldots \ldots \ldots \ldots \ldots \ldots . \ldots 64$

5. Demographics of sample...............................................67

6. Timelines of survey distribution and follow-up..............................69

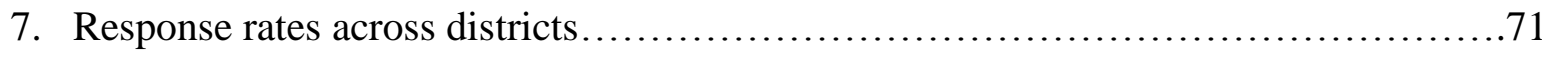

8. Demographic characteristics of respondents by district..........................72

9. Frequency of teachers reported to be highly qualified.......................... 76

10. Descriptives, all respondents, perceived importance of culturally responsive practices......................................................... 84

11. Descriptives, all respondents, reported use of culturally responsive

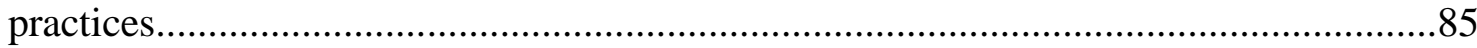

12. Descriptives, all respondents, total professional development....................86

13. Quiz on knowledge of second language acquisition, percent correct responses........88

14. Descriptives, all respondents, attitudes and perceptions towards ELLs ...............89

15. Regression analysis summary for teacher characteristics predicting perceived importance of culturally responsive practices........................................ 91

16. Final regression model predicting perceived importance of culturally responsive practices 
17. Differences in perceived importance of culturally responsive practices between teachers who reported a highly qualified status and those who did not ......................93

18. Regression analysis summary for teacher characteristics predicting reported use of culturally responsive practices............................................... 95

19. Final regression model for predicting reported use of culturally responsive

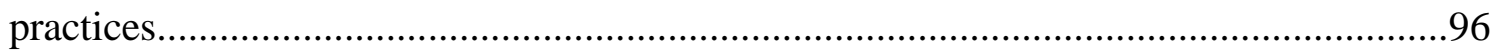

20. Differences in perceived importance of culturally responsive practices between teachers who reported a highly qualified status and those who did not......................97 


\section{LIST OF FIGURES}

Figure $\quad$ Page

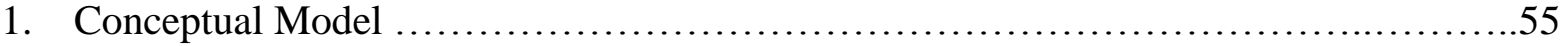




\title{
AN EXPLORATORY STUDY OF CULTURALLY RESPONSIVE TEACHING \\ PRACTICES FOR STUDENTS WHO ARE ELLS
}

Sushama Nagarkar

Dr. Erica Lembke, Dissertation Supervisor

\begin{abstract}
The purpose of this study was to explore whether teacher characteristics such as teacher quality, skills in teaching English language learners (ELLs), knowledge of second language acquisition, and attitudes towards ELLs impacted teachers' perceived importance and reported use of culturally responsive practices within their classrooms. The numbers of ELLs in US classrooms has increased substantially over the past three decades and districts are mandated by federal law to provide these students appropriate high quality instruction for their language learning needs, as well as their academic achievement. Research suggests that teachers need to be culturally responsive while trying to meet the needs of these students (Gay, 2002). This study examined what teacher characteristics contributed to the regular utilization of culturally responsive practices within classrooms. The study was conducted in three school districts in a midwestern state and teachers who chose to participate took an anonymous on-line survey. Findings from the study indicated that the single most important predictor of teachers' perceived importance and reported use of culturally responsive practices in the classroom was teacher attitudes towards ELLs. Professional development proved to be somewhat important for reported use of culturally responsive practices. Additionally, the perceived importance of culturally responsive practices was a strong predictor of reported use of culturally responsive practices.
\end{abstract}


There was a weak relationship between teacher knowledge of second language acquisition and perceived importance of culturally responsive practices. Implications for current practice and future research are discussed. 


\section{CHAPTER I}

\section{INTRODUCTION}

In the past 30 years, the numbers of U.S. students who come from homes in which English is not the primary language spoken and whose cultures are substantially different from that of the schools they attend has grown significantly. As a group, English language learners (ELLs) ${ }^{1}$ represent one of the fastest growing among the school-age population in this nation. During the 2007-08 school year, 4.7 million students were identified as ELLs, and made up ten percent of the school-age population (Boyle, Taylor, Hurlburt \& Soga, 2010). The largest and fastest growing segment of this population is made up of students who immigrated before kindergarten and U.S. born children of immigrants (Capps et al., 2005). Currently, one in five students speaks a language other than English at home, and the majority of these students are learning English as a second language in school (Kindler, 2002).

The ELL population is characterized by significant variability in English proficiency. For instance, as Lesaux (2006) points out there may be some U.S. born kindergarteners who have been exposed to varying amounts of English since birth, while there may be other ELLs who are recent arrivals and have had uninterrupted schooling in their native language and adequate educational preparation, including native language and literacy skills. Another group of ELLs within the U.S. schools are those who are recent arrivals with limited or considerable gaps in educational experiences and who may not have developed native language literacy skills to the same extent as peers with

\footnotetext{
${ }^{1}$ In the research literature, the terms Limited English Proficient (LEP) and ELL have both been used. In this research, the term ELL will be used, since the term LEP connotes a deficit or limiting condition.
} 
uninterrupted schooling. From an educational perspective, each of these groups represents a very different learner and context of second language learning.

Many related factors influence academic outcomes for ELLs. These include educational history, cultural and social background, length of exposure to the English language, and access to appropriate and effective instruction to support second language development (Artiles \& Klingner, 2006; Hamayan, Marler, Sanchez-Lopez \& Damico, 2007). Younger ELLs, unlike their native English speaking peers, are required to acquire a second language while simultaneously developing their first. Depending on their early experiences (or lack thereof), ELLs develop literacy in English at varying rates. There is an unfortunate persistent underachievement of many ELLs in U.S. schools (Klingner, Artiles, \& Barletta, 2006); one of the reasons being that the intersection of second (or third) language development and literacy acquisition in that language is not clearly understood (Genesee, Lindholm-Leary, Saunders, \& Christian, 2006).

Thus a major challenge to districts is to provide adequate instruction to students as they are in the process of acquiring a new language and also need to learn to read and write in it. The majority of ELLs who struggle academically exhibit reading difficulties (Klingner \& Edwards, 2006) and several studies have indicated that these students demonstrate lower reading achievement in English than their native English speaking peers (August \& Shanahan, 2006; Slavin \& Cheung, 2003). Ironically this is occurring at a time when Public Law 107-100, the No Child Left Behind Act of 2001 (NCLB, 2001) continues to demand improvement in reading achievement for all subgroups of students including ELLs.

NCLB (2001) mandates that school districts must hold the same high standards 
for ELLs ${ }^{2}$ as for all other students; meaning that ELLs have to be included in annual state assessments, be subject to annual assessments of English language proficiency (ELP), and be included in reporting of Adequate Yearly Progress (AYP) performance targets. The federal legislation has made very clear that the needs and progress of ELLs are as important as any other sub group. However, the diversity among ELLs in terms of their education history, level of literacy, background experiences, socio-cultural practices, and socioeconomic status pose challenges to states as they try to meet the accountability requirements of NCLB. The current reality is that many ELLs continue to score below basic levels of academic proficiency (NCES, 2009). In addition, ELLs drop out of high school at rates higher than their English speaking peers (Ballantyne, Sanderman, \& Levy, 2008; Cataldi, Laird, \& Kewalramani, 2009).

Another major challenge to districts is the over-identification of students with linguistic and cultural differences for special education services in some categories of disabilities. This over-identification tends to occur primarily in the categories of Specific Learning Disabilities, Speech/Language Impairments or intellectual disabilities (Zehler et al., 2003). Often, ELLs exhibit academic failure in the classroom, leading educators to make referrals for special education evaluations and services. Ortiz and Garcia (1995) enumerate several sources of concern with the identification and assessment processes. For example, the researchers write that while characteristics of second language learners

\footnotetext{
${ }^{2}$ Under NCLB (2001), if a student (a) is age 3 to 21 years; (b) is enrolled or preparing to enroll in elementary or secondary school; (c) was not born in the U.S. or whose native language is not English; (d) is a Native American, Alaskan Native, or a resident of outlying areas; (e) comes from an environment in which a language other than English has had a significant impact on an individual's English language proficiency (ELP); (f) is migratory and comes from an environment where English is not the dominant language; and (g) has difficulties in speaking, reading, writing, or understanding the English language that may deny the individual the ability to meet the state's proficient level of achievement, to successfully achieve in classrooms where English is the language of instruction, or to participate fully in society, then he or she would fall into this category of learners.
} 
and those with language disorders are often similar, teachers are unable to distinguish between typical linguistic development and processing disorders associated with learning disabilities. According to Ortiz and Garcia, language proficiency evaluations are often inadequate, resulting in inappropriate referrals. Citing results from a small quasiexperimental study, Layton and Lock (2002) posit that training in the second language acquisition process and appropriate evaluation techniques are critical to improving a teacher's ability to discern the subtle differences between typical language development and the presence of possible learning disabilities.

\section{Statement of the Problem}

Every year increasing numbers of teachers who have not had any special training in teaching ELLs are faced with the challenge of educating these students (Gandara \& Rumberger, 2006). These are teachers mandated to be highly qualified under NCLB (2001), meaning that they are required to have at a minimum (a) a bachelor's degree, (b) state certification or licensure, and (c) competence in the core subject areas they teach and yet for the most part have not developed the necessary skill set to teach ELLs (Gandara, Maxwell-Jolly, \& Driscoll, 2005). While a strong and supportive learning environment is a necessary prerequisite for ELLs to demonstrate successful second language acquisition and academic achievement, even the most committed teachers cannot provide high quality education without appropriate skills and knowledge. Hamayan et al. (2007) propose that general education teachers may use inappropriate strategies and assessments that have been designed and implemented with monolingual learners. 
Thus, to the uninformed teacher, an ELL's apparent inability to learn English quickly may be seen as a sign of a learning disability or a lack of aptitude for learning a second language (de Jong \& Harper, 2005). There is a strong tendency among teachers to quickly try to determine whether the cause of an ELL's difficulty is a disability, without providing adequate opportunities to learn (Hamayan et al.). Other researchers in the area of ELL (Rhodes, Ochoa \& Ortiz, 2005) write that teachers of ELLs often have referral concerns that are more related to language and cultural factors, than to evidence of a disability; a lack of knowledge of cultural factors and second language acquisition processes are contributing factors to the tendency among teachers to refer ELLs to special education. The reality is that the ability of schools to achieve equal access to quality education for all students depends, as Phuntsog (2001) points out, on teachers being prepared to create multiple learning environments for meeting the varying experiences, needs and interests of all students from culturally and linguistically diverse backgrounds.

In order to teach diverse learners more effectively, Gay (2002) recommends that teachers use cultural characteristics and experiences of the students themselves. Culturally responsive models require teachers and administrators to have a good understanding of their students' communicative styles and literary experiences (Klingner \& Edwards, 2006) and to have specific knowledge of cultural similarities and differences. Hamayan et al. (2007) suggest that teachers should assess ELLs' abilities to function within the school culture in order to recommend appropriate culturally responsive interventions for those who are experiencing difficulty. Effective teaching practices for ELLs are best implemented by teachers who acquire additional linguistic and cultural knowledge and skills and learn to apply these to curriculum planning, pedagogy, and 
assessment for ELLs (de Jong \& Harper, 2005). Additionally as Nieto (2000) notes, teaching ELLs successfully is also about changing one's own attitudes about ELLs and their families and communities.

In sum, the constellation of teacher characteristics important to teaching ELLs effectively, include having knowledge of second language acquisition processes, skills in using a variety of methodologies, positive attitudes towards and beliefs that ELLs can be successful learners, and being able to implement culturally responsive teaching practices. These are the focal points of this study. The study is based on teachers self-report because reflection and willingness to think through one's own attitudes, beliefs and behaviors is critical to developing a culturally responsive pedagogy (Howard, 2003); a pedagogy that encompasses the belief that students from all diverse are capable learners (LadsonBillings, 1994).

\section{Purpose of the Study}

The purposes of this study are threefold. The first purpose is to explore whether specific teacher characteristics are related to the perceived importance of culturally responsive practices within classrooms. The second purpose is to explore whether specific teacher characteristics are related to reported use of culturally responsive practices within classrooms. The third is to examine the relationship between reported implementation of culturally responsive teaching practices and their perceived importance as reported by teachers. These purposes lead to the research questions for this study. 


\section{Research Questions}

1. Are specific teacher characteristics associated with the perceived importance of culturally responsive teaching practices for ELLs within the classroom setting as measured by a self-report questionnaire?

a. Is there a relationship between No Child Left Behind indicators of teacher quality and teachers’ perceived importance of culturally responsive teaching practices for ELLs within the classroom setting?

b. Is there a relationship between knowledge of second language acquisition and teachers' perceived importance of culturally responsive teaching practices for ELLs?

c. Is there a relationship between the amount of professional development on teaching ELLs and teachers' perceived importance of culturally responsive teaching practices for ELLs?

d. Is there a relationship between teachers' attitudes towards and perceptions of ELLs and teachers' perceived importance of culturally responsive teaching practices for ELLs?

2. Are specific teacher characteristics associated with the reported use of culturally responsive teaching practices for ELLs within the classroom setting as measured by a self-reported questionnaire?

a. Is there a relationship between No Child Left Behind indicators of teacher quality and teachers' reported use of culturally responsive teaching practices for ELLs within the classroom setting? 
b. Is there a relationship between knowledge of second language acquisition and teachers' reported use of culturally responsive classroom teaching practices for ELLs?

c. Is there a relationship between the amount of professional development on teaching ELLs and teachers' reported use of culturally responsive classroom teaching practices for ELLs?

d. Is there a relationship between teachers' attitudes towards and perceptions of ELLs and teachers' reported use of culturally responsive classroom teaching practices for ELLs?

3. How do teachers' overall perceived importance ratings for culturally responsive teaching practices correlate with overall reported implementation ratings as measured by a self-report questionnaire?

\section{Significance of the Study}

The number of ELLs enrolled in US schools is growing exponentially (Kindler, 2002) and will comprise 40 percent of elementary and secondary students by the year 2030 (U.S. Census Bureau). ELLs are currently not performing at par with their native English speaking peers on measures of academic achievement (NAEP, 2009) and their high school drop-out rate is high (Ballantyne et al., 2008). In addition, ELLs are being inappropriately identified as having disabilities (Artiles \& Ortiz, 2002; Artiles, Rueda, Salazar, \& Higareda, 2005; Zehler et al., 2003).

Currently all teachers, whether they are regular educators, special educators, or bilingual/ESL teachers, are being challenged to accommodate these students. They are 
required to do this by the federal mandate of NCLB, which requires districts to adequately meet ELLs’ educational needs in terms of academic achievement as well as English language development. There is a growing consensus that teachers require additional skills including an understanding of second language development, the role of language and culture, and the nature of language proficiency (Flynn \& Hill, 2005). Teachers have to be able to understand the implications of linguistic differences and seek out resources to improve their own instructional programs (Griffiths, 2007; Spinelli, 2008). In addition, teachers need to be aware of their own attitudes towards linguistic and cultural diversity, which are as important as their skills and competencies (Brisk, 1998).

In sum, meeting the needs of linguistically and culturally diverse populations requires a deeper understanding of the interaction of a student's language and culture because as Garcia (2009) suggests, without attending to the distinctiveness of the contribution of culture, educational endeavors for diverse students are likely to fail. Moreover, as Garcia, Arias, Murri, and Serna (2010) point out; there is a demographic imperative to do it.

\section{Rationale for the Study}

Relatively few studies have examined teacher characteristics as related to student outcomes for ELLs. In 1993, according to a survey of a nationally representative sample of school districts, only 55 percent of teachers of ELLs had received recent professional development through in-services related to the instruction of these students or had taken college courses relevant to delivering effective instruction (Fleischman \& Hopstock, 1993). Eight years later in 2001, NCLB required that all students be taught by teachers who were highly qualified. But the law failed to provide specific mandates or guidance 
for the preparation of teachers to meet the needs of ELLs (Cadeiro-Kaplan \& Rodriguez, 2008) apart from mandating that ELLs be taught by language teachers who are highly qualified; they need to be "fluent in English and any other language used for instruction, including having written and oral communication skills” (Title III, Part A, sec 3116 [c]). Research indicates that teachers who are highly qualified may become better equipped to teach an increasingly diverse student body by availing themselves of appropriate professional development experiences (Cadeiro-Kaplan \& Rodriguez, 2008; Gandara et al., 2005; Karabenick \& Noda, 2004) and by developing a knowledge base about second language acquisition processes (Antunez, 2002). Another set of teacher characteristics, that are salient to research conducted within the educational context, are teachers' attitudes and beliefs. As Ajzen (2001) explains, behaviors are better understood and predicted from one's attitudes. However, at this time, there is a paucity of research concerning teacher attitudes toward ELLs (Youngs \& Youngs, 2001).

Research suggests that ELLs need to receive culturally responsive, appropriate, high quality instruction (Klingner \& Harry, 2006) that is delivered in such a manner that students can draw on their prior knowledge and build new concepts on their experiential foundation (Flynn \& Hill, 2005). However not enough is known about what impacts teachers' implementation of culturally responsive practices in the classroom. With respect to students who are ELLs, there is the need to consider second language issues as well as teachers' attitudes towards diverse languages and cultures. Additionally it is imperative to know whether teachers who have sought out professional development opportunities are able to be more responsive to the needs of ELLs. This study is an 
endeavor to explore whether these characteristics are related to the implementation of culturally responsive practices as they pertain to ELLs.

\section{Definition of Terms}

BICS: An acronym for basic interpersonal communication skills. The language ability required for verbal face-to-face communication (Office for Civil Rights, n.d., Developing Programs for English Language Learners).

CALP: An acronym for cognitive academic language proficiency. The language ability required for academic achievement (Office for Civil Rights, n.d., Developing Programs for English Language Learners).

Comprehensible Input: An explanation of language learning that maintains that language acquisition is a result of learners being exposed to language constructs and vocabulary that are slightly beyond their current level. This "input" is made comprehensible to students by creating a context that supports its meaning (Krashen, 1981).

Culturally Responsive Classrooms: Classrooms that specifically acknowledge the presence of culturally diverse students, recognize the need for these students to find connections among themselves and with the subject matter being taught and where teachers recognize the differing learning styles of their students and develop instructional approaches that accommodate these styles (Montgomery, 2001).

Culturally Responsive Teaching: Using the cultural characteristics, experiences, and perspectives of ethnically diverse students as conduits for teaching them more effectively (Gay, 2002).

English Language Learner (ELL): A national-origin-minority student who is limited English-proficient. This term is often preferred over limited English-proficient (LEP) as it 
highlights accomplishments rather than deficits (Office for Civil Rights, n.d., Developing Programs for English Language Learners).

ELD: English language development (ELD) means instruction designed specifically for English language learners to develop their listening, speaking, reading, and writing skills in English. This type of instruction is also known as "English as a second language" (ESL), "teaching English to speakers of other languages" (National Clearinghouse for English Language Acquisition and Language Instruction Educational Programs, n.d., Glossary of Terms).

$E L P$ : English language proficiency is the ability to use English to ask questions, to understand teachers, and reading materials, to test ideas, and to challenge what is being asked in the classroom.. (Adapted from Council of Chief State School Officers,1992). Highly Qualified Teachers: A teacher who: has at least a bachelor’s degree; has demonstrated content expertise by passing a state-approved test or has completed an academic major or coursework equivalent to a major; and who holds full certification for his or her current teaching assignment (Missouri Department of Elementary and Secondary Education, n.d. definition of terms).

L1: Represents the first language (native language) that a child first speaks (National Clearinghouse for English Language Acquisition and Language Instruction Educational Programs, n.d., Glossary of Terms).

L2: Represents the second language that a child speaks (National Clearinghouse for English Language Acquisition and Language Instruction Educational Programs, n.d., Glossary of Terms). 
Language Acquisition: The term, often used interchangeably with language learning process, is acquiring a first or second language. Some linguists distinguish between acquisition and learning of a second language, using the former to describe the informal development of a person's second language and the latter to describe the process of formal study of a second language. Other linguists maintain that there is no clear distinction between formal learning and informal acquisition. The process of acquiring a second language is different from acquiring the first (Baker, 2000).

Language Proficiency: Refers to the degree to which the student exhibits control over the use of language, including the measurement of expressive and receptive language skills in the areas of phonology, syntax, vocabulary, and semantics and including the areas of pragmatics or language use within various domains or social circumstances. Proficiency in a language is judged independently and does not imply a lack of proficiency in another language (Office for Civil Rights, n.d., Developing Programs for English Language Learners).

Sheltered English Instruction: An instructional approach used to make academic instruction in English understandable to ELL students. In the sheltered classroom, teachers use physical activities, visual aids, and the environment to teach vocabulary for concept development in mathematics, science, social studies, and other subjects (Office for Civil Rights, n.d., Developing Programs for English Language Learners).

\section{Summary}

As the numbers of ELLs enrolling in schools continue to grow, there is a critical need to understand these students' linguistic and cultural differences and use them to foster academic success (Cadiero-Kaplan \& Rodriguez, 2008). Given the diversity within 
the population, teachers struggle with providing effective instruction that is culturally responsive. There is evidence in the literature that many ELLs are performing poorly on measures of academic achievement, being disproportionately represented on special education rosters (Artiles \& Ortiz, 2002; Artiles et al., 2005; Ortiz \& Garcia, 1995;

Zehler et al., 2003) and dropping out of schools at higher rates that their English speaking counterparts (Ballantyne et al., 2008). This study seeks to explore whether specific teacher characteristics relate to the perceived importance of and reported implementation of culturally responsive teaching strategies within classrooms. 


\section{CHAPTER II}

\section{LITERATURE REVIEW}

The demographic reality of today’s schools is that there are growing numbers of ELLs in all classrooms and mainstream teachers are increasingly responsible for providing most of the instruction to these students (Capps et al., 2005). In order for these students to succeed in school, researchers advocate for the use of culturally responsive teaching practices (Cartledge \& Kourea, 2008; Gay, 2002) although, as Fillmore and Snow (2000) point out, too few teachers understand these students' cultural or linguistic backgrounds or the inherent challenges students face in learning to simultaneously speak and read in English. Teachers may be ill-equipped because they have not had welldesigned professional preparation for these challenges (Garcia et al., 2010), do not have a knowledge base of the process of second language acquisition (Crawford \& Krashen, 2007), and have uncertain attitudes and beliefs about ELLs (Ballantyne et al., 2008).

Yet teachers have to successfully teach all students in an era of increased accountability under NCLB (2001), a law that mandates high quality instruction by teachers who are highly qualified. In sum, while NCLB provides the milieu for current education practices, it is essential for teachers to accommodate diverse learners through culturally responsive practices within their classrooms. There are likely to be a variety of staff needs to increase cultural responsivity, including adjustments in pedagogy, capacity building for collaborative work, improved skills in identifying and addressing varying learning styles, and training in ELL instructional methods (Cadeiro-Kaplan \& Rodriguez, 2008). 
For teachers the importance of cultural responsiveness and whether they make an effort to provide instruction that is culturally relevant depends on several factors. The more salient of these relate to teacher attitudes and beliefs about linguistically and culturally diverse learners as well as whether they have knowledge as to the process of second language development, and whether they have sought out opportunities to improve their skills in teaching ELLs (Paradis, Genesee \& Crago, 2010; Reeves, 2006; Youngs \& Youngs, 2001. The federal law requires teachers to be highly qualified, but that may not necessarily mean that they are competent to teach ELLs using culturally responsive instruction. The present study seeks to examine whether the teacher characteristics described above impact the utilization of culturally responsive teaching practices that are recommended in the research literature (Cartledge \& Kourea, 2008; Klingner \& Harry, 2006).

This review of related literature begins with an exploration of the research on cultural responsiveness and then examines the literature on the teacher characteristics that are relevant to the present study: highly qualified status as defined by NCLB (2001), level of knowledge of second language acquisition processes, participation in professional development in teaching ELLs, and attitudes towards and perceptions of ELLs.

\section{Cultural Responsiveness}

For students from diverse background, learning is enhanced when it occurs in contexts that are linguistically and culturally meaningful and relevant to them (Lee, 2003). According to researchers (Gay, 2000; Noel, 2008; Richards, Brown \& Forde, 2006; Villegas, 1991), culturally responsive teaching originates from the notion of 
culturally responsive pedagogy, a framework that recognizes learning as occurring differently across cultures and yet facilitating and supporting the achievement of all students. The underlying belief is that schools are agents in the promotion of a more equitable and just society and therefore academic inequities are addressed by teaching through students’ cultural backgrounds and prior experiences.

\section{Culturally Responsive Pedagogy}

Richards et al. (2006) explain that the broad framework of culturally responsive pedagogy is comprised of three dimensions: (a) institutional, (b) personal, and (c) instructional. The institutional dimension reflects the administration and its policies and values. For example, when the institution is responsive to diverse needs, there is a strong focus on ensuring that allocation of resources such as quality teachers and planning of physical spaces is equitable across all schools. The personal dimension refers to the cognitive and emotional processes teachers must engage in to become culturally responsive. The instructional dimension includes materials, strategies, and activities that form the basis of instruction. Gay (2000) describes four necessary components for the practice of culturally relevant pedagogy: caring, communication, curriculum and instruction. These parallel the personal and instructional dimensions of Richards, Brown and Forde's framework.

Caring. The first component of Gay's framework relates to teacher attitudes, expectations and behaviors about students' human value, intellectual capability and performance responsibilities. Gay suggests that teachers need to examine their own current attitudes and behaviors and how these may impact student achievement. Teachers are in charge of classrooms; teachers control interactions and decide who will participate 
in what activities. Gay believes that such decisions are directly influenced by teacher attitudes towards and expectations for their students.

Communication. The second component requires cultural communication in the classroom. Gay writes that communication is strongly culturally influenced, situated in experiences and consists of a dynamic set of skills. The implications are that the more that the teachers know about the discourse styles of ethnically and linguistically diverse students, the more they will be able to improve academic achievement. Thus situations where students may know more than they are able to communicate and or where they may be communicating more than teachers are able to discern, might be avoided.

Curriculum. The third component requires teachers to incorporate culturally diverse content in the curriculum. Gay writes that curriculum sources that provide accurate representations of diversity help to clear myths for those students who have never had close personal contact with diverse students and enhances participation and active involvement from diverse learners.

Instruction. The fourth component, as highlighted by Gay, emphasizes establishing congruence between different aspects of the learning processes of diverse students and the strategies of instruction used by the teacher. Teachers accept and use the cultural knowledge and skills of diverse learners as valuable teaching and learning resources and use them as scaffolds towards increasing achievement. Villegas (1991) cautions that there are no specific prescriptions for culturally responsive pedagogy and that teachers have an ethical responsibility to seek out information about the communities represented in their classrooms and to find ways of using that information in their teaching. 


\section{Culturally Responsive Teaching}

Gay (2002) defines culturally responsive teaching as using the cultural characteristics, experiences, and perspectives of ethnically diverse students as conduits for teaching them more effectively. This translates to making the classrooms learnercentered (Richards, et al., 2006) and using, among other techniques, the students' frame of reference so that instruction is meaningful. Gay believes that when instruction is personally relevant, there is a higher interest appeal and material is learned more thoroughly. Other characteristics of culturally responsive teaching include using a wide variety of instructional strategies that are connected to different learning styles, teaching students to know each other's cultural heritages and incorporating multicultural information, resources and materials in all subjects and all skills that are routinely taught in schools (Noel, 2008; Villegas \& Lucas, 2002).

Villegas (1991) specifically identifies five cultural criteria that teachers should strive to acquire in order to instruct effectively in a multicultural society. First, teachers should have an attitude of respect for cultural differences, a belief that all students are capable of learning, and a sense of efficacy. Thus Villegas suggests that when teachers accept the responsibility for teaching their students, they treat the students' difficulties as challenges to their own ingenuity rather than as excuses for ineffectiveness. Teachers with a sense of efficacy find ways of restructuring learning activities to meet student needs. Second, teachers must know the cultural resources their students bring to the class, and they must be aware of the culture of the students in their classrooms. Third, teachers should implement an enriched curriculum for all students. Thus teachers need to plan and implement a curriculum that challenges students to develop higher-order knowledge 
and skills. Fourth, teachers must link instructional contents, materials and methods to the cultural background of their students. Teachers need a repertoire of instructional approaches that will enable them to reach students of different background in culturally appropriate ways. Fifth, teachers should be aware of cultural difference when evaluating students. There are culturally specific ways of displaying knowledge, and teachers need to use a variety of methods to assess students in a multicultural setting. In short, teachers need to utilize materials and examples, engage in practices, and demonstrate values that include, rather than exclude, students from different backgrounds.

According to Richards et al. (2006), teachers are essential conduits and must provide a bridge when the curriculum falls short in addressing the needs of all students. In effect, teachers as "institutional agents" have to transfer the prescribed content to their students; where the system reflects cultural and linguistic insensitivity, teachers must demonstrate understanding and support. Within such a milieu, teachers keep students academically engaged within the classroom and help them acquire critical social skills and appropriate behaviors that are possibly not yet part of their repertoire.

Additionally, effective classroom management requires reflection on the ELLs specific needs. Teachers have to work towards avoiding linguistic and cultural miscommunication (Curran, 2003). For example, an ELL's inability to comprehend classroom input should not be misconstrued as the student being bored, inattentive, or lazy. Curran suggests that teachers need to try and structure classroom activities to support language acquisition and engage the ELLs.

Teachers who make a conscious effort to incorporate strategies such as structuring classroom activities so that several perspectives are encouraged, providing opportunities 
for students to experience success and so on, see an increase in their own self-esteem and fulfillment (Nias, 1996). Other researchers have found that teaching with cultural responsiveness encourages appreciation and understanding of other cultures as well as one's own (Brown, 2007; Cartledge \& Kourea, 2008; Gay, 2002).

Teachers are one of the most important contributors to student learning in school, beyond what students learn at home (Darling-Hammond, 2000) and students have successful school experiences and achieve at higher rates when their teachers are culturally sensitive and utilize culturally relevant pedagogy (Gay, 2000; Howard, 2001). Teachers need to consciously connect lessons to students' lives as well as ensure that instruction and curriculum are contextualized in students' existing experiences in the home, community and school (Hamayan et al., 2007). Additionally teachers need to implement strategies that help ELLs strengthen previously learned material and create opportunities for acquiring new knowledge; teachers need to understand how differences in language and culture affect students' classroom participation (Antunez, 2002).

The culturally responsive framework is grounded in the beliefs that schools are agents in the promotion of a more equitable and just society (Gay, 2000). While the conceptualization of cultural responsivity seems to be well explored, relatively little empirical research is available (Cochran-Smith, Davis \& Fries, 2004). Morrison, Robbins \& Rose (2008) culled the research literature for empirical studies related to teachers’ implementation of culturally relevant approaches. The researchers chose the terms “culturally responsive” and “culturally relevant” as a means of conducting a systematic search and thereby targeted articles that focused on how teachers operationalize social justice in the classroom through cultural pedagogical approaches. Examining 45 
classroom-based research studies from 1995 onwards that highlighted culturally relevant pedagogy as enacted in the classroom, Morrison, Robbins and Rose found that the majority of available studies were qualitative and action research studies that provided descriptive accounts and that there were very few quantitative studies. Another interesting finding was that many of the studies were about homogenous classes of students and there were very few that addressed how teachers worked with a variety of populations. Morrison, Robbins and Rose point out that a culturally relevant pedagogy may at times clash with the traditional manner in which education is carried out. For example, teachers are under strong pressure to conform to the standardized curriculum in order to prepare students for standardized tests, and the natural inclination in that case would be to steer away from giving students more choice and voice in the classroom. McCray and Garcia (2002) examined the special education literature for evidence of culturally responsive special education practices and found empirical studies to be absent. McCray and Garcia postulate that the field of multicultural and bilingual special education is still in the conceptual stages.

\section{Teacher Characteristics}

All individuals have, at one time or another, experienced great teachers who brought some of their own unique traits to the job and created an unforgettable learning environment. Over the past four decades or more, research has consistently reported positive associations between teacher characteristics and student achievement. These teacher characteristics include years of teaching experience (Darling-Hammond, 2000), content knowledge, as measured by number of courses or major (Darling-Hammond, 2000; Goldhaber \& Brewer, 2000); and participation in professional development 
activities (Wenglinsky, 2002).

Other studies examining teacher characteristics have focused on specific aspects such as the importance of teacher quality to student achievement (Buddin \& Zamarro, 2009; Hanushek, 1971; Rivkin, Hanushek \& Kain, 2005). Some researchers have found positive effects of teacher experience, education, and licensure test scores on student achievement (Clotfelter, Ladd \& Vigdor, 2007); whereas others (Hanushek, 1971; Jacob \& Lefgren, 2008) have found very small effects of teacher qualifications like experience and education on student achievement. There is some evidence that even within the same certification status ( i.e. certified, uncertified or alternately certified), there are large differences in teacher effectiveness (Kane, Rockoff \& Staiger, 2006). Evidence collected from six years worth of data from New York City public schools by Kane, Rockoff and Staiger seems to suggest that for beginning teachers, classroom performance during the first two years is a more reliable indicator of future effectiveness.

Recent research on teachers certified by the National Board for Professional Teaching Standards (NBPTS) finds that student achievement is higher in classrooms taught by NBPTS certified teachers (Goldhaber \& Anthony, 2005; Vandevoort, AmreinBeardsley \& Berliner, 2004). From their analysis of statewide longitudinal data covering students in grades 3,4, and 5 during the years 1995-2004, Clotfelter, Ladd and Vigdor (2007) found similar results but questioned whether the greater effectiveness of Board certified teachers is because the teachers who become Board certified are the more effective teachers to begin with or whether the rigorous process of Board certification makes them better teachers. Jepsen (2005) using an extensive teacher survey and data for more than 10,000 students, additionally suggests that though teachers and their peers play 
a large role in improving student achievement for all students, the attributes of a highquality teacher are hard to measure. These attributes are even harder to measure when it comes to high-quality teachers of ELLs. In order to effectively meet the needs of ELLs, teachers have to acquire additional linguistic and cultural knowledge and skills and learn to apply these to curriculum planning and assessment of ELLs (de Jong \& Harper, 2005)

Hanushek (1971) conducted a statistical inquiry into the educational process from a public policy point of view by analyzing a sample of data of $3^{\text {rd }}$ grade students that was drawn from a large school system in California during 1969. Information on family background, scores on the Stanford Achievement tests and names of teachers were gleaned from cumulative records of over 2,400 White and Mexican-American students. In analyzing the data, Hanushek found that teaching experience and graduate education did not contribute to gains in achievement for Mexican-American students, whereas it did for the White students. He hypothesized that this result may have been due to a language issue. At the time, he did not have a measure for this built into his study but broadly concluded that there was a considerable part of teaching that could not be explained by standard variables; a conclusion that was echoed three decades later by Wayne and Youngs (2003). Wayne and Youngs write that sound research designs have not been used in studying salient teacher characteristics such as experience, race, and teaching methods. Thus results are often inconclusive. Goldhaber (2002) agrees and writes that about three percent of the contribution that teachers make to student learning and achievement is associated with teacher experience, degree attained and other observable characteristics. The remaining 97 percent of their contribution is associated with qualities and behaviors that are not easily identifiable. Goldhaber concludes that while it is known that good 
teaching is important, what makes a good teacher is less clear.

It is not surprising then that relatively fewer studies have examined teacher characteristics as related to ELLs. Some researchers have specifically studied attitudes and beliefs about language minority students (Bustos Flores \& Smith, 2008; Karabenick \& Noda, 2004; Youngs \& Youngs, 2001); others have surveyed the challenges that teacher have felt in teaching ELLs and found that teachers who seek out professional development in this area believe themselves to be better equipped (August \& Hakuta, 1998; Gandara et al.,2005).

Cirino, Pollard-Durodola, Foorman, Carlson, and Francis (2007) investigated the relation of teacher characteristics, including ratings of teacher quality, to classroom instructional variables and to bilingual students' literacy and oral language outcomes at the end of the kindergarten year. Their study sample included four sites and 141 teachers. Observational measures were used to assess characteristics such as teachers’ oral language proficiency in English and Spanish, teacher quality, and classroom activity structure; questionnaires were used to survey teacher knowledge of reading-related skills. Teacher quality was conceptualized as including content knowledge, pedagogical skill, language of instruction and oral language proficiency in bilingual classrooms. Cirino et al. found that teacher quality, but not teacher knowledge, was related positively to student engagement and negatively to time spent in non-instructional activities. Using the English Language Learners Classroom Observation Instrument (ELLCOI), a 30-item observational tool, Graves, Gersten, and Haager (2004) rated classroom instruction in six areas (explicit teaching, sheltered English techniques, instruction geared towards low performing students, interactive teaching, phonemic awareness and decoding, and 
vocabulary development) on a one-to-four-point Likert scale. The researchers found that teachers with high overall scores on the observation protocol (closer to four on the scale) had English learners who made relatively greater gains in oral reading fluency in $1^{\text {st }}$ grade.

Research has demonstrated that for ELLs, as for other groups of students, good teaching which includes instructional activities that promote active, effective student learning, is associated with improved academic outcomes (Doherty, Hilberg, Pinal, \& Tharp, 2003). Nevertheless, Genesee et al. (2006) believe that teacher variables such as levels and kinds of professional development necessary to incorporate different teaching approaches, teacher understanding of second language acquisition, and processes that are required to ensure that new teachers develop the needed competencies, are areas that need to be further researched.

\section{Teacher Quality}

Beginning in the 2003-2004 school year, schools were required by NCLB (2001) to hire only "highly qualified teachers" defined as teachers having at least (1) a bachelor's degree; (2) full state certification; and (3) demonstrated knowledge in core academic subjects they teach ${ }^{3}$. The law also required each local education agency (LEA) to develop a plan to ensure that all teachers were highly qualified no later than the end of 2005-2006 school year. Before discussing how this impacts the teaching of ELLs, it is important to briefly put into perspective the impact of the law.

NCLB. The law is the most recent reauthorization of the Elementary and Secondary Education Act of 1965 and has been designed to ensure accountability and

\footnotetext{
${ }^{3}$ This definition of a highly qualified teacher is specified in Title IX, Section 9101 of the No Child Left Behind Act.
} 
flexibility as well as increased federal support for education. The focus of NCLB has been to provide an education system that is more inclusive, responsive, and fair; to raise the achievement levels of all students and, according to Darling-Hammond (2007), to close the achievement gap that parallels race and class distinctions. The Act focuses on improving test scores for all sub-groups of students, providing parents more educational choices and ensuring better qualified teachers.

The intent of NCLB is commendable, but has led to unintended consequences. More than 20 states and many school districts have officially protested the Act and resisted specific provisions (Darling-Hammond, 2007). There seem to be incentives for schools to keep out or push out their neediest students in order to raise average test scores. In their exploratory qualitative study, Gardiner, Canfield-Davis, \& Anderson (2009) found that of six principals, three were engaged in meaningful and practical work to both fulfill the requirements of NCLB and meet the needs of their students. The others were solely focused on meeting the requirements of the law. The researchers recommended that principals develop a multicultural leadership approach to meeting accountability requirements under NCLB in that they should encourage staff to be sensitive and knowledgeable about the communication styles, backgrounds, ethnicities, cultures, and learning needs of students and families and at the same time maintain a high expectation for all students. Fielding (2004) conducted a survey of 866 educational diagnosticians working in Texas for the 2001-02 school year. In the survey, educational diagnosticians were asked to approximate the percentage of initial referrals to special education that were driven primarily by low performance on the Texas Assessment of Academic Skills (TAAS) and to explain the basis for their answers. The results of the 
survey indicated that pressure to increase district accountability ratings appeared to generate greater numbers of students labeled as having a disability.

Specifically for ELLs, NCLB seeks to ensure language instruction and expansion of educational opportunities for students who are learning the English language and those who are new to this country. While the law provides a measure of accountability for districts across the country, ELLs continue to struggle and are not achieving at par with their native speaking counterparts. For example, during the $2008-2009$ school year, $4^{\text {th }}$ grade ELLs scored 35 points below non-ELLs in reading and 24 points below in math with the achievement gaps being larger in higher grades (NAEP, 2009). Importantly, these gaps have been persistent over all the years that this data has been available.

As Goldenberg (2008) points out, given the heterogeneity of the population, it is difficult to ascertain whether the gaps in achievement are due to lagging content knowledge and skills or because of limited English proficiency or both. Nevertheless, one fact is clear and that is that achievement for this group of students has to improve. Unfortunately, given the inherent diversity of the students and their needs, it is highly unlikely that any single instructional approach or method is likely to be the most effective for all ELLs (Lesaux, 2006).

Highly qualified. Research has shown that highly effective teachers increase student achievement more than ineffective teachers and that teachers' knowledge influences student outcomes (Gelman, Pullin, \& Kaufman, 2004). NCLB recognizes that beyond what students learn at home, teachers are one of the most important contributors to student learning in school; thus the law requires all schools to provide "highly qualified” teachers to all students. 
A relatively unexplored area of research is how teachers view NCLB, given that they are charged with implementing policies handed down by the federal and state governments. Guggino and Brint (2010) surveyed 740 Nationally Board Certified Teachers in California. A large majority of the respondents perceived the law as not honoring the skills and experience that teachers bring to the art of teaching. Murphy (2008) writes that teaching in today's schools has become more intense during this era of high-stakes accountability wherein teachers are experiencing higher levels of stress and feeling more pressure to improve student achievement and raise individual test scores. In her qualitative research study, Murphy interviewed 12 teachers from two Title 1 buildings serving large at-risk populations. Nine of the 12 teachers she interviewed believed their crucial role as a teacher was to be a good role model, be a motivator, guide students to their futures, and to help them believe in themselves. The teachers recognized that these goals were not as achievement oriented as those outlined in NCLB; yet the teachers appreciated the value of data, assessments, enhanced teamwork, and collaboration that was occurring across their schools in order to raise achievement levels of all students.

Perhaps the biggest hurdle concerning ELLs is that mainstream teachers considered highly qualified in their content areas, may not possess the skills, the experience, or pedagogical practice to teach students whose native language is not English. Cadiero-Kaplan and Rodriguez (2008) point out that the importance of pedagogical knowledge and approaches to learning of ELLs are ignored under the law. Scott and Mumford (2007) question why the law does not mention increasing teachers' cultural awareness. 
As mentioned previously, research demonstrates that teachers who are appropriately prepared to work with ELLs may have a positive impact on their academic achievement (Gandara \& Maxwell-Jolly, 2000; Gandara et al., 2005; Rumberger \& Gandara, 2004). All students achieve at higher rates when their teachers are culturally sensitive, utilize culturally relevant pedagogy (Wink, 2005) and are responsive, in that they implement policies and practices that promote equity and excellence through the recognition, understanding and utilization of students' linguistic and cultural assets (Cadiero-Kaplan \& Rodriguez, 2008).

Clewell, de Cohen, and Murray (2007) conducted a research study to determine implementation of NCLB requirements in schools with a high percentage of ELLs. The researchers found that none of the three districts in their sample were able to provide precise information on the proportion of teachers employed in their districts who met the NCLB requirements. All districts were on the search for ESL/bilingual teachers who met the criteria for "highly qualified" and two of the three districts provided teachers with financial support for undertaking undergraduate course work related to teaching ELLs. The researchers recommended that districts should assume responsibility for the training and professional development of teachers in methodologies for teaching ELLs. They also recommended that districts should work with the local colleges to incorporate courses on instruction of ELLs as a part of the required general teacher education curriculum.

As growing numbers of ELLs populate U.S. schools, districts will have to make additional resource investments to ensure that highly qualified teachers are also truly responsive to diverse needs. For example, as Gandara, et al. (2005) point out, teachers need additional tools in their repertoire in order to appropriately identify student needs as 
well as to measure their learning. Ideally, teachers should receive professional development in areas such as second language acquisition, literacy development among ELLs, using formative assessment data to guide instruction and so on. In addition, they should be provided with ongoing support to apply this training to their professional practice as well as time to work collaboratively with their colleagues to review the progress of ELLs (Garcia, 2009).

\section{Knowledge of Second Language Acquisition Processes}

With the increasing numbers of ELLs in U.S. classrooms, it becomes imperative that teachers possess an enhanced knowledge base geared to the education of students learning English. Antunez (2002) suggests that teachers need an additional skill set such as understanding of the basic constructs of bilingualism and second language development; the nature of language proficiency and the role of first language and culture in learning. They need to develop the capacity to make academic content accessible and to be able to integrate language and content instruction. Teacher sensitivity to second language acquisition issues is critical to the development of skills necessary for both instruction and evaluation of ELLs (Layton \& Lock, 2002).

Many teachers erronoeusly believe that if ELLs are exposed to comprehensible English and provided with meaningful opportunities to interact in English, they will develop English-language skills naturally and fully, just as native speakers develop their mother tongue (Harper \& de Jong, 2004). The reality is that mere exposure to the target language is largely insufficient to develop adequate English (Lightbown \& Spada, 2006). ELLs need explicit opportunities to practice using the new language to negotiate meaning 
in interactive settings. Teachers, for their part, need an understanding of language differences and the developmental stages of second language acquisition.

Stages of second language acquistion. According to Krashen and Terrell (1983), there are five sequential stages of second language acquisition that students proceed through: Preproduction stage, Early Production stage, Speech Emergence stage, Intermediate Fluency stage and Advanced Fluency stage.

Preproduction stage. This stage may last anywhere from zero to six months and during this time students may have a few hundred words in their receptive vocabulary but do not verbalize. Students may have minimal comprehension and may draw or point or nod “yes” or "no".

Early production stage. During this stage students have limited comprehension. They may be able to produce one or two word responses and be able to participate using key words or familiar phrases or language chunks that have been memorized Students in this stage will often use only present-tense verbs.

Speech emergence stage. During this stage students demonstrate good listening comprehension and are able to produce simple sentences, although there may be grammatical and pronunciation errors. Students at this stage frequently initiate short conversations with peers, although they may continue to misunderstand jokes.

Intermediate fluency stage. During this stage, students have excellent comprehension and make very few errors in grammar. Students at this stage are beginning to use more complex sentences when speaking and writing and are willing to express opinions and share their thoughts. Students will often ask questions to clarify what they are learning in class. 
Advanced fluency stage. During this stage, students acquire near-native levels of language and most ELLs will have exited from language-support programs, however they may continue to need support in areas such as writing..

Teachers need to be able to identify these stages in order to provide effective differentiated instruction. Hill and Flynn (2006) strongly urge teachers to explore which stage of language acquisition their students are in so that instruction can be scaffolded in such a way that the students will progress.

Second language proficiency. In the early 1980s, Jim Cummins, an educational psychologist at the University of Toronto hypothesized that there were two types of second language proficiency (Cummins, 1981). He termed these as Basic Interpersonal Communication Skills (BICS) and Cognitive Academic Language Proficiency (CALP). For Cummins, this was not a dichotomy between conversational and academic language; rather the distinction between the two was based on a funtional analysis of linguistic skills required in different situations.

BICS are considered to be the "surface" skills of listening and speaking which are typically acquired quickly by many ELLs; particularly by those from language backgrounds similar to English and who spend a lot of their school time interacting with native speakers. According to Crawford (2004), a good example of BICS is "playground English,” which relies heavily on nonlinguistic cues such as gestures and intonation to facilitate communication.

At the other end of the continuum is CALP or "classroom English" (Crawford, 2004). This is the kind of proficiency requires for an ELL to be able to cope with the academic demands of the various subjects. Cummins (1981) believes the advanced skills 
of CALP are literacy related in that they are primarily acquired through the written word. Cummins states that while many students develop BICS within two years of immersion in the target language, it takes between five and seven years to develop CALP.

Although the distinction between BICS and CALP remains controversial (Crawford, 2004), and there is very little consensus regarding the nature of second language proficiency and its relationship to academic achievement (Saunders, Foorman, \& Carlson, 2006), several state guidelines on serving ELLs recommend that teachers need to be aware of the distinction between BICS and CALP (e.g. see DESE Educating Linguistically Diverse Students, 2006, Mississippi Guidelines for English Language Learners, 2011).

Oral language development. The fundamental importance of English oral language development as part of daily instruction for ELLs has been emphasized by several researchers (Gersten et al., 2007; Graves et al., 2004). For certain students who experience difficulty as they transition from their native languages to English as their primary mode of communication for learning and their academic achievement, Harry and Klingner (2006) advocate developing conversational language proficiency in order to be able to use English to learn academic content. According to Gersten and Baker (2006), there is confusion at the elementary level about the focus and content of language development instruction; however they recommend that providing ELLs opportunities to work on all aspects of language development and academically challenging content instruction is necessary.

Vocabulary development. Some researchers advocate for the use of specific vocabulary learning for ELLs (Gersten \& Baker, 2006; August \& Snow, 2007). 
According to the National Reading Panel report (NICHD, 2000), vocabulary occupies an important position in learning to read; as a learner begins to read, reading vocabulary is mapped onto the oral vocabulary that the learner brings to the task and oral vocabulary is key to making the transition from oral to written forms. There are very few explicit evidence-based vocabulary interventions for ELLs in the research literature (August \& Snow, 2007). While the NRP found 47 experimental studies of vocabulary teaching with first-language students (NICHD, 2000, p. 19); August and Snow found seven at the elementary level and one at secondary level for ELLs.

Bilingualism. Early childhood bilingualism is common in large parts of the world. It is a myth that learning more than one language is problematic (Paradis, Genesee \& Crago, 2010) and studies show that simultaneous bilingual students (those who learn more than one language at the same time) achieve high levels of proficiency in both languages (Bialystock, 1997). Of concern may be the situation with current immigrants where the learning of English has become a subtractive process -- where the family language or native language (L1) slows or stalls before a second language is securely developed. Known as subtractive bilingualism, this loss may negatively impact the child's achievement (Lightbown \& Spada, 2006). Fillmore (2000) believes the loss is much larger in terms of the child not being able to learn what family members teach and inculcate in the socialization process. Fillmore believes that parent involvement lessens when children no longer understand their native language and that the psychological and emotional well being of the child is also affected. Language loss, she says, is the result of both internal and external forces operating on children. The internal factors have to do with the desire for social inclusion, conformity, and the need to communicate with others. 
The external forces are the sociopolitical ones operating within society such as Proposition 227 in California eliminating bilingual education as the preferred instruction program.

When the native languages of ELLs are considered liabilities to learning, and excluded from educational programming and the formal curriculum, subtractive schooling occurs. Menken and Kleyn (2010) examined the long-term impact of subtractive schooling on a lesser-known population of students known as long-term English language learners (LTELLs). LTELLs are students who have attended school in the US for more than seven years. In their research, Menken and Kleyn conducted indepth interviews of 29 LTELLs, five school administrators, and four teachers who worked with LTELLs in three New York city high schools. Student interviews provided information about past and present schooling experiences, language usage and preferences. Teacher and administrator interviews provided information about current educational programming provided to LTELLs as well as perceptions of students' strengths and weaknesses and to learn what approaches educators believed were most successful in meeting the needs of this population. Together the data collected from these schools offered a portrait of LTELLs and the services being provided to them in New York City schools. The students in the study sample were oral bilinguals. Thus when language was used for social purposes, they were able to move easily from one language to another. However, their schooling had largely been subtractive. These students had moved in and out of bilingual education, ESL and mainstream classrooms and the researchers explained that lack of consistency in programming had served to prolong the length of time it took these students to acquire sufficient academic English to succeed in 
school. Menken and Kleyn recommend that ELLs be offered the opportunity to develop their native languages in schools.

Implications for teachers. As mentioned earlier, many more teachers are working with increasingly diverse populations (Kindler, 2002) and they may not have had any prior experience to fall back on and may end up developing fallacious beliefs ( Lightbown\& Spada, 2006). McLaughlin (1992) writes that teachers may believe that children learn second languages easily and quickly and have unrealistic expectations. The reality is that children do not easily acquire proficiency in a second language because they do not have the command of vocabulary or memory techniques to help them. McLaughlin states that due to their cognitive maturity, older children are better language learners in a school setting, but younger children may have an advantage in learning correct pronunciation. McLaughlin additionally notes that proficiency in face-to-face communication does not imply that the students have acquired the more complex cognitive proficiency that is required in classroom activities and therefore suggests that oral language should not be used to gauge English proficiency. Children learn a second language more easily if they participate in meaningful activities that require using the second language; thus the curriculum should encourage children to speak, read, and write the second language in meaningful ways (McLaughlin, 1995).

In a major review of literature, Deussen, Autio, Miller, Turnbaugh-Lockwood, and Stewart (2008) highlight five "big ideas” or concepts about second language acquisition and the challenges that ELLs face. They recommend all teachers of ELLs should be cognizant of these concepts and plan instruction while considering these. The first of these emphasizes the stages of acquiring English proficiency, as described by 
Krashen and Terrell (1983). At all stages, Deussen et al. recommend that students need information to be conveyed in a manner that they can understand. Second, while making the distinction between BICS and CALP, Deussen et al. caution that knowledge of the former (BICS) does not ensure that ELLs are able to understand English in every setting. Third, it is imperative that students continue to learn grade-level content while they are acquiring English. Deussen et al. point out that ELLs may take multiple years to learn English commensurate with their native speaking peers and unless teachers focus on providing them with content, the students will fall further and further behind than their native speaking peers. Fourth, as other researchers (Cartledge \& Kourea, 2008; de Jong \& Harper, 2005) have also discussed, teachers need to tap into their ELLs' background knowledge and home cultures and not focus exclusively on the gaps in their knowledge base. Lastly, teachers need to be aware that assessments measure language proficiency as well as actual content knowledge and should use testing accommodations appropriately. It is up to districts to decide what accommodations and modifications may be utilized in the classrooms (Badji, personal communication, July 2010).

In terms of making English learning less subtractive, Fillmore (2000) suggests that parents and teachers need to find ways to work together to support children's development and retention of their primary languages. Parents should be encouraged to create opportunities for talking to and reading to their children in their native language; families with rich oral tradition should be encouraged to find the time to continue these cultural practices. For a population of young ELLs with a documented language impairment, Kohnert, Yim, Nett, Kan, and Duran, (2005) suggest that speech and language pathologists should proactively support the development of the child's native 
language through strategic parent and paraprofessional training along with peer-mediated models of intervention.

In the current context, teachers of ELLs are challenged to think of language much more carefully and change their instructional practices in order to accommodate their ELLs (Flynn \& Hill, 2005). It is critical that teachers modify instruction for ELLs in order to address their specific language needs (August \& Shanahan, 2006; Goldenberg, 2008). However, the reality is that many current and prospective teachers do not receive adequate training in teaching ELLs; teachers may feel isolated and under-supported by both colleagues and the research base in their attempts to provide effective instruction for these ELLs struggling in mainstream classrooms (Lesaux, 2006).

\section{Professional Development in Teaching ELLs}

Critical need. In the decade from 1991-2001, the proportion of teachers who taught at least one ELL more than doubled (Zehler et al., 2003). According to survey results from the National Center for Education Statistics (U.S. Department of Education, NCES, 2001), at the time, the professional development area in which teachers were least likely to participate was addressing the needs of ELLs (26 percent) as compared to 80 percent participation in professional development related to state or district curriculum and performance standards.

More recently, fewer than 40 percent of elementary teachers and secondary math and English teachers who may have had ELLs in their classes have participated in at least one hour of professional development on instructional strategies for teaching these students (Department of Education, 2009). Consequently, most teachers do not feel they 
are prepared to meet the needs of these students (Karabenick \& Noda, 2004; Lewis et al., 1999).

This phenomenon occurs despite the fact that a body of research has established that teachers with good professional preparation make a difference to student learning (Darling-Hammond, 2002; Wayne \& Youngs, 2003). Gándara et al. (2005) surveyed 5300 teachers of ELLs from 22 small, medium and large districts in California and found that, over the past five years, $43 \%$ of teachers with $50 \%$ or more English learners in their classrooms had received no more than one in-service that focused on the instruction of English learners. For those teachers with 26-50\% English learners in their classes, half had had no, or only one, such professional development. Moreover, about one third of respondents complained that sessions were of low quality and limited utility. Additionally, as a recent study (Rumberger \& Gándara, 2004) points out, ELLs have more uncertified and beginning teachers who lack essential pedagogical knowledge and skills than do students who are native English speakers.

Batt (2008) conducted a mixed methods study of 161 educators in Idaho, all of whom worked with large numbers of ELLs; the teachers in the study recognized that they were not equipped to meet the needs of ELLs. In response to an open-ended question that asked what the three greatest challenges in teaching ELLs were, many respondents said that their colleagues’ lack of knowledge and skills was the greatest challenge, as was their (their colleagues) lack of understanding of diversity. Three of the highest professional development priorities, according to the respondents, were ESL methods, sheltered instruction, and literacy methods in the first and second language. Batt 
concluded that teacher education programs needed to modify course offerings and in the interim, professional development in these areas need to be routinely offered.

Fortunately, as Tellez and Waxman (2005) report, districts are realizing that many new teachers are underprepared and veteran teachers are unprepared for teaching ELLs. They routinely have begun to provide professional development for teachers of ELLs through their own in-service programs or they may rely upon the expertise of other organizations to provide such information. As such, the need to explicitly train educators in methodologies for understanding the needs of and teaching ELLs are being addressed by individual districts. The key is to make the professional development effective and beneficial to the teachers keeping in mind the diversity of the populations they serve.

Qualities of effective PD. Some of the most widely known standards in staff development have been produced by the National Staff Development Council (NSDC, 2001). NSDC recommends that long-term and continuous staff development incorporating critical analysis and interpretation of research by educators themselves is the most beneficial. Ballantyne et al. (2008) offer several suggestions to improve the standards as they pertain to the education of ELLs. For example, they suggest that staff development should be driven by local data about ELLs and ELL outcomes; the research base should address language skills and teacher knowledge base should include the learning styles as well as improving collaboration across cultural boundaries.

Researchers have found that in general terms, the most effective professional development opportunities are those whose topics emerge from teacher interests, require a long-term commitment from all parties, and engage in clear measurement and evaluation of goals and teaching targets (Darling-Hammond \& McLaughlin, 1995). 
Tellez and Waxman (2005) argue that the additional time and resources required for ongoing professional development activities are deterrents, mainly because of costs that many schools cannot afford.

García and Guerra (2004) describe the work of the Organizing for Diversity Project (ODP), a research and development project that emerged in response to a request from superintendents of large school districts in the southwest region. The superintendents believed that the achievement gap between the poor and culturally and linguistically diverse students was a result of inadequate teacher preparation of their White, middle-class teachers. The ODP resulted in the development and the validation of a 33-hour staff-development program focused on addressing issues of diversity and of equity for predominantly Caucasian teachers working with Hispanic students. Several of the participants began the project with a general assumption that many students do not enter school ready to learn, that their own role is to provide a safe and caring environment for their students, thereby often disguising lowered teacher expectations. Garcia and Guerra report that participants also lacked a critical cultural framework in that their views of culture were limited to artifacts and behaviors and failed to encompass its deeper impact. The project emphasized various aspects of culturally relevant instruction, intercultural communication, and cultural sensitivity that help teachers overcome some of their negative biases and stereotypes towards Hispanic students. While Garcia and Guerra were not able to follow-up on the project's impact on student achievement, the researchers write that anecdotal evidence suggests that participation in the project made a positive difference in some classrooms. They cite examples from the field wherein one participating school was recognized for making the highest gains on the state's 
accountability test and two participants reported that 100\% of their students passed the state-mandated achievement test. The researchers have managed to build upon their original work and replicate the project in other districts.

While professional development makes a difference in how confident teachers feel meeting the challenge of teaching ELLs (Gandara et al., 2005), provision of opportunities is the responsibility of the institution (whether building or the district) and is connected to the level of cultural responsiveness of the organization as a whole. This is because school policies and procedures impact the allocation of resources (Richards et al.,2006). In the meanwhile, research findings support that a growing number of teachers see the need for-and feel the lack of—-professional development (Alexander, Heaviside \& Farris, 1999; Reeves, 2006).

\section{Attitudes Towards and Perceptions of ELLs}

According to Richards et al. (2006), in order to become culturally responsive, teachers must examine their attitudes and beliefs about themselves and others. Attitudes affect teachers' motivation to engage with their student, and this engagement in turn may translate into higher student motivation and performance (Karabenick \& Noda, 2004). In this study, the researchers surveyed 729 teachers in one midwestern suburban district about their beliefs, attitudes, and practices, related to ELLs. Results indicated that in general In general, teachers held positive attitudes toward ELLs, bilingual education, and bilingualism; however, there was considerable variability, with sizeable proportions of teachers holding less supportive beliefs, attitudes, and practices. Karabenick and Noda found that teachers with more favorable attitudes towards ELLs were more likely to believe that culture is enriching and not divisive. 
Deficit beliefs. There are many ways in which teachers view student learning or struggles within a classroom. Garcia and Guerra (2004) point out that teacher beliefs about ELLs may stem from ideas related to deficit thinking. Educators are often unwilling to examine the root causes of underachievement and failure among students from low-income and racially or ethnically diverse backgrounds beyond their tendency to locate the problems within students, families, and communities.

At times, these deficit beliefs become a filter that blocks educators’ abilities to examine their assumptions and to look beyond traditional solutions for real and meaningful change. Such thinking focuses blame for failure on students and families rather than the educational processes. When educators do not view themselves as part of the problem, there is little willingness to look for solutions within the educational system itself. Garcia and Guerra posit that deficit thinking can be deconstructed through staff development and assumptions and beliefs about low achieving students can be successfully reframed. Garcia and Guerra have found in their work that staff development experiences create cognitive dissonance for some participants between their beliefs and assumptions and those reflected in culturally responsive pedagogy. When participants are confronted with the task of resolving these conflicts, those who find solutions are able to question and often reject their previously held negative views and seem more likely to reflect on instructional practices and recognize their role in student learning and success.

The current reality is that teachers may not possess the knowledge, skills and experience necessary to effectively meet the needs of students from diverse cultural, linguistic and socioeconomic backgrounds. When teacher and student characteristics differ along any or all of these dimensions, the potential for conflict and failure increases 
considerably. Youngs and Youngs (2001) write that teachers' attitudes toward ELLs are likely to affect what ELLs learn; similarly lacking sensitivity to cultural differences, even well-intentioned teachers often interpret the behaviors of minority students in ways that underestimate their academic potential (Villegas, 1991). These may translate into low expectations for the students.

Orientations toward language diversity. Some researchers posit that teachers, administrators, and teacher educators have become part of the culture of schooling in the United States that sees language differences as problems to be eradicated rather than resources to be nurtured and developed and that we tacitly accept deficit notions of linguistic and cultural diversity (Harry \& Klingner, 2006). In 1984, Ruiz proposed that there are three basic orientations toward language diversity and that school programs for linguistically diverse students are based on attitudes that communities have toward these orientations. The first of these is the "language as a problem" orientation wherein linguistic diversity is viewed as a problem to be solved and learning English is thought to be the best answer. The "language as a right" orientation acknowledges that students and communities should not be discriminated against on the basis of language but recognizes language as a "problem" with regard to school achievement. The "language as a resource orientation” views linguistic diversity as a source of expertise to be developed. Ruiz argued that schools have, by and large, adopted the language as a problem orientation, and he called for a shift away from deficit-driven conversations and perspectives to those where linguistic and cultural diversity is viewed as a resource. Harry and Klingner believe that attitudes have changed little over the past two decades and that schools continue to maintain the language as a problem orientation 
Escamilla, Chavez and Vigil (2005) surmise that high stakes testing has additionally enhanced the orientation of language as a problem. In their Colorado-based study, Escamilla et al. compared teacher and policy maker perceptions about ELLs, particularly Spanish speaking students, their achievement and the bilingual education program to existing state data. Participants in their study believed that there is a gap in achievement between Spanish-speaking students and other Colorado students and that language in particular is a problem.

Difference orientation. Teachers who adopt a "difference" orientation (Noel, 2008; Villegas, 1991), do not believe that the student is deficient or that family or community is lacking in some way; they see possible strengths in the differences. Teachers who hold this orientation examine their own ways of teaching and take responsibility for examining the curriculum of the classroom and the structure of the school to find a way to build upon the strengths of the student. This orientation requires educators to determine ways to teach that includes the experiences of all students. These teachers believe that observations and conversations with family members, as well as formal test information, can help the teacher build upon each child's strengths (Sanchez, Li, \& Nuttall, 1995). As a solution, supporters of the cultural difference orientation propose a model of mutual accommodation in which both teachers and students adapt their actions to the common goal of academic success (Cummins, 1986; Delpit, 1988). Delpit further advocates the fostering of meaningful interpersonal relationships in schools, affirmation of the belief that all students can learn and the establishment of high academic standards for all students. An advocacy orientation such as this can have positive results in empowering students notes Cummins (1991) and is in positive contrast 
to the approach that labels a student as deficient and produces a program to provide what the student lacks.

People first orientation. Recognizing that ELLs are not primarily “representative” of a certain group, but students first, will increase an educator’s awareness and cultural competence suggests Roseberry-McKibbin (2008). This argument is akin to the one that Snow (2001) makes about persons with disabilities being people first. Just as the disability does not define who these individuals are, so also, it may be argued that being an ELL does not define the individual. Snow suggests that all too often a person's value and potential and expectations for the future are predicted based on the disability, instead of the person's unique and individual needs and recommends that a change of attitude is warranted. Along the same lines, it is imperative that teachers create a classroom culture where all students regardless of their cultural and linguistic background are welcomed and supported and researchers strongly recommend that teachers seek out all resources available to them to meet these end goals (Gollnick \& Chinn, 2002; Richards et al., 2006).

Tapping into funds of knowledge. Cummins (2001) believes that educators are capable of determining for themselves the social and educational goals they want to achieve with their students. In order to do this, it is imperative that educators explore the funds of knowledge that is, the cultural, linguistic, imaginative, and intellectual resources that children bring to school and discuss how these resources might be developed and expanded in classroom interactions and learning (Moll, Amanti, Neff, \& González, 1992). 
In his research work spanning almost three decades, Luis Moll has analyzed the quality of classroom teaching, examined literacy instruction in English and Spanish, and studied how literacy takes place in the broader social contexts of households and community life. Moll (1992) suggests that a collaborative working relationship between the bilingual child and his community helps to enhance instruction. He describes what he calls "funds of knowledge" which are cultural practices and information that exist in the student's community and can be harnessed to educate the child. According to Gonzales, Moll and Amanti (2005), the conceptualization of funds of knowledge adopts an anthropological perspective for viewing the households of low-income and minority students as repositories of diverse knowledge bases. For example, Moll (1992) details vignettes of a sixth grade teacher successfully using community resources to teach a construction theme within the classroom (she brought in a Hispanic construction worker). The success of the endeavor was attributed to the ability of the teacher to think creatively and assume the role of a facilitator. According to Moll et al. (1992), there are three major obstacles that can impede innovative practices within the classroom. The first of these is resistance to change on the part of the teachers; this translates to a resistance to making learning more connected to authentic experiences of their diverse learners. The second is that along with changed teaching practices, students need to embrace the change by relearning their own roles and developing more responsibility for their own learning. The third factor is the importance of teachers being able to articulate how they are teaching and why they are teaching in that way. In sum, classroom practices have to be authentic and flexible such that students are able to make as many of the multiple connections that are possible with their own social and cultural world. 
The family as an important social and cognitive resource for education and success with connecting academic content to learners' existing social worlds has been discussed by other researchers (Gonzalez, et al., 2005; Moll, Ibanez-Velez, Greenberg, \& Rivera, 1990). Moll's research confirms that the Latino community is an enormous and largely untapped resource towards educational success of Hispanic students. The teacher is the one who bridges the gap between these knowledge bases of the family and classroom practices (Moll et al.,1992). The researchers caution, however, that to be successful in these endeavors, teachers need to have their own professional network of educators in place. In this network, teachers should be able to access assistance to analyze information that they gather to inform instructional practices.

It should be noted that effective instruction for children from culturally diverse backgrounds requires the unconditional support of school administrators (Gardiner et al., 2009). Such support may include funding, materials and staff development. Garcia's (1991) review of research indicates that schools with effective practices for linguistically and culturally diverse students have principals who are highly supportive of their instructional staff and support their autonomy while simultaneously aligning building practices with the need to conform to district policies on curriculum and academic accountability.

\section{Summary}

Over the past three decades, there has been a rapid rise in the number of ELLs attending U.S. schools; currently one in five students is an ELL (Kindler, 2002). These students have significant variability in English proficiency and academic outcomes, for a variety of reasons such as educational history, cultural and social background, length of 
exposure to the English language, and access to appropriate and effective instruction to support second language development (Artiles \& Klingner, 2006; Hamayan et al., 2007), are poor (NAEP, 2009). However, under NCLB (2001), districts are mandated to provide programming to effectively meet the educational needs of ELLs and other groups of atrisk students. One of the law's requirements is that all teachers of core content areas be highly qualified; it is unclear whether these teachers are adequately prepared to teach ELLs. Nonetheless, school districts are constantly challenged to find creative ways of working with ELLs to ensure that they receive high quality and equitable education (Brown, 2007) and achieve at rates commensurate with their native English-speaking peers. Occasionally, when these students do not achieve adequately, inappropriate referrals to special education are made (Zehler et al., 2003).

Researchers contend that in order to improve the academic achievement of these students, all educators need to ensure that classroom instruction is responsive (Gay, 2000) and channeled through the cultural reality and experiences of the learners (Durden, 2008). Thus teachers need to use a wide variety of instructional strategies that are connected to different learning styles, teaching students to know each other's cultural heritages and incorporating multicultural information, resources and materials in all subjects and all skills that are routinely taught in schools (Noel, 2008; Villegas \& Lucas, 2002). Culturally responsive teachers are sensitive to the linguistic and behavioral skill gaps that many ELLs bring to school and recognize that good intensive instruction can prevent or minimize learning difficulties for these students (Klinger \& Edwards, 2006). The question of whether cultural responsivity is important to teachers and if so, whether their 
classroom instruction is incorporates diverse learners' needs, is governed by several factors.

First, teachers need to acquire the requisite skills in order to provide effective instruction to ELLs. For example, teachers have to acquire additional linguistic and cultural knowledge and skills and learn to apply these to curriculum planning and assessment of ELLs (de Jong \& Harper, 2005). Research findings support that a growing number of teachers see the need for-and feel the lack of — professional development in teaching ELLs (Alexander et al.,1999; Reeves, 2006). Teachers may seek out opportunities to get professional development on their own.

Second, as Antunez (2002) suggests, teachers specifically need an additional skill set such as understanding of the basic constructs of bilingualism and the developmental stages of second language acquisition. They also need to understand the need to build on activities to foster oral language and vocabulary development.

Third, in order to become culturally responsive, teachers must examine their attitudes and beliefs about themselves and others (Richards et al., 2006). Attitudes affect teachers' motivation to engage with their students (Karabenick \& Noda, 2004) and may additionally translate to low expectations for diverse learners.

This study is an exploration of whether culturally responsive teaching is important to teachers and whether they implement such practices in their day-to-day work. The study also examines whether salient teacher characteristics such as being highly qualified as defined by NCLB, skilled through professional development, knowledgeable in second language acquisition and teacher attitudes and beliefs towards ELLs are related to teacher 
beliefs of the importance of culturally responsive teaching and its reported implementation. 


\section{CHAPTER III}

\section{METHODS}

This chapter presents the methods and procedures that were utilized in the research study that employed a survey design wherein data was collected at one point in time. The intent of the study was to explore whether specific teacher characteristics were associated with perceived importance of and reported use of culturally responsive teaching practices in the classroom. The following teacher characteristics were included in the study: teacher quality as defined by NCLB, teacher knowledge of second language acquisition, attitudes and perceptions of ELLs and participation in professional development related to teaching ELLs. All information was gathered by means of a selfreported questionnaire that was internet based. In this chapter, the research questions guiding the study will be reviewed, followed by a description of the research design, a discussion of the procedures used, and a listing of the data analyses.

\section{Research Questions}

The methods and procedures of the study were designed to answer the following research questions:

1. Are specific teacher characteristics associated with the perceived importance of culturally responsive teaching practices for ELLs within the classroom setting as measured by a self-report questionnaire?

a. Is there a relationship between No Child Left Behind indicators of teacher quality and teachers’ perceived importance of culturally responsive teaching practices for ELLs within the classroom setting? 
b. Is there a relationship between knowledge of second language acquisition and teachers' perceived importance of culturally responsive teaching practices for ELLs?

c. Is there a relationship between the amount of professional development on teaching ELLs and teachers' perceived importance of culturally responsive teaching practices for ELLs?

d. Is there a relationship between teachers' attitudes towards and perceptions of ELLs and teachers' perceived importance of culturally responsive teaching practices for ELLs?

2. Are specific teacher characteristics associated with the reported use of culturally responsive teaching practices for ELLs within the classroom setting as measured by a self-reported questionnaire?

a. Is there a relationship between No Child Left Behind indicators of teacher quality and teachers' reported use of culturally responsive teaching practices for ELLs within the classroom setting?

b. Is there a relationship between knowledge of second language acquisition and teachers' reported use of culturally responsive classroom teaching practices for ELLs?

c. Is there a relationship between the amount of professional development on teaching ELLs and teachers' reported use of culturally responsive classroom teaching practices for ELLs? 
d. Is there a relationship between teachers' attitudes towards and perceptions of ELLs and teachers' reported use of culturally responsive classroom teaching practices for ELLs?

3. How do teachers' overall perceived importance ratings for culturally responsive teaching practices correlate with overall reported implementation ratings as measured by a self-report questionnaire?

The questions guiding the study are presented in the conceptual model in Figure 1.The comprehensive independent variable is teacher characteristics: teacher quality as required by NCLB, knowledge of second language acquisition processes, attitudes towards and perceptions of ELLs and amount of professional development on teaching ELLs. The dependent variable of culturally responsive teaching practices is examined in terms of its perceived importance and reported use.

Figure 1

\section{Conceptual model}

Independent Variable: Teacher Characteristics
Dependent Variable: Culturally Responsive Teaching Practices

Teacher Quality (NCLB Highly Qualified Indicators)

Knowledge of Second Language Acquisition

Attitudes Towards and Perceptions of ELLs

Amount of Professional Development on Teaching ELLS

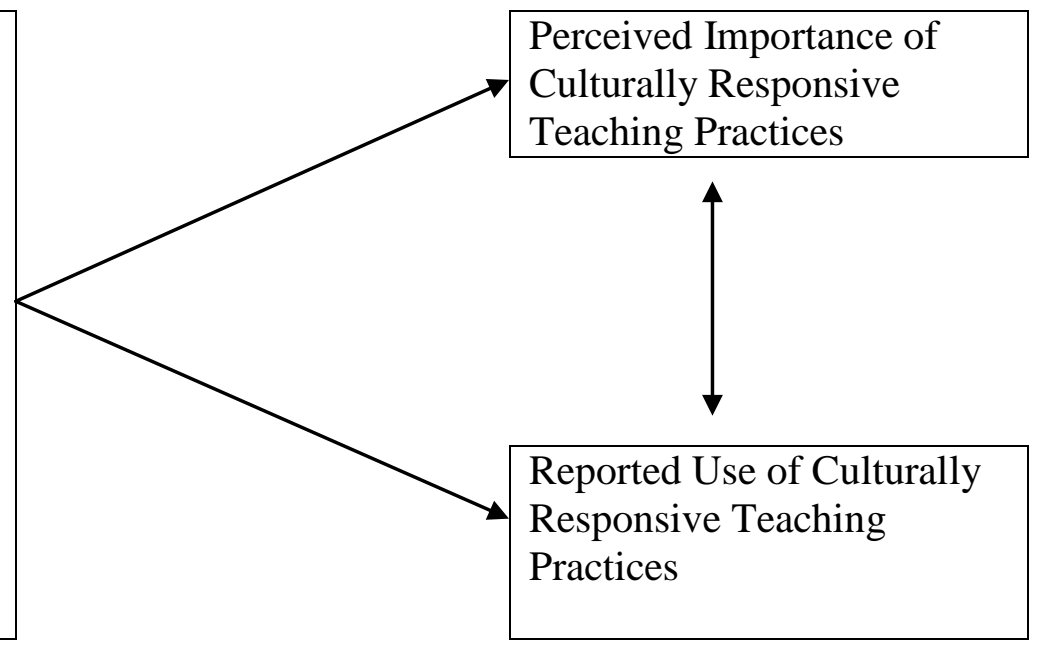


Broadly, the impact of certain teacher characteristics such as teacher quality as required by NCLB, knowledge of second language acquisition, attitudes towards and perceptions of ELLs, and amount of professional development in teaching ELLs on perceived importance and reported use of the dependent variable of culturally responsive practices was investigated. The constructs for the study are defined in Table 1. It should be noted that while attitudes towards ELLs and perceptions of ELLs were defined separately in Table 1, they were combined into one section in the survey and called attitudes towards ELLs.

Table 1

Definition of constructs

\begin{tabular}{ll}
\hline Construct & Definitions \\
\hline $\begin{array}{l}\text { Culturally responsive } \\
\text { teaching practices }\end{array}$ & $\begin{array}{l}\text { Teacher behaviors that use the cultural characteristics, } \\
\text { experiences, and perspectives of ethnically diverse } \\
\text { students as conduits for teaching them more effectively } \\
\text { (adapted from Gay, 2002). } \\
\text { Predispositions to respond favorably or unfavorably } \\
\text { towards ELLs (adapted from Ajzen, 2001). } \\
\text { Propositions or assertions about ELLs that are accepted } \\
\text { as being true (adapted from Kohler, 1988). } \\
\text { SLA is used as being synonymous with second language } \\
\text { language acquisition (SLA) } \\
\text { learning and refers to an individual developing } \\
\text { knocesses }\end{array} \quad \begin{array}{l}\text { language that has been learned (adapted from Lightbown } \\
\text { \& Spada, 2006). Knowledge of SLA was defined as the } \\
\text { number of correct answers a respondent } \\
\text { gave to eleven multiple-choice questions on } \\
\text { second language acquisition processes. }\end{array}$ \\
\hline
\end{tabular}


Table 1 (contd.)

Definition of constructs

$\begin{array}{ll}\text { Teacher quality } & \text { Highly Qualified Teacher: has at least a } \\ \text { bachelor’s degree; has demonstrated content } \\ \text { expertise by passing a state-approved test or has } \\ \text { completed an academic major or coursework } \\ \text { equivalent to a major; and who holds full } \\ \text { certification for his or her current teaching } \\ \text { assignment (Missouri Department of Elementary } \\ \text { and Secondary Education, n.d. definition of } \\ \text { terms). } \\ \text { That which involves a comprehensive, and } \\ \text { intensive approach to improving teachers’ } \\ \text { effectiveness in raising student achievement } \\ \text { (adapted from NSDC, n.d.). }\end{array}$

\section{Research Design}

Since the aim of this quantitative study was a single-time description (Babbie, 1990), a survey design was utilized. Data were collected from a sample and the intent was to determine the relationship between variables at that point in time. The study was conducted in four phases: (1) the development of the questionnaire by the investigator, (2) a review of the questionnaire by a panel of experts in the field of research involving ELLs and culturally competent practices ( 3) a pilot study (4) the distribution of the final questionnaire to respondents, followed by an analysis of the results. 


\section{Procedures}

\section{Phase 1: Development of Questionnaire}

During the first phase, after reviewing the extant literature, a questionnaire with clear and unambiguous, concise, close-ended statements was developed and contained five sections. This included a statement of Informed Consent that detailed the purpose of the study, the procedures, the potential risks and benefits, and contact information (see survey in Appendix A). Respondents were asked to either agree or disagree to participate in the study before they accessed the questionnaire.

The first section of the questionnaire dealt with culturally responsive practices that teachers reportedly employ in the classroom. Fourteen individual statements of teaching practices were listed; teachers were asked to rate their perceived importance for each of the practices on a six-point scale ranging from extremely unimportant to extremely important. Teachers were also asked to rate their reported use of each of these practices on a seven-point Likert type scale ranging from never to daily.

Table 2

Research base for questionnaire

\begin{tabular}{ll}
\hline Area & Research base \\
\hline $\begin{array}{l}\text { Culturally responsive } \\
\text { teaching practices }\end{array}$ & Brown, 2007; Cartledge \& Kourea, 2008; Gay, \\
& $\begin{array}{l}\text { 2000; Phuntsog, 2001; Richards, Artiles, Klingner } \\
\text { \& Brown, 2005; Spanierman et al., (in press); }\end{array}$ \\
Attitudes towards and & Ponterotto, Mendelsohn \& Belizaire, 2003; \\
perception of ELLs & Ponterotto, Potere \& Johansen, 2002; Reeves, \\
& 2006; Youngs \& Youngs, 2001. \\
\hline
\end{tabular}


Table 2 (contd.)

Research base for questionnaire

Knowledge of second

language acquisition

Attitudes towards and perception of ELLs
Crawford, 2004; Crawford \& Krashen, 2007;

Gersten, Baker, Shanahan, Linan-Thompson \&

Collins, 2007; Harper \& de Jong, 2004; Krashen \&

Terrell, 1983; Klingner, de Schonewise, de Onis

\& Barletta, 2008; Lightbown \& Spada , 2006

Ponterotto, Mendelsohn \& Belizaire, 2003;

Ponterotto, Potere \& Johansen, 2002; Reeves, 2006; Roseberry-McKibbin,2008; Youngs \&

Youngs, 2001

The second section of the questionnaire dealt with attitudes towards and perceptions about ELLs. Teachers were asked to rate each of the ten statements on a sixpoint Likert scale ranging from strongly disagree to strongly agree.

The third section of the questionnaire dealt with knowledge of second language acquisition. Eleven questions in a multiple-choice format comprised this section. Teachers picked their response from four possible answer choices. The fourth section of the questionnaire asked for demographic information including years of experience, education, ethnicity, and knowledge of another language. The research base for the three sections of culturally responsive practices, attitudes and perceptions, and knowledge of second language acquisition is detailed in Table 2.

\section{Phase 2: Expert Review}

The next phase of the study consisted of the expert review. There is evidence in the research literature to suggest that consulting with experts offers good feedback to the investigator and stimulates further critical thinking (Campanelli, 2008). Campanelli 
further recommends consulting several experts due to the variation in what experts might notice and recommend. Thus during the second phase of the study, the questionnaire was sent out to a panel of five experts who agreed to review it and provide expert feedback to the investigator.

Individual experts were chosen based on their expertise in research dealing with the education of ELLs and cultural responsiveness.

- Dr. Russell Gersten is executive director of Instructional Research Group, a nonprofit educational research institute, as well as Professor Emeritus in the College of Education at the University of Oregon. Dr. Gersten's main areas of expertise include instructional research on ELLs, reading comprehension research and evaluation methodology.

- Dr. Janette Klingner is a Professor of Education at the University of Colorado at Boulder. Dr. Klingner specializes in bilingual special education. Her research interests include reading comprehension strategy instruction for culturally and linguistically diverse students, Response to Intervention for English language learners, the disproportionate representation of culturally and linguistically diverse students in special education, and professional development that enhances teacher quality in diverse schools.

- Dr. Lisa Spanierman is Associate Professor in the Department of Educational \& Counseling Psychology at McGill University with research interests in white individuals' racial attitudes, understanding diversity related attitudes of students, and improving cultural competence among professionals and educators. 
- Dr. Cara Richards-Tutor is an Associate Professor in the Department of Advanced Studies in Education and Counseling at the California State University at Long Beach. Dr. Richards-Tutor’s research and publications mainly focus on interventions for students at-risk for learning disabilities and English Learners as well as the Response to Intervention Model.

- Dr. Robert Rueda is a Professor at the Rossier School of Education, University of Southern California. Dr. Rueda’s current research interests include sociocultural processes in motivation, classroom learning, and instruction, with a focus on reading and literacy in students who are English learners and students who are in at-risk conditions.

The questionnaire was sent to all five experts simultaneously and feedback was requested. With respect to feedback, Dr. Janette Klingner and Dr. Russell Gersten commented exclusively on the section detailing knowledge of second language acquisition, suggesting that some of the items should be deleted and changing the questions from a True/False format to another type of format. The rationale for this suggestion was that the True/False format did not entirely capture the subtle nuances of second language acquisition. For example, Dr. Janette Klingner wrote:

"For some of the questions, my thought was "it depends," so the True-False format might be hard. For instance, it is possible that a bilingual student is equally proficient in both languages. (so "true"), though I'm sure you're thinking that the correct answer here is "false" because most bilingual individuals are not equally proficient in both languages-so a person does not need to be equally proficient in both to be considered bilingual... \#11 and \#12 are also ones where I'd say "it 
depends." For \#11, I think it's possible to acquire a second language "naturally" as described, but explicit instruction does help. For 12, younger students are better at learning the sound system/pronunciation so that they sound like native speakers than older students, but older students are better at other aspects of second language acquisition....” (J. K. Klingner, personal communication, December 21, 2010)

Dr. Gersten suggested deleting some of the original items due to an incomplete research base. Dr. Richards-Tutor and Dr. Spanierman suggested editing changes for clarity in the sections that dealt with culturally responsive practices and attitudes and perceptions. Dr. Richards-Tutor additionally recommended that some distracter items or items worded in the negative be incorporated into the section on culturally responsive practices to assure that the obtained responses were authentic teacher perceptions and not due to a response set, the tendency to answer a series of questions in a certain direction.

Dr. Robert Rueda cautioned:

“...educated guesses are not always on target...you might want to be cautious about self-reported teaching practices ....there is some evidence that what is reported does not always match what teachers actually do...” (R. Rueda, personal communication, November 24, 2010).

Overall, the section dealing with second language acquisition processes required the most revision. This is not surprising in the light of the incomplete knowledge base (Genesee, Lindholm-Leary, Saunders \& Christian, 2006). After receiving all the feedback and making the suggested changes, the investigator piloted the entire questionnaire. The section that was designed to assess knowledge of second language acquisition was piloted 
in a multiple choice and a $\mathrm{T} / \mathrm{F}$ format and the pilot study participants were asked to choose their preference between the two formats.

Validity. Face and content validity of the questionnaire were established through the expert review process. The experts believed that the constructs and questionnaire items were aligned and that the instrument would solicit accurate information needed to fully address the study's research questions.

\section{Phase 3: Pilot Study}

Research suggests that a pilot study should be directed at a representative sample of the target population (Babbie, 1990). A sample of ten educators who would replicate the demographic elements of the actual population were selected and the instrument was piloted in the same manner that was planned for the real study (see Table 3). The link to the survey was sent to the participants via email and they completed the questionnaire online.

Babbie (1990) suggests that the pilot study should contain all the intended questions in the wording, the format and sequencing and should not be an avenue for trying out new items. The questionnaire sent out to the pilot study participants was housed on http://www.qualtrics.com/ and was very similar to the final questionnaire except for one major difference. According to Babbie, it is reasonable for the pilot study instrument to contain more questions than are intended to be included in the final survey. The pilot survey (see Appendix B) contained two versions of the section that assessed knowledge of second language acquisition and respondents were asked to indicate which format they preferred to answer. 
Table 3

Demographics of pilot study participants

\begin{tabular}{llll}
\hline Demographic variable & Pilot study participants & $\begin{array}{l}\text { Teacher Demographics } \\
\text { (DESE, 2010) }\end{array}$ \\
\hline Gender & Male & $20 \%$ & $21.1 \%$ \\
& Female & $80 \%$ & $78.9 \%$ \\
Ethnicity & White & $80 \%$ & $93.3 \%$ \\
& African & $20 \%$ & $5.7 \%$ \\
& American & & \\
\end{tabular}

It should be noted that the only difficulty that pilot study participants described was with the intentional distracters that had been inserted in the section that dealt with culturally responsive practices. Other questions that were collapsed or changed as a result of responses received during the pilot study are detailed in Table 4.

Table 4

Comparison of questions between the pilot study and final survey

Pilot study $\quad$ Final survey

Which items on the survey were unclear Omitted

or ambiguous? Please explain.

Which questions, if any, did you find Omitted

difficult to answer? Please explain.

During the current school year

Changed to a multiple choice one since

approximately what percentage of your respondents qualified answers indicating a

students are ELLs? $\quad$ lack of clarity (Babbie, 1990)

During the previous school year, Changed to a multiple choice one since

approximately what percentage of your respondents qualified answers indicating a students were ELLs? lack of clarity (Babbie, 1990) 
Table 4 (contd.)

Comparison of questions between the pilot study and final survey

How would you describe the community in which your school district is located?

- City -- a territory inside an urbanized area and inside a principal city

- Suburban - a territory outside a principal city and inside an urbanized area

- Town - a territory inside an urban cluster

- While you were in elementary school, what percentage of your fellow students were from diverse cultural and/or linguistic backgrounds?

- While you were in middle school, what percentage of your fellow students were from diverse cultural and/or linguistic backgrounds?

- While you were in middle school, what percentage of your fellow students were from diverse cultural and/or linguistic backgrounds?

- While you were in middle school, what percentage of your fellow students were from diverse cultural and/or linguistic backgrounds?
The item was omitted from the final survey because some respondents in the pilot study found it difficult to answer

These four questions were combined into a table with three columns (elementary, secondary and post-secondary school) and four rows (less than $25 \%, 26$ to 50\%, 51 to $75 \%, 76$ to $100 \%)$ 
Knowledge of SLA section. Five respondents or 50\% of the respondents in the pilot sample preferred the multiple-choice format to the T/F format for the section that measured respondents’ knowledge of second language acquisition. Coupled with Dr. Klingner's comments during the expert review phase that a T/F format may be difficult to answer, it was decided to retain the multiple-choice format for this section. The final survey was housed on the site http://www.qualtrics.com/.

\section{Phase 4: Distribution of Survey}

According to researchers, the four cornerstones of survey research are sampling, coverage, nonresponse, and measurement (de Leeow, Hox \& Dillman, 2008). Three of the four features (coverage, sampling, nonresponse) refer to the fact that surveys typically collect data from a sample. All four aspects of survey research create four separate sources of error and the goal of a researcher would be to minimize these. This section discusses how the survey was distributed and how these sources of error were minimized.

Sampling. The intended population for this study was educators who teach kindergarten through fifth grade in the regular public school setting. Purposive sampling was used to obtain a sample from three school districts in mid-Missouri. Each school district was located in a different type of community, town, mid-size city, suburban area. Permission was obtained from the administrations of the districts and the Institutional Review Board (IRB) at the University of Missouri. While two of the districts permitted the research study to be conducted in all elementary schools, the school district in the mid-size city permitted the investigator to conduct the study in 15 of 20 elementary schools. Table 5 lists the demographics of the three districts according to the 2010-2011 Missouri school directory. 
Table 5

Demographics of sample

\begin{tabular}{lccc}
\hline School District/ Community & $\begin{array}{l}\text { \# Elementary } \\
\text { Schools }\end{array}$ & $\begin{array}{l}\text { \# Certificated } \\
\text { Staff }\end{array}$ & $\begin{array}{l}\text { Student } \\
\text { Enrollment }\end{array}$ \\
\hline Town & 3 & 79 & 1154 \\
Suburban area & 20 & 443 & 7981 \\
Mid-size City & 15 & 505 & 7257 \\
\hline
\end{tabular}

Coverage. Coverage errors are the most often mentioned limitation of on-line surveys (Manfreda \& Vehovar, 2008) and are defined as errors that occur when the list from which the sample is drawn does not include all elements of the population leading to unequal chances of being included in the sample survey (Dillman, 2007). At the outset of the distribution phase of the study, a prenotification email was sent out to the principals of the 38 schools in three districts inviting their K-5 teachers to participate in the study. Coverage errors were minimized since all potential respondents in the study had equal access to the internet and an equal chance of participating in the study and taking the survey.

Other difficulties associated with web-based surveys are that not every potential respondent may have similar computer skills and that the researcher has no control over who responds to the questionnaire (Manfreda \& Vehovar, 2008). In the present study, the sample of potential respondents was elementary teachers requiring similar competencies. Potential respondents received a link to the survey through their email from their building principals, thereby ensuring that they themselves were the participants. 
Invitation and contact with respondents. Researchers suggest that sending out personalized individual invitations to participants is far more effective that general invitations (Manfreda \& Vehovar, 2008); a prerequisite being that up-to-date contact information is available. Prenotifications are used to inform participants about the importance of the survey, and to increase response rates (Dillman, 2007). Some researchers have found that web surveys may need a shorter time lag between request and reminder than would a mail survey (Dillman, 2000); whereas others have found that, the number of reminders and how these should be timed is still an open research question (de Leeuw \& Hox, 2008). Dillman suggests that after a first email contact, a tailored thank you-reminder by email may be used, a finding that has been replicated by other researchers in that follow-ups do increase response rates (Vehovar, Batagelji, Manfreda \& Zaletel, 2002).

The number of contacts that need to be made has been an area of research that has no definitive answers. For example, in a meta-analysis of internet surveys, Cook, Heath and Thompson (2000) found that average response rates increased with number of contacts up to three contacts, including prenotifications and follow-up contacts, but decreased with four and five contacts whereas Czaja and Blair (2005) suggest four contacts after the initial prenotification. The current study was designed to include three follow ups after the initial invitation to participate. In all, five contacts with the building principals were made (See Table 6). The principal received a prenotification (see Appendix C) on day 1. This was followed by an invitation to participate (see Appendix D) on day 4 of the data collection period. On day 11, the principal was sent a follow up email (see Appendix E) Another follow up (see Appendix F) was sent on day 18 and a 
final reminder was sent on day 25 (Appendix G). The survey was closed out five weeks after the initial prenotification.

Table 6

Timelines of survey distribution and follow-up

\begin{tabular}{ll}
\hline Schedule & Procedures \\
\hline Day 1 & Prenotification to principals \\
Day 4 & Email detailing survey link and invitation to participate to principals \\
Day 11 & Follow-up email sent to principals \\
Day 18 & $2^{\text {nd }}$ follow-up email to principals \\
Day 25 & $3^{\text {rd }}$ reminder \\
Day 35 & Survey closed \\
\hline
\end{tabular}

Nonresponse. Nonresponse is the inability to obtain data for all sampled units on all questions (de Leeuw, Hox \& Dillman, 2008) and researchers believe that nonresponse is more of a problem with internet based surveys than with other forms (de Leeuw \& Hox, 2008). Manfreda, Bosjnak, Berzelak, Hass and Vehovar (2008) conducted a metaanalysis of 45 published and unpublished experimental comparisons between web and other survey modes. They found that web surveys yield an $11 \%$ lower response rate compared to other modes such as mail and telephone surveys. Some reasons for these phenomena include the impersonal nature of the web-based survey, computer literacy of the respondents, lack of the constant reminder of the paper-pencil survey and so on.

Leeuw, Hox and Dillman (2008) suggest that the two main approaches to cope with nonresponse are to reduce the number of noncontacts and refusals and to adjust for 
nonresponse after the data is collected. They suggest that internet-based surveys have to rely on incentives and gifts. Dillman (2007) believes that respondents must be motivated to go through the process of answering a questionnaire and others believe that while incentives increase response rates, the types and value of the incentives need to be tailored to the population in question (Manfreda \& Vehovar, 2008). During the present study, after completion of the questionnaire, participants were invited to enroll their names in a drawing for ten $\$ 20$ gift cards to Amazon.com. Other attempts to reduce nonresponse such as multiple contacts have been detailed above.

Measurement. According to de Leeuw, Hox and Dillman (2008), measurement errors are associated with the data collection process itself. They enumerate three main sources of measurement error: the questionnaire, the respondent and the method of data collection. Through the pilot study, the questionnaire was determined to be user-friendly with appropriate wording and potential respondents were deemed to have the required level of computer expertise necessary to participate. Researchers have found that the cost of data collection in internet surveys is low and there is a potential for a high speed of returns, but there is a challenge for enlisting cooperation (Fowler, 2009). Enlisting teacher participation proved to be a challenge in the present study.

Participants. A complete-case analysis approach, using only complete questionnaires, was utilized. Subsequently, response rates for the total sample and by district were calculated as a percentage: the number of respondents who completed the survey was divided by the total number teachers in the sample and the quotient was multiplied by 100. Response rates are detailed in Table 7 . 
Table 7

Response rates across districts

\begin{tabular}{lccc}
\hline & Respondents & $\begin{array}{c}\text { Total number of } \\
\text { Teachers }\end{array}$ & $\begin{array}{c}\text { Response Rate in } \\
\%\end{array}$ \\
\hline Town & 38 & 79 & 48.10 \\
Midsize city & 113 & 505 & 22.37 \\
Suburban area & 79 & 443 & 17.83 \\
Total & 230 & 1027 & 22.39 \\
\hline
\end{tabular}

Demographic characteristics of respondents that were collected during the study are listed by district in Table 8 . 
Table 8

Demographic characteristics of respondents by district

\begin{tabular}{ccccccc}
\hline & \multicolumn{2}{c}{ Midsize City } & Suburban Area & \multicolumn{2}{c}{ Town } \\
\hline Characteristic & $\mathrm{n}$ & $\%$ & $\mathrm{n}$ & $\%$ & $\mathrm{n}$ & $\%$
\end{tabular}

Current position

$\begin{array}{lcccccr}\text { Classroom teacher } & 68 & 60.2 & 54 & 68.4 & 23 & 60.5 \\ \text { Special educator } & 22 & 19.5 & 7 & 8.9 & 5 & 13.2 \\ \text { Specialist } & 23 & 20.4 & 18 & 22.8 & 10 & 26.3\end{array}$

Highest education level attained

$\begin{array}{lcrrrrr}\text { Bachelors degree } & 5 & 4.4 & 8 & 10.1 & 7 & 18.4 \\ \text { Bachelors degree + hrs } & 14 & 12.4 & 13 & 16.5 & 13 & 34.2 \\ \text { Masters degree } & 15 & 13.3 & 24 & 30.4 & 12 & 31.6 \\ \text { Masters degree + hrs } & 74 & 65.5 & 32 & 40.5 & 6 & 15.8 \\ \text { Specialist degree } & 5 & 4.4 & 1 & 1.3 & 0 & 0 \\ \text { Doctoral degree } & 0 & 0 & 1 & 1.3 & 0 & 0\end{array}$

Teaching full time

$\begin{array}{lcccccc}1-5 \text { years } & 26 & 23.0 & 9 & 11.4 & 10 & 26.3 \\ 6 \text { to } 10 \text { years } & 28 & 24.8 & 21 & 26.6 & 6 & 15.8 \\ 11 \text { to } 15 \text { years } & 22 & 19.5 & 18 & 22.8 & 7 & 18.4 \\ 16 \text { and more years } & 37 & 32.7 & 31 & 39.2 & 15 & 39.5\end{array}$


Table 8 (contd.)

Demographic Characteristics of Respondents By District

\begin{tabular}{|c|c|c|c|c|c|c|}
\hline Gender & \multicolumn{2}{|c|}{ Mid-size city } & \multicolumn{2}{|c|}{ Suburban Area } & \multicolumn{2}{|c|}{ Town } \\
\hline Male & 1 & 0.9 & 5 & 6.3 & 1 & 2.6 \\
\hline Female & 112 & 99.1 & 74 & 93.7 & 37 & 97.4 \\
\hline \multicolumn{7}{|l|}{ Ethnicity } \\
\hline White/Caucasian & 107 & 94.7 & 67 & 84.8 & 38 & 100.0 \\
\hline African American & 5 & 4.4 & 11 & 13.9 & 0 & 0 \\
\hline Hispanic & 1 & 0.9 & 1 & 1.3 & 0 & 0 \\
\hline Other & 0 & 0 & 0 & 0 & 0 & 0 \\
\hline \multicolumn{7}{|l|}{ Speak another language } \\
\hline Yes & 7 & 6.2 & 6 & 7.6 & 0 & 0 \\
\hline No & 106 & 93.8 & 73 & 92.4 & 38 & 100.0 \\
\hline \multicolumn{7}{|c|}{ In 2010, have ELLs in class } \\
\hline $0 \%$ & 19 & 16.8 & 32 & 40.5 & 6 & 15.8 \\
\hline $1 \%$ to $5 \%$ & 49 & 43.4 & 41 & 51.9 & 13 & 34.2 \\
\hline $6 \%$ to $10 \%$ & 21 & 18.6 & 5 & 6.3 & 8 & 21.1 \\
\hline $11 \%$ to $15 \%$ & 8 & 7.1 & 0 & 0 & 5 & 13.2 \\
\hline $16 \%$ to $20 \%$ & 9 & 8.0 & 0 & 0 & 3 & 7.9 \\
\hline over $20 \%$ & 7 & 6.2 & 1 & 1.3 & 3 & 7.9 \\
\hline
\end{tabular}




\section{Data Analyses}

The survey was conducted on-line and data collected anonymously and once the window for data collection was closed, all data was exported and subsequently analyzed using the SPSS software package. The following section details the preliminary analyses that were conducted for each of the independent and dependent variables.

\section{Dependent Variables}

The dependent variables consisted of perceived importance of culturally responsive practices and reported use of culturally responsive practices. Each of these variables consisted of 14 multi-item scales and the items were the same for both variables. For perceived importance of culturally responsive practices, respondents were expected to rate the level of importance of each item on a six-point scale ranging from 1 (extremely unimportant) to 6 (extremely important) and for reported use of culturally responsive practices, they were expected to rate the frequency of use on a seven-point scale ranging from 1 (never) to 7 (daily).

As a preliminary step, the internal consistency of these multi-item scales were assessed using coefficient alpha and inter-item correlations to examine item characteristics. Following the suggestion of Dr. Richards-Tutor, one of the expert reviewers, the subscale measuring culturally responsive teaching practices was developed to include two distracter items (see final survey in Appendix A). Thus, the final scale had 14 items and included two distracters (item \# 3 and item \# 8). Field (2009) suggests that an $\alpha$ value between .7 and .8 may be considered acceptable, particularly when measuring psychological constructs. The reported use and perceived importance measures had adequate internal consistency ( $\alpha=.883$ for reported use and $\alpha=.839$ for perceived 
importance) Tables Hi through $\mathrm{H}$ ii in Appendix $\mathrm{H}$ show the results of the analysis of the internal consistency for each variable of perceived importance of culturally responsive practices, and reported use of culturally responsive practices. For the dependent variable of perceived importance of culturally responsive practices, the item "I utilize instructional materials that reflect cultural elements of diverse groups such as English language learners" had the highest internal consistency $(\alpha=.618)$; whereas the item "I modify my instruction so that diverse students such as English language learners will have an equal opportunity to learn" had the lowest internal consistency ( $\alpha=.364)$. Similarly, for the dependent variable, reported use of culturally responsive practices, the item "I establish strong, supportive relationships with linguistically diverse minority parents” had the highest internal consistency $(\alpha=.707)$; whereas the item "I encourage linguistically diverse families to make every effort to maintain their home language" had the lowest internal consistency $(\alpha=.449)$.

\section{Independent Variables}

Teacher quality. The independent variable of teacher quality, as defined by NCLB, consisted of three requirements: full State certification or license to teach, a bachelor's degree, and having demonstrated subject-matter proficiency. This variable was intended to be assessed using an ordinal scale as to whether participants possessed one, two, or all three criteria and the median and frequency were to be reported. On the survey, while $93.9 \%$ of respondents indicated that they considered themselves to be highly qualified, only $26 \%$ indicated how they had met the three criteria. Therefore, a post-hoc decision was made to use the categorical variable answering the question of 
whether respondents were highly qualified towards answering the relevant research questions. Data for responses to this question is detailed in Table 9.

Table 9

Frequency of teachers reported to be highly qualified

\begin{tabular}{|c|c|c|c|}
\hline \multicolumn{2}{|l|}{ Question } & $\mathrm{n}$ & $\%$ \\
\hline Would you describe yourself as being a Highly & Yes & 216 & 93.9 \\
\hline Qualified Teacher (HQT) according to the requirements & & & \\
\hline of NCLB (college degree, full state certification or & No & 14 & 6.1 \\
\hline & Total & 230 & 100 \\
\hline
\end{tabular}

Knowledge of second language acquisition. The independent variable of knowledge of second language acquisition was an 11-item multiple choice quiz and the total score obtained by each respondent was used for the analysis.

Professional development. Indicators of professional development included hours of training (i.e., District in-services, NABE, undergraduate and graduate level course work). Descriptive data was used to quantify the amount of training that each respondent had undertaken. For the purposes of the analyses, district level training was considered to be the most basic level of training that a respondent could participate in. Thus, whatever hours of training at the district level that respondents reported they had had was reported as such. It was assumed that training offered by professional organizations such as NABE or TESOL would be of a higher quality than that offered by district level trainings. Thus hours of training acquired from a professional organizations were multiplied by 2 and added to the total. Similarly, it was assumed that undergraduate 
course work would be more rigorous than either district level training or training offered by professional organizations. Therefore hours of undergraduate course work were multiplied by 3 and added to the total. In a similar manner, graduate level course work was assumed to be the most demanding and therefore hours of graduate level course work was multiplied by 4 and added to the total. The equation below details how the variable Total PD was obtained:

Total PD = hrs. of district level training +2 (hrs. of training through organizations) +3 (undergraduate hrs.) +4 (graduate hours)

In this manner, a composite score of professional development was obtained for each respondent and used for the analyses.

Attitudes towards ELLs. Attitudes towards and perceptions of ELLs were measured using a 10-item multi-item Likert scale. As a first step, the internal consistency of this multi-item scale was assessed using coefficient alpha and inter-item correlations to examine item characteristics The subscale had adequate internal consistency, Cronbach’s $\alpha=.791$ (see Appendix H iii). The item "It is unreasonable to expect a regular classroom teacher to teach a child who is not fluent in English” had the highest internal consistency $(\alpha=.561)$; whereas the item “Adapting classroom instruction for English language learners is difficult” had the lowest internal consistency $(\alpha=.395)$. Descriptive analyses including means, skewness and kurtosis were calculated. 


\section{Specific Analyses}

Research questions 1 and 2

1. Are specific teacher characteristics associated with the perceived importance of culturally responsive teaching practices for ELLs within the classroom setting as measured by a self-report questionnaire?

2. Are specific teacher characteristics associated with the reported use of culturally responsive teaching practices for ELLs within the classroom setting as measured by a self-reported questionnaire?

The first research question examined whether specific teacher characteristics were associated with the perceived importance of culturally responsive teaching practices for ELLs within the classroom setting. The second research question explored whether these same teacher characteristics were associated with the reported use of culturally responsive teaching practices for ELLs within the classroom setting. Both of these research questions relied on the same pattern of independent variables with a multi-item importance scale (i.e., $1=$ extremely unimportant to $6=$ extremely important) as the dependent variable in research question 1 and a multi-item frequency of behavior scale (i.e., $1=$ never to $7=$ daily) as the dependent variable in research question 2.

The teacher characteristics of teacher quality, knowledge of second language acquisition, amount of professional development, and attitudes and perceptions of ELLs were the independent variables for both questions. Since each research question focused on the relationship between the independent variables and the respective dependent variables, similar data analysis procedures were applied to both. 
As a first step, descriptive analyses including the overall values of means, and SDs were calculated for each dependent variable. The subsequent analyses for both questions consisted of running a multiple regression model. Thus, a multiple regression model was run to explore the impact of the four teacher characteristics on the outcomes of perceived importance of culturally responsive practices (Research Question 1) and reported implementation of culturally responsive practices (Research Question 2). In each model, the amount of variance accounted for by each predictor variable, when compared to other predictors, was examined to assess the importance that each might have in predicting the dependent variable.

Prior to running the multiple regression, a residual analysis was conducted for each of the two dependent variables of perceived importance of culturally responsive practices and reported use of culturally responsive practices in order to check for the appropriateness of the analysis.

A residual analysis allows an investigator to evaluate whether the regression model that has been fit to the data is an appropriate model and determine whether any of the assumptions of the regression model have been violated.

Graphical representations of the residual analyses for each dependent variable are included in Appendix I. These indicate that for the dependent variable of perceived importance of culturally responsive practices as well as for the dependent variable of reported use of culturally responsive practices, the assumptions for regression were not violated. There was a constant variance of residuals across levels of the independent variables and independent and normally distributed residuals were evident. Additionally, the tolerance and variance inflation factor (VIF) were both within the acceptable limits 
(see Table I.i and Table I.ii). The residual analyses indicated that the linear regression model was appropriate for the data analysis.

Research question 3

3. How do teachers' overall perceived importance ratings for culturally responsive teaching practices correlate with overall reported implementation ratings as measured by a self-report questionnaire?

This research question focused on the relationship between overall importance ratings for culturally responsive teaching practices and their reported use. A simple linear regression was utilized wherein the relationship between perceived importance of culturally responsive teaching practices and their reported implementation was calculated to determine how one variable would predict the outcome of the other and provide estimates of whether the relationship was statistically significant. The linear regression was calculated using the linear regression command in SPSS.

Supplementary research questions. The study also included a series of subquestions examining the association between each individual predictor with each of the two dependent variables of perceived importance of culturally responsive practices and reported implementation of culturally responsive practices.

Specific analyses that were conducted for each set of the sub-questions are as follows: Research Questions 1a and 2a:

1a. Is there a relationship between indicators of teacher quality (specifically NCLB requirements) and teachers' perceived importance of culturally responsive teaching practices for ELLs within the classroom setting? 
2 a. Is there a relationship between indicators of teacher quality (specifically NCLB requirements) and teachers' reported use of culturally responsive teaching practices for ELLs within the classroom setting?

As mentioned earlier in this chapter, teacher quality was treated as a categorical variable. The association between teacher quality and each of the two dependent variables of perceived importance and reported use of culturally responsive practices was explored by calculating the point- biserial correlation for each relationship. Further, the Independent-Samples $t$ test was calculated to explore whether there was a difference in the means of perceived importance and reported implementation across the two groups, those who considered themselves to be highly qualified and those who did not. Research Questions $1 b$ and $2 b$ :

1b. Is there a relationship between knowledge of second language acquisition and teachers' perceived importance of culturally responsive teaching practices for ELLs? 2b. Is there a relationship between knowledge of second language acquisition and teachers' reported use of culturally responsive classroom teaching practices for ELLs?

Research questions $1 \mathrm{~b}$ and $2 \mathrm{~b}$ which examined whether knowledge of second language acquisition processes was related to the dependent variables was examined using Pearson's correlation coefficient as the independent variable and the dependent variables of perceived importance and reported use of culturally responsive practices which were interval scaled.

Research Questions 1c and 2c: 
1c. Is there a relationship between the amount of professional development on teaching ELLs and teachers' perceived importance of culturally responsive teaching practices for ELLs?

2c. Is there a relationship between the amount of professional development on teaching ELLs and teachers' reported use of culturally responsive classroom teaching practices for ELLs?

Pearson's correlation coefficients were calculated to determine the relationship between professional development and perceived importance and implementation of culturally competent teaching practices.

Research Questions 1d and 2d:

1d. Is there a relationship between teachers' attitudes towards and perceptions of ELLs and teachers' perceived importance of culturally responsive teaching practices for ELLs? 2d. Is there a relationship between teachers' attitudes towards and perceptions of ELLs and teachers' reported use of culturally responsive classroom teaching practices for ELLs?

Research questions 1d and 2d examined the strength of correlations (Pearson's coefficient) between the independent variable of attitudes and perceptions and the outcomes that were perceived importance of and reported implementation of culturally responsive teaching practices. 


\section{CHAPTER IV}

\section{RESULTS}

This chapter presents an analysis of the data collected during the study. The first section details the descriptive statistics for the dependent variables of perceived importance of culturally responsive practices and reported use of culturally responsive practices. The next section provides the descriptive statistics for the independent variables. Finally, the specific analyses for the research questions are discussed. At the outset, descriptives including the mean, and SD, were calculated for the two dependent variables of perceived importance of culturally responsive classroom practices and reported implementation of culturally responsive practices. For the dependent variable of perceived importance of culturally responsive practices (Table 10), respondents were asked to score items on a range from 1 (Extremely Unimportant) to 6 (Extremely Important). For all items, the mean ranged from 4.67 to 5.49 and SD ranged from 0.71 to 1.11 , with the item "I help all students to connect and apply what they have learned to the home and the community” being scored the highest (5.49) and the item, "I provide extensive opportunities for parents and families of my diverse learners to participate in classroom instructional activities” being scored the lowest (4.67).

For this variable, skewness, which refers to the symmetry of the distribution (Aron, Aron \& Coups, 2006) ranged from -2.69 to -0.55 and indicated that there were more scores to the left of the distribution; whereas kurtosis, which reflects the shape of the distribution (DeCarlo, 1997), ranged from 0.31 to 12.93 indicating a peakedness to the distribution. 
Table 10

Descriptives, all respondents, perceived importance of culturally responsive practices

N Mean SD

I modify my instruction so that diverse students such as English language learners will have an equal opportunity to learn.

$230 \quad 5.15 \quad 1.11$

I utilize instructional materials that reflect cultural elements of diverse

groups such as English language learners.

$\begin{array}{lll}230 & 4.93 \quad .92\end{array}$

I relate content and instructional strategies to the cultural background of my students.

$230 \quad 5.03 \quad .84$

I utilize information from several sources, including families, to assess student achievement.

$\begin{array}{lll}230 & 5.07 \quad .90\end{array}$

I use a variety of teaching strategies to assist my students who are from

diverse ethnic, racial, cultural, and language backgrounds in meeting

State standards and other mandated requirements such as NCLB.

$230 \quad 5.46 \quad .71$

I establish strong, supportive relationships with linguistically diverse

minority parents.

$230 \quad 5.23 \quad .82$

My instructional activities include a discussion of what the students, including English language learners, already know from the home, community and school.

$\begin{array}{lll}230 & 5.36 & .72\end{array}$

I plan activities to celebrate diverse cultural practices in my classroom. $\quad 230 \quad 4.79 \quad .94$ For the English language learners or other diverse learners in my class, I make time to preview the upcoming lesson.

I help all students to connect and apply what they have learned to the home and the community.

I provide extensive opportunities for parents and families of my diverse learners to participate in classroom instructional activities.

I encourage linguistically diverse families to make every effort to maintain their home language. 
Table 11

Descriptives, all respondents, reported use of culturally responsive practices

N Mean SD

I modify my instruction so that diverse students such as English

language learners will have an equal opportunity to learn.

$230 \quad 6.09 \quad 1.59$

I utilize instructional materials that reflect cultural elements of diverse

groups such as English language learners.

$230 \quad 5.08 \quad 1.59$

I relate content and instructional strategies to the cultural background of my students.

$230 \quad 5.53 \quad 1.43$

I utilize information from several sources, including families, to assess

student achievement.

$230 \quad 4.88 \quad 1.68$

I use a variety of teaching strategies to assist my students who are from

diverse ethnic, racial, cultural, and language backgrounds in meeting

State standards and other mandated requirements such as NCLB.

$\begin{array}{lll}230 & 6.28 & 1.19\end{array}$

I establish strong, supportive relationships with linguistically diverse

minority parents.

$230 \quad 4.37 \quad 1.77$

My instructional activities include a discussion of what the students,

including English language learners, already know from the home,

community and school.

$230 \quad 5.97 \quad 1.41$

I plan activities to celebrate diverse cultural practices in my classroom. $230 \quad 3.20 \quad 1.59$

For the English language learners or other diverse learners in my class, I

make time to preview the upcoming lesson.

$230 \quad 5.38 \quad 1.79$

I help all students to connect and apply what they have learned to the

home and the community.

$230 \quad 6.36 \quad 1.08$

I provide extensive opportunities for parents and families of my diverse

learners to participate in classroom instructional activities.

$230 \quad 3.21 \quad 1.90$

I encourage linguistically diverse families to make every effort to

maintain their home language.

$230 \quad 3.23 \quad 2.22$ 
For the dependent variable of reported use of culturally responsive practices (Table 11), participants were asked to score items on a range from 1 (Never) to 7 (Daily). For all items, the mean ranged from 3.20 to 6.36 and SD ranged from 1.08 to 2.22. The item, "I help all students to connect and apply what they have learned to the home and the community" scored the highest (6.36) and the item, "I plan activities to celebrate diverse cultural practices in my classroom” scored the lowest (3.20). Skewness, which refers to the symmetry of the distribution (Aron, Aron \& Coups, 2006) ranged from -2.45 to 0.89, and was almost within the acceptable range. Kurtosis, which reflects the shape of the distribution (DeCarlo, 1997), ranged from -1.03 to 7.24, indicating a peakedness of scores that is somewhat above the acceptable range.

Table 12

Descriptives, all respondents, total professional development

\begin{tabular}{lccc}
\hline & $\mathrm{n}$ & Mean & $\mathrm{SD}$ \\
\hline District level PD & 230 & 2.59 & 8.93 \\
Professional Organization Trainings & 230 & .86 & 7.56 \\
Undergraduate course work & 230 & 1.23 & 6.39 \\
Graduate course work & 230 & 1.08 & 4.68 \\
Total PD & 230 & 12.34 & 35.53 \\
\hline
\end{tabular}

The results from the survey for the independent variable of professional development are presented in Table 12. As mentioned in the previous chapter, this variable was computed as a total of each of four levels of trainings that respondents had reportedly undertaken, multiplied by a corresponding integer. For example, if a teacher reported four hours of district in-service and two hours of undergraduate course work, the 
total PD recorded would have been $4+3 * 2=10$ hours of PD. Means for this variable ranged from 0.86 to 2.59 , the SDs ranged from 4.68 to 8.93. Skewness, which characterizes the degree of asymmetry of a distribution around its mean, ranged from 6.16 to 12.04 indicating that the distribution was asymmetrical. Kurtosis ranged from 42.71 to 164.90 indicating that the distribution was peaked or that outliers were present (DeCarlo, 1997).

The independent variable of knowledge of second language acquisition was ascertained through a multiple-choice quiz and the total correct was the score used in the analyses. The percent of respondents who got each item correct are listed in Table 13. The item, “Comprehensive literacy programs for ELLs need to have components of which of the following?” was the item respondents most often answered correctly (95.2\%) and "According to current research, the best method for English language learners to acquire all aspects of English in the same way they acquire their first language, is which of the following?” was the item that respondents least frequently got correct (5.2\%). The mean correct for all respondents was $60 \%$.

For the independent variable of attitudes towards ELLs, participants were asked to score items on a range from 1 (Strongly Disagree) to 6 (Strongly Agree) (Table 14). For all items, the mean ranged from 3.00 to 5.40 and SD ranged from 0.73 to 1.42 . The item "English language learners would be a welcome addition to my classroom" scored the highest (5.40) and the item, “Adapting classroom instruction for English language learners is difficult” scoring the lowest (3.00). Both skewness, ranging from -1.34 to 0.46 and kurtosis, ranging from -0.98 to 2.33 were considered to be within acceptable limits. 
Table 13

Quiz on knowledge of second language acquisition, percent correct responses

\begin{tabular}{ll}
\hline & $\%$ correct \\
& responses
\end{tabular}

An English language learner's native language can best be described as which of the following?

$230 \quad 66.5$

Code-switching, described as a switch among languages during

conversation, occurs at which of the following levels?

230

81.7

Which of the following is not true about errors in second language

learning?

Which of the following is not true about ELLs who demonstrate

fluent conversational English?

Students who do not know enough English to hold a conversation are often able to demonstrate which of the following?

According to current research, the best method for English language

learners to acquire all aspects of English in the same way they acquire their first language, is which of the following?

Which of the following would most likely help ELLs to read and write in English?

When a parent declines their child's participation in a program designed for providing language support for ELLs, the district retains a responsibility for which of the following?

In the education of English language learners, which of the following aspects of instruction is most important to ensure effective outcomes?

Comprehensive literacy programs for ELLs need to have components of which of the following?

In the assessment of ELLs, accommodations may be provided to which of the following? 
Table 14

Descriptives, all respondents, attitudes and perceptions towards ELLs

\begin{tabular}{|c|c|c|c|}
\hline & $\mathrm{N}$ & Mean & SD \\
\hline $\begin{array}{l}\text { As school populations become more linguistically } \\
\text { diverse, teachers’ jobs become increasingly rewarding. }\end{array}$ & 230 & 4.33 & 1.16 \\
\hline $\begin{array}{l}\text { Having English language learners in my class would be } \\
\text { socially challenging for many students. }\end{array}$ & 230 & 4.09 & 1.42 \\
\hline $\begin{array}{l}\text { Having English language learners in my class would } \\
\text { enrich the educational experiences of all students in the } \\
\text { class. }\end{array}$ & 230 & 5.38 & .74 \\
\hline $\begin{array}{l}\text { Adapting classroom instruction for English language } \\
\text { learners is difficult. }\end{array}$ & 230 & 3.00 & 1.21 \\
\hline $\begin{array}{l}\text { Parents of English language learners are a valuable } \\
\text { resource for school activities. }\end{array}$ & 230 & 4.91 & .92 \\
\hline $\begin{array}{l}\text { English language learners should not be included in my } \\
\text { class unless they attain a minimum level of English } \\
\text { proficiency. }\end{array}$ & 230 & 4.90 & 1.19 \\
\hline $\begin{array}{l}\text { I believe that English language learners should be } \\
\text { encouraged to use their native language as often as } \\
\text { possible. }\end{array}$ & 230 & 3.97 & 1.20 \\
\hline $\begin{array}{l}\text { English language learners would be a welcome addition } \\
\text { to my classroom. }\end{array}$ & 230 & 5.40 & .73 \\
\hline $\begin{array}{l}\text { It is unreasonable to expect a regular classroom teacher to } \\
\text { teach a child who is not fluent in English. }\end{array}$ & 230 & 4.65 & 1.18 \\
\hline $\begin{array}{l}\text { English language learners should avoid using their native } \\
\text { language while at school. }\end{array}$ & 230 & 4.16 & 1.20 \\
\hline
\end{tabular}


Research Questions 1, 2 and 3 were central to the entire study and analyses were completed in stages. This next section details the results for Research Question 1 and its sub-questions.

Research Question 1: Are specific teacher characteristics associated with the perceived importance of culturally responsive teaching practices for ELLs within the classroom setting as measured by a self-report questionnaire?

Research Question 1 explored the impact of the four teacher characteristics of knowledge of second language acquisition, highly qualified status (NCLB), amount of professional development, and attitudes towards ELLs on the dependent variable of perceived importance of culturally responsive teaching practices. The linear regression function of SPSS was used to arrive at the analysis. The mean perceived importance of culturally responsive teaching practices was entered as the dependent variable and the mean scores on the attitudes subscale, total professional development, mean score of the quiz measuring knowledge of second language acquisition and highly qualified status were entered as the independent variables. This model was significant $(\mathrm{F}=11.417, \mathrm{p}<$ .000) suggesting that at least one of the four independent variables had a significant effect on the dependent variable of perceived importance of culturally responsive practices. Results, as shown in Table 15, indicated that one of the teacher characteristics, attitudes towards ELLs, was a significant predictor of perceived importance of culturally responsive teaching practices, while the remaining three, knowledge of second language acquisition, professional development, and highly qualified status were not significant predictors. 
Specifically, results obtained indicated that the more favorable the respondent's attitudes, the higher their perceived importance of culturally responsive practices $(\beta$ $=.383, \mathrm{t}=6.029, \mathrm{p}<.000)$.

Table 15

Regression analysis summary for teacher characteristics predicting perceived importance of culturally responsive practices

\begin{tabular}{lccccc}
\hline Variable & B & SE B & $\beta$ & $\mathrm{t}$ & $p$ \\
\hline Knowledge of second language & .005 & .023 & .015 & .239 & .812 \\
acquisition & & & & & \\
Highly qualified status & -.090 & .151 & -.036 & -.597 & .551 \\
Professional development & .001 & .001 & .085 & 1.384 & .168 \\
Attitudes towards ELLs & .345 & .057 & .383 & 6.029 & .000 \\
\hline
\end{tabular}

Note: $R^{2}=.169$ (Adjusted $\left.R^{2}=.154\right),(N=230, p<.05)$

The final regression model for perceived importance of culturally responsive practices included one significant predictor, that of attitudes towards ELLs $(\beta=.400, \mathrm{t}=$ 6.586, $\mathrm{p}=.000$ ). Attitudes seemed to make a significant positive difference to teachers' perceived importance of culturally responsive practices and as indicated by Table 16, accounted for $15.6 \%$ of the variance in perceived importance of culturally responsive practices across all respondents (Adjusted $R^{2}=.156$ ). The variables of knowledge of second language acquisition, professional development, and teacher quality were not significant predictors. 
Table 16

Final regression model predicting perceived importance of culturally responsive practices

\begin{tabular}{llcccc}
\hline Variable & B & SE B & $\beta$ & $\mathrm{t}$ & $p$ \\
\hline Attitudes towards ELLs & .360 & .055 & .400 & 6.586 & .000 \\
\hline
\end{tabular}

Note: $R^{2}=.160$ (Adjusted $\left.R^{2}=.156\right),(N=230, p<.05)$

Research Question 1 a. Is there a relationship between No Child Left Behind indicators

of teacher quality and teachers' perceived importance of culturally responsive teaching practices for ELLs within the classroom setting?

As mentioned in the earlier chapter, the variable for No Child Left Behind indicators of teacher quality could not be appropriately determined from the data gathered during the study. Therefore responses to the question in the survey that asked teachers whether they were highly qualified was used for further analysis. Of the 230 respondents, 216 reported that they were highly qualified and 14 reported that they were not.

In order to answer the research question and explore the relationship between highly qualified status and perceived importance of culturally responsive teaching practices, a point-biserial correlation was calculated. Results indicated that perceived importance of culturally responsive teaching practices was not positively associated with whether teachers considered themselves highly qualified.

Additionally an analysis of group differences (between respondents who considered themselves highly qualified and those who did not) in the mean responses to the statements that measured their perceived importance of culturally responsive 
practices, was conducted using a t-test for independent samples. The results, as presented in Table 17, indicated no significant differences between the two groups.

Table 17

Differences in perceived importance of culturally responsive practices between teachers who reported a highly qualified status and those who did not

\begin{tabular}{lccccccc}
\hline Teachers & $\mathrm{n}$ & $\mathrm{M}$ & $\mathrm{SD}$ & $\mathrm{df}$ & $t$ & $p$ & Cohen's $d$ \\
\hline $\begin{array}{l}\text { Highly } \\
\text { qualified }\end{array}$ & 216 & 5.0910 & .57 & 228 & .811 & .418 & 0.178 \\
$\begin{array}{l}\text { Not highly } \\
\text { qualified }\end{array}$ & 14 & 4.9583 & .88 & 13.715 & .555 & .588 & \\
\hline
\end{tabular}

Q. 1 b. Is there a relationship between knowledge of second language acquisition and teachers' perceived importance of culturally responsive teaching practices for ELLs?

Knowledge of second language acquisition was assessed through a 11-item multiple-choice quiz. The total score that individuals achieved on the quiz was used as the independent variable. A Pearson's product moment correlation coefficient was calculated and found to demonstrate a small relationship between knowledge of second language acquisition and perceived importance of culturally responsive teaching practices: $\mathrm{r}=.139, \mathrm{n}=230, \mathrm{p}=.025$ (one-tailed). There was a weak relationship between respondents' knowledge of second language acquisition and their perceived importance of culturally responsive teaching practices. It should be noted that if a relationship existed, one would have expected it to be directional in that, more knowledge of second language acquisition would be expected to increase perceived importance. 
Q1 c. Is there a relationship between the amount of professional development on teaching ELLs and teachers' perceived importance of culturally responsive teaching practices for ELLs?

Pearson's product moment correlation coefficient was calculated between the amount of professional development for teaching ELLs and perceived importance of culturally responsive teaching practices to determine the relationship between the two variables. Results indicated that there was a small statistically significant relationship between the amount of professional development teachers accrue and their perceived importance of culturally responsive teaching practices: $\mathrm{r}=.138, \mathrm{n}=230, \mathrm{p}=.018$ (onetailed). As with knowledge of second language acquisition, if a relationship had existed, one would have expected it to be directional in that, more professional development would be expected to increase perceived importance of culturally responsive practices. Q 1 d. Is there a relationship between teachers' attitudes towards and perceptions of ELLs and teachers' perceived importance of culturally responsive teaching practices for ELLs?

A significant and positive relationship emerged between teachers’ attitudes and their perceived importance of culturally responsive practices: $\mathrm{r}=.400, \mathrm{n}=230, \mathrm{p}<.01$. Q 2. Are specific teacher characteristics associated with the reported use of culturally responsive teaching practices for ELLs within the classroom setting as measured by a self-reported questionnaire?

Research Question 2 explored the impact of the four teacher characteristics of knowledge of second language acquisition, highly qualified status, professional development, and attitudes towards ELLs on the dependent variable of reported 
implementation of culturally responsive teaching practices. This model was significant $(\mathrm{F}=10.205, \mathrm{p}<.000)$ suggesting that at least one of the four independent variables had a significant effect on the dependent variable of reported use of culturally responsive practices.

The results of the preliminary multiple regression model, as shown in Table 18, demonstrated that, unlike in the case of Research Question 1, two of the teacher characteristics had a significant and positive impact on the outcome. Specifically, attitudes towards ELLs had a significant and positive effect $(\beta=.338, \mathrm{t}=5.277, \mathrm{p}<.000)$ and indicated that the more favorable the respondents' attitudes, the higher their reported implementation of culturally responsive practices. Additionally, professional development also demonstrated a significant and positive outcome $(\beta=.180, \mathrm{t}=2.901, \mathrm{p}$ $=.004)$. Knowledge of second language acquisition and teacher quality as specified by NCLB, were not significant predictors.

Table 18

Regression analysis summary for teacher characteristics predicting reported use of culturally responsive practices

\begin{tabular}{|c|c|c|c|c|c|}
\hline Variable & B & SE B & $\beta$ & $\mathrm{t}$ & $p$ \\
\hline \multicolumn{6}{|l|}{ Knowledge of second language } \\
\hline acquisition & -.044 & .038 & -.075 & -1.163 & .246 \\
\hline Highly qualified status & -.118 & .252 & -.029 & -.467 & .641 \\
\hline Amount of professional development & .005 & .002 & .180 & 2.901 & .004 \\
\hline Attitudes towards ELLs & .502 & .095 & .338 & 5.277 & .000 \\
\hline
\end{tabular}

Note: $R^{2}=.154$ (Adjusted $\left.R^{2}=.139\right)(N=230, p<.05)$ 
The final regression model, as Table 19 indicates, included the variables that were significant and omitted the ones that were not. Thus knowledge of second language acquisition, and teacher quality were excluded. As in Research Question 1, the most significant predictor continued to be attitudes towards ELLs; although for Research Question 2, professional development additionally impacted teachers' reported use of culturally responsive practices.

Table 19

Final regression model for predicting reported use of culturally responsive practices

\begin{tabular}{lccccc}
\hline Variable & B & SE B & $\beta$ & $\mathrm{t}$ & $p$ \\
\hline Professional development & .005 & .002 & .174 & 2.822 & .005 \\
Attitudes towards ELLs & .475 & .092 & .320 & 5.177 & .000 \\
\hline
\end{tabular}

Note: $R^{2}=.148$ (Adjusted $\left.R^{2}=.140\right),(N=230, p<.05)$

The two variables of attitudes towards ELLs and professional development accounted for $14 \%$ of the variance in reported use of culturally responsive practices across all respondents (Adjusted $R^{2}=.140$ ).

Q 2 a. Is there a relationship between No Child Left Behind indicators of teacher quality and teachers' reported use of culturally responsive teaching practices for ELLs within the classroom setting?

As in Research Question 1a, a categorical variable questioning whether teachers believed themselves to be highly qualified or not was used to answer this research question.

In order to answer the research question and explore the relationship between teacher quality and reported use of culturally responsive teaching practices, a point- 
biserial correlation was calculated. Results indicated that reported use of culturally responsive teaching practices was not associated with whether teachers considered themselves highly qualified.

Additionally an analysis of group differences (between respondents who considered themselves highly qualified and those who did not) in the mean response to the statements that measured their perceived importance of culturally responsive practices, was conducted using the t- test for independent samples. The results, as presented in Table 20, indicated an insignificant differences between the two groups.

Table 20

Differences in perceived importance of culturally responsive practices between teachers who reported a highly qualified status and those who did not

\begin{tabular}{lccccccc}
\hline Teachers & $\mathrm{n}$ & $\mathrm{M}$ & $\mathrm{SD}$ & $\mathrm{df}$ & $t$ & $p$ & Cohen's $d$ \\
\hline $\begin{array}{l}\text { Highly } \\
\text { qualified }\end{array}$ & 216 & 4.9715 & .97 & 228 & .533 & .594 & 0.137 \\
$\begin{array}{l}\text { Not highly } \\
\text { qualified }\end{array}$ & 14 & 4.8274 & 1.13 & 14.27 & .466 & .648 & \\
\hline
\end{tabular}

Q 2 b. Is there a relationship between knowledge of second language acquisition and teachers' reported use of culturally responsive classroom teaching practices for ELLs? As mentioned earlier, knowledge of second language acquisition was assessed by using an 11-item multiple-choice quiz. The total score that individuals achieved on the quiz was used as the independent variable. A Pearson’s product moment correlation coefficient was calculated between knowledge of second language acquisition and reported use of culturally responsive practices with no relationship noted, $\mathrm{r}=.038, \mathrm{n}=$ 
230, $\mathrm{p}=.285$ (one-tailed). There was no relationship between respondents' knowledge of second language acquisition and their reported use of culturally responsive teaching practices.

Q 2 c. Is there a relationship between the amount of professional development on teaching ELLs and teachers' reported use of culturally responsive classroom teaching practices for ELLs?

The analysis used for this research question was a Pearson's product moment correlation analysis. Results indicated that there was a statistically significant relationship between the amount of professional development teachers accrued and their reported use of culturally responsive teaching practices: $\mathrm{r}=.218, \mathrm{n}=230, \mathrm{p}<.000$ (one-tailed). One would expect this relationship to be directional, in that the more professional development teachers received, the higher the reported use of culturally responsive practices.

Q 2 d. Is there a relationship between teachers' attitudes towards and perceptions of ELLs and teachers' reported use of culturally responsive classroom teaching practices for ELLs?

As anticipated, a significant and positive relationship emerged between teachers' attitudes and their perceived importance of culturally responsive practices: $\mathrm{r}=.344, \mathrm{n}=$ $230, \mathrm{p}<.01$.

Q 3. How do teachers' overall perceived importance ratings for culturally responsive teaching practices correlate with overall reported implementation ratings as measured by a self-report questionnaire? 
This research question was answered by using a simple linear regression. Teachers' overall perceived importance significantly and positively impacted their reported use of culturally responsive teaching practices: $\beta=.569, \mathrm{t}=10.443, p<.01$. Perceived importance also explained a significant proportion of variance in scores for reported use: $R^{2}=.324$ (Adjusted $\left.\mathrm{R}^{2}=.321\right), F(1,228)=109.050, p<.01$. In other words, perceived importance accounted for 32.1\% of the variance in reported use of culturally responsive practices.

In exploring what impacts teachers' perceived importance and reported use of culturally responsive practices in the classrooms, the predictor accounting for the most variance was found to be teacher attitudes towards ELLs. Professional development proved to be somewhat significant, particularly for reported use of culturally responsive practices. There was a weak relationship between teacher knowledge of second language acquisition and perceived importance of culturally responsive practices as well as professional development and perceived importance of culturally responsive practices. In the present study, teacher quality as measured by NCLB indicators of highly qualified status did not prove to be significant. 


\section{CHAPTER V \\ DISCUSSION}

With the large numbers of ELLs in U.S. schools who are not making adequate progress (NAEP, 2009), are at-risk for dropping out (Ballantyne, Sanderman, \& Levy, 2008) or are being inappropriately identified for special education services (Artiles, Rueda, Salazar \& Higareda, 2005), the need to study factors that impact their education and overall success is great. Student outcomes are impacted by teacher variables such as years of teaching experience (Darling-Hammond, 2000), content knowledge, as measured by number of courses or major (Darling-Hammond, 2000; Goldhaber, \& Brewer, 2000); and participation in professional development activities (Wenglinsky, 2002). However, specifically with regard to what works for ELLs, the research in terms of teacher variables is sparse (Genesee, Lindholm-Leary, Saunders, \& Christian, 2005). The present study attempted to add to the growing body of literature in the area of cultural responsivity within classrooms and provide initial information regarding teacher characteristics that are related to providing ELLs with culturally responsive instruction.

The purposes of this study were to explore whether certain teacher characteristics such as teacher quality, knowledge of second language acquisition, attitudes towards and perceptions of ELLs, and skills in teaching ELLs were related to the perceived importance and reported use of culturally responsive practices within classrooms. The research questions that guided the study examined the collective effect of the predictor variables mentioned above first on teachers' perceived importance of culturally responsive practices and second on reported use of culturally responsive practices. 
Subsequently, the subsidiary questions examined each predictor variables unique relationship with the two dependent variables of perceived importance and reported use of culturally responsive practices. The last research question examined the relationship between perceived importance and reported use of culturally responsive practices.

Data for the study were collected in the mid-West through an on-line self-report survey with a 22.39\% response rate. In 1979, Cook and Campbell pointed out that selfreport data was in itself questionable because respondents tend to report what they believe the researcher expects or what reflects them in a positive light. Therefore, Cook and Campbell believed that data collected by self-report methods may be flawed in its ability to measure the intended constructs. However, more recently, Chan (2009) has pointed out that respondents do not provide researchers with inaccurate data as often as was previously thought; particularly in non-experimental settings. Other researchers tend to agree, believing that self-report methodology is suitable for the study of human characteristics (Razavi, 2001).

The biggest challenge in most survey research is achieving response rates that are considered adequate by study authors since there is no agreed upon standard for a minimum acceptable rate (Fowler, 2009). According to de Leeuw and de Heer (2002), declining response rates is an international phenomenon, and a five to 20 percent response rate is often considered the norm (Fowler). On-line surveys are cost effective in many ways such as reduced time and costs for data collection (Gaiser \& Schreiner,2009) and although the ease of taking the survey on the internet seems to suggest a high response rate, non-response to web-based surveys is a serious problem (Kaplowitz, Hadlock, \& Levine, 2004; Vehovar, Batagelj, Manfreda \& Zalatel, 2002). 
Non-response may occur across different stages of a web survey process and may occur due to several reasons (Vehovar, Batagelj, Manfreda \& Zalatel, 2002). In the current study, once principals received the email pre-notification, the expectation was that they would send the survey link on to their teaching staff. One principal initially decided that she was not going to email her faculty the survey link. Subsequently, after the second reminder notice was sent out, she decided to send out the survey link. After a reminder, another principal responded saying that she had junked the first email because she did not recognize the sender. She asked for the initial email to be re-sent and then forwarded the link to the faculty. Similarly, the initial pre-notification, or subsequent reminders that were sent to the other principals may have gone unnoticed or into the receiver's junk email box thereby adding to the potential for non-response.

Non-response may also have occurred if the teachers were not persuaded by the invitation or the incentive of the drawing for a $\$ 20$ gift card to Amazon.com that was being offered. Teachers may have read some of the initial questions without answering, or started answering and then stopped. If incentives for completing the survey had been built in to the study, it is probable that response rates would have increased substantially as Singer (2002) found. Researchers have found that survey participation depends largely on the survey topic, its salience, and the respondent's involvement in the topic (Groves, 2006). In the present study almost 70 percent of respondents had less than five percent ELLs in their respective classrooms. It is encouraging that these teachers took the time to respond when so few of their students were ELLs, more so in the light of the projected 50\% increase in school age ELLs by 2030 (U.S. Census Bureau). 
The single biggest predictor for increasing response rates, according to research, has been a surface mail notification (Kaplowitz, Hadlock, \& Levine, 2004). In the present study, while a surface mail notification was not built in to the design, a pre-notification email was sent out, followed by the survey link and three subsequent reminders.

The following section provides results of the study, specifically in terms of the three main research questions.

The research questions guiding the present study sought to explore whether specific teacher characteristics contributed to the perceived importance and reported use of culturally responsive practices for ELLs in the classroom. The teacher characteristics under consideration were knowledge of second language acquisition processes, highly qualified status as required by NCLB, professional development and attitudes towards ELLs.

Previous research has examined the role of diversity preparation in fostering cultural responsivity among teachers (Bustos Flores \& Smith, 2008). While levels of diversity preparation were not explored in the present study, respondents clearly indicated that culturally responsive practices were perceived to be important $(M=5.08, S D=0.59)$. On the subscale measuring this variable, respondents gave the highest rating to the item "I help all students to connect and apply what they have learned to the home and the community” ( $\mathrm{M}=5.49, \mathrm{SD}=0.73)$; thereby supporting the notion that making the link between home and school is critical (Villegas, 1991). Not surprisingly, this was also the highest rated item in terms of reported use of culturally responsive practices (M=6.36; SD 1.08). 
The lowest rated item on the subscale measuring perceived importance was "I provide extensive opportunities for parents and families of my diverse learners to participate in classroom instructional activities” $(\mathrm{M}=4.67, \mathrm{SD}=0.99)$ and was rated as being somewhat important. Reported use of the same item was rated lower than perceived importance $(M=3.21, S D=1.899)$. The lowest rated item on the reported use subscale was "I plan activities to celebrate diverse cultural practices in my classroom" $(M=3.20$, SD 1.59). The data indicated that teachers believed it was important to help all students connect what they had learned to the home, yet the opportunities for family members to participate and involve themselves in instructional activities were less frequently available. These results could be indicative of language and cultural barriers (Karabenick \& Noda, 2004) or institutional barriers such as administrative policies (Richards, Brown \& Forde, 2006). There is substantial evidence to suggest that learning for ELLs is optimal when teachers capitalize on the linguistic and cultural strengths of their students (Iddings \& Katz, 2007) and involve culturally and linguistically diverse families in classroom activities (Cartledge \& Kourea, 2008).

The most conclusive finding of the present study was that attitudes towards ELLs was an important predictor in both the perceived importance and reported use of culturally responsive practices in the classroom. Similarly, perceived importance was found to be a strong predictor in the reported use of culturally responsive practices in the classroom. The findings are important in that, as Ajzen (2001) has pointed out in his survey of attitude theory and research, attitudes are relevant for understanding and predicting social behavior. Other research exploring the needs of ELLs has consistently 
documented the impact of teacher attitudes on teacher behavior, instruction and on student outcomes (Bai \& Ertmer, 2008; Youngs \& Youngs, 2001).

Previous research has made efforts to identify predictors that are likely to explain attitudes towards ELLs and has been inconclusive (e.g. Youngs \& Youngs, 2001), but does suggest that positive attitudes are developed through a multitude of factors, most importantly diversity preparation both at the pre-service and in-service levels. Bustos Flores and Smith (2008) attempted to analyze the relationships of teacher characteristics to attitudinal beliefs about language minority students. In a survey of 564 teachers, using a 34-item survey, the researchers explored teachers' attitudinal beliefs towards language diversity; whether there were group differences in relation to ethnicity, linguistic proficiency, number of minority students in class and preparation for diversity, and whether these personal characteristics mediated teachers' attitudinal beliefs towards language diversity. They found that teacher attitudes were influenced by multiple factors to varying degrees and that teachers held a moderate language as a problem orientation (Ruiz, 1995). In terms of group differences among personal characteristics and diversity training, Bustos Flores and Smith found that ethnicity was important in relation to a positive orientation towards language-diversity constructs and that teachers with more diversity training held a more positive outlook towards language diversity. They concluded that all teachers, regardless of their ethnicity, need to have exposure to diversity issues and some degree of second language proficiency when working with ELLs.

Another noteworthy outcome of the present study was that even though 70 percent of the study respondents had fewer than five percent ELLs in their classes, the 
mean score on the scale measuring attitudes was 4.47 out of 6 ; where six represented a strong agreement with a positively worded attitudinal statement. In examining mean responses to each of the ten attitudinal statements, the statement "English language learners would be a welcome addition to my classroom” had the highest mean score $(M=5.40 ; S D=0.734)$ whereas “Adapting classroom instruction for ELLs is difficult” achieved the lowest mean score $(\mathrm{M}=3.00$; $\mathrm{SD}=1.211)$. This data supports the notion that teachers may not feel adequately prepared to instruct ELLs (Garcia, Arias, Murri \& Serna, 2010) and that there is a little variability in how prepared teachers feel about teaching ELLs (Bustos Flores \& Smith, 2008; Karabenick \& Noda, 2004). Previous research has suggested that when the district enrolls a large linguistic-minority population, teachers will hold a more positive view of ELLs (Byrnes, Kiger \& Manning, 1997). The present study suggests that having positive attitudes towards ELLs may not necessarily be associated with having large populations of linguistic minority students.

Perceived importance of culturally responsive teaching practices positively impacted teachers’ reported use of culturally responsive teaching practices and accounted for 32 percent of the total variance for reported use of culturally responsive practices. This finding suggests that teachers who believe that being culturally responsive has positive results for students, will make every effort to do so. Barriers to implementation may arise from an inadequate knowledge base (Karabenick, \& Noda, 2004) or inadequate resources (Richards, Brown \& Ford, 2006).

In the present study, along with attitudes towards ELLs, amount of professional development was found to be a significant predictor in the reported use of culturally responsive teaching practices. A statistically significant correlation between amount of 
professional development and reported use of culturally responsive teaching practices ( $\mathrm{r}$ $=.218, \mathrm{p}<.000$ ) was also found. Additionally, there was a weak statistically significant relationship between professional development and teachers' perceived importance of culturally responsive teaching practices $(\mathrm{r}=.138, \mathrm{p}=.018)$. This relationship was too weak however to be reflected in the regression model. Although most professional development offered to teachers is brief and infrequent (Casteel \& Ballantyne, 2010), data obtained in this study suggests that it is an important variable in fostering culturally responsive practices in school settings. This is similar to other research findings (Bustos Flores \& Smith, 2008).

Research has demonstrated that educators themselves recognize that receiving adequate PD is an on-going necessity particularly with respect to the education of ELLs, Batt (2008) conducted a survey of ELL educators in Idaho to investigate what they perceive as greatest challenges and needs for improvement of ELL education. The study aimed at soliciting solutions and priorities from participants in order to design professional development for the short-term, and address issues of teacher education in the long-term. The top six ranked areas in which respondents expressed a need for professional development were parent involvement (30 percent); ESL curriculum development (29 percent); Spanish language class (28 percent); first and second language literacy methods (26 percent); sheltered English instruction (25 percent); ESL methods (24 percent); and how to establish a newcomer center (24 percent). Batt recognizes that some of the identified recommendations may not be logistically or fiscally feasible, yet recommends that three of the identified priorities (ESL methods, sheltered instruction, 
and first and second language literacy methods) could be addressed through in-service professional development for the short term to overcome gaps in teacher preparation.

Findings from the present study would indicate that the role of professional development is critical to teachers being more responsive to the needs of ELLs and parallel the recommendations from research (Tellez \& Waxman, 2005). Wilde (2010) proposes five principles in order that the professional development is productive and meaningful: to build on existing knowledge and skills, to engage participants as learners, to provide practice, feedback and continuing follow-up, to measure change in teacher knowledge, skills, and measure changes in student performance. Additionally, Wilde suggests that both knowledge and skills of the participants should be assessed at the conclusion of the PD. The assessment procedures should include the results of ongoing monitoring and feedback, as well as a general evaluation of each participant's learning of the professional development content. de Jong and Harper (2005) argue that teachers of ELLs need to acquire specific knowledge and skills related to language and culture and propose a framework consisting three dimensions that help describe the nature of these ELL-specific knowledge and skills. First, de Jong and Harper suggest that teachers must understand the process of second language acquisition and acculturation; second teachers should be aware how language and culture mediate learning. The third dimension considers the importance of including linguistic and cultural diversity as explicit goals of curriculum and instruction. They acknowledge that their framework is a conceptual rather than an empirical framework and propose that future research will be necessary to support, expand or change the model. They conclude by pointing out that just good 
teaching practices are too generic and fail to account for linguistic and cultural diversity, which are two of the most important learner variables affecting ELLs’ success.

Results of the study indicated that knowledge of second language acquisition as assessed by an 11-item multiple-choice quiz was not a significant predictor of perceived importance or reported use of culturally responsive teaching practices in the regression models. A weak relationship was demonstrated between knowledge of second language acquisition and perceived importance of culturally responsive practices. Research suggests that teacher sensitivity to second language acquisition issues is critical to the development of skills necessary for instruction of ELLs (Layton \& Lock, 2002). Therefore, it should also hold true that the teachers who know more about second language acquisition also give more credence to the importance of being more culturally responsive. Interestingly, there was no relationship between reported use of culturally responsive practices and knowledge of second language acquisition. The lack of relationship between reported use of culturally responsive practices and knowledge of second language acquisition suggests that teachers may practice cultural responsiveness without a clear understanding of how their ELLs are learning English. A more plausible explanation, however, is that the construct of knowledge of second language acquisition as developed for this study was too broad and multidimensional in nature.

Researchers caution that teachers of ELLs must think of language carefully and modify their instructional practices to accommodate ELLs (August \& Shanahan, 2006; Flynn \& Hill, 2005). There are clear recommendations that all teachers of ELLs should have a clear understanding of the processes of second language acquisition (Clewell, de Cohen \& Murray, 2007; de Jong \& Harper, 2008; Goldenberg, 2008). 
Research has shown that highly effective teachers increase student achievement more than ineffective teachers and that teachers' knowledge influences student outcomes (Darling-Hammond, 2000; Gelman, Pullin, \& Kaufman, 2004) and therefore NCLB requires all schools to provide "highly qualified" teachers to all students. Teacher quality, as reflected by NCLB requirements, was not a significant predictor in the regression models, nor was it independently associated with the dependent variables of perceived importance of culturally responsive practices and reported use of culturally responsive practices. An overwhelming majority (93.9 \%) of respondents reported that they met criteria for highly qualified status under NCLB. However, when asked how they met the criteria, they did not clearly indicate how they demonstrate content knowledge of the subjects that they are teaching (i.e. whether they had taken the Praxis). While NCLB does not require mainstream teachers of ELLs to have more cultural awareness (CadieroKaplan \& Rodriguez, 2008; Scott \& Mumford, 2007), findings from the current study indicate that there are no significant differences on perceived importance and reported use of culturally responsive practices across respondents who rate themselves as being highly qualified $(\mathrm{N}=216)$ and those who do not $(\mathrm{N}=14)$.

Miller, Strosnider and Dooley (2002) implemented a study to ascertain the status of diversity requirements in teaching licensure. They found little consistency across the states and propose that professionals who are concerned about teacher preparation for diversity need to develop standards and requirements for all teachers. In the meantime, as Clewell, de Cohen and Murray (2007) recommend, districts should assume responsibility for the training and professional development of teachers, including bilingual/ESL teachers, who meet the NCLB requirements for a high-quality teacher. They additionally 
suggest that courses in instruction of ELLs should be required for certification or employment of all teachers in high-ELL enrollment districts.

\section{Limitations of the Study}

This study was based on the results of respondents' self-report to a web-based survey. Despite widespread use, self-report questionnaires have been criticized in that there may be potentially inaccurate recall or estimation of specific behaviors or possible differential interpretations of items (Constantine \& Ladany, 2000). Relying solely on self-report instruments for data about teachers' cultural responsiveness may have failed to yield accurate information about their true culturally responsive behaviors.

The use of the on-line format, while convenient and cost-effective, had its own unique set of challenges. Once pre-notifications were sent out, no mechanism was in place to ensure that principals had received and read the email. The same held true for the survey link and the subsequent reminders. As described earlier in this chapter, there was no control over principals' forgetting, delaying or refusing to send out the survey link. There was also no control over how the principals sent out the link. Participation of potential respondents may have varied depending on how interesting the principals made the study sound. If the survey link was sent out in an enthusiastic email from principals, participation may have been different from that resulting from a cursory forward.

Caution needs to be used in generalizing results because participants were selfselected in that they had a choice of whether to participate or not. The sample of respondents represented a limited geographic area and the demographics may be different from another sample elsewhere, thereby confounding the replicability of the study. 
The survey instrument that was developed for the study was based on prior research conducted in the areas of culturally responsive practices, attitudes towards ELLs and second language acquisition. The construct of knowledge of second language acquisition was developed for this study from existing literature. More research is needed to identify the items that are related to this construct.

\section{Implications for Practice}

The ideas and practices associated cultural responsiveness are well- grounded conceptually (Brown, 2007); however, there is a paucity of empirical evidence in the research literature (Cochran-Smith, Davis \& Fries, 2004; Morrison, Robbins \& Rose, 2008).

As mentioned in an earlier chapter, the culturally responsive framework is grounded in a belief that schools are agents for promoting equity and social justice (Gay, 2000). A critical component of culturally responsivity is that learning should be channeled through the cultural reality and experiences of the learner. In other words, schools should connect children's school experiences with their cultural reality (Durden, 2008). Therefore, an important characteristic of a culturally responsive teacher is the belief that prior knowledge, past experiences, and cultural references be used while teaching students from diverse background. Montgomery (2001) additionally suggests that a culturally responsive teacher utilizes instructional strategies and teaching behaviors that lead to improved academic achievement for all students.

Results from the study suggest that attitudes towards and perceptions of ELLs are critical to teachers' ability to provide culturally responsive instruction to these diverse 
learners. Results also indicate that teachers who are able to participate in professional development in instructing ELLs are more responsive to their needs.

These findings provide guidance to administrators and others with decisionmaking authority as they work to ensure that their faculties have scheduled collaboration times to reflect and dialogue as to how to cater to their diverse learners both at their grade levels and at the building level. Research suggests that pre-service and practicing teachers should be given guided opportunities to delve purposefully and productively into their comprehension of what cultural responsivity means to them and how to work through their own barriers and resistance to using inclusive practices (Gallavan, 2005). The key is that opportunities for personal reflection have to be systematically provided (Howard, 2003) and the underlying premise is that developing cultural responsiveness is a priority to school districts and their administrators.

In addition, as research suggests, ELLs are often inappropriately identified as needing special education services (Artiles \& Klingner, 2006) It is imperative, therefore, that special education teachers explore how to deliver their services within a culturally responsive framework (Cartledge, \& Kourea, 2008).

\section{Implications for Future Research}

The findings of this study have significant implications for future research. For example, it is possible that a self-report measure such as this may actually be assessing socially desirable responses or as Pope-Davis and Dings (1994) point out, anticipated versus actual culturally responsive behaviors and attitudes/beliefs, knowledge, and skills. Given these findings, there is a need for research that examines the relationships among actual culturally responsive behaviors across a variety of situations and to use more direct 
means (e.g., direct observation, videotaped sessions) for assessing this construct. It is also important to empirically demonstrate how culturally responsive practices impact student achievement.

Future research should explore whether there are differences in reported use of culturally responsive practices across teachers i.e. across classroom teachers, special educators and specialists. Whether these results hold true for different samples of teachers across other districts would require further research. An additional line of research would be to explore whether culturally responsive practices of special educators are different due to the requirements of following procedures for special education programming. Whether teacher preparation or years of experience in the classroom are significant predictors in providing culturally responsive instruction are important factors to investigate.

Future studies need to investigate how second language acquisition processes may be facilitated within the classroom and how this impacts student achievement. For example, while research has documented that explicit oral language development as a part of daily instruction is beneficial (Graves, Gersten, \& Haager, 2004); the focus and content of this instruction is still confusing to teachers (Gersten \& Baker, 2006). Similarly, research suggests that explicit vocabulary interventions for ELLs are necessary (August \& Snow, 2007), yet there is a paucity of research as to what these are and how they need to be implemented. 


\section{Conclusion}

This study has been an exploratory endeavor to examine how certain teacher characteristics impact teachers' perceived importance and reported use of culturally responsive teaching practices, particularly for ELLs. Knowledge of second language acquisition, attitudes towards ELLs, professional development and teacher quality were examined in their ability to impact the dependent variables of perceived importance and reported use of culturally responsive teaching practices. The most significant finding of the study was that teachers' attitudes towards and perceptions of ELLs was a significant predictor for both perceived importance as well as reported use of culturally responsive teaching practices. The study also found that professional development was a significant predictor for reported use of culturally responsive teaching practices. Additionally perceived importance was found to be a significant predictor for reported use of culturally responsive teaching practices. These results indicate that there is a need for teachers to continuously reflect and explore their own biases and frameworks if they are to continue developing the skills needed to adequately instruct ELLs meaningfully.

Future research in the area that includes observational data may unveil the mechanisms of effective culturally responsive instruction, but until that time, it is imperative that researchers continue to explore teacher variables that affect the education of ELLs. It is also imperative that the expanding knowledge base is shared with practitioners such that all stakeholders can purposefully work towards improving teacher effectiveness and student achievement for all linguistically and culturally diverse learners. 


\section{REFERENCES}

Ajzen, I. (2001). Nature and operation of attitudes. Annual Review of Psychology, 52, 2758

Alexander, D., Heaviside, S., \& Farris, E. (1998). Status of education reform in public elementary and secondary schools: Teachers' perspectives. Washington DC: U.S. Department of Education, National Center for Education Statistics. Retrieved September 4, 2010 from http://nces.ed.gov/pubs99/1999045.pdf

Antunez, B. (2002). The preparation and professional development of teachers of English language learners. ERIC Digest: ERIC Clearinghouse on Teaching and Teacher Education, American Association of Colleges for Teacher Education. Washington, DC.

Aron, A., Aron, E.N., \& Coups, E.J. (2006). Statistics for psychology, $4^{\text {th }}$ Edtion. New Jersey: Prentice Hall.

Artiles, A. J., \& Klingner, J. K. (2006). Forging a knowledge base on English language learners with special needs: Theoretical, population and technical issues. Teachers College Record, 108 (11), 2187-2194.

Artiles, A. J., \& Ortiz, A. (2002). English language learners with special education needs: Contexts and possibilities. In A. J. Artiles and A. A. Ortiz (Eds.) English language learners with special needs: Identification, placement, and instruction (pp.3-27). Washington, DC: Center for Applied Linguistics.

Artiles, A. J., Rueda, R., Salazar, J. J., \& Higareda, I. (2005). Within-group diversity in minority disproportionate representation: English language learners in urban school districts. Exceptional Children, 71(3), 283-300. 
August, D., \& Hakuta, K. (1998). Educating language-minority children .Washington, DC: National Academy Press.

August, D., \& Shanahan, T. (2006). Developing literacy in second language learners: Report of the national literacy panel on language-minority children and youth (Executive Summary). Mahwah, NJ: Lawrence Erlbaum. Retrieved July 9, 2010 from http://www.cal.org/projects/archive/nlpreports/Executive_Summary.pdf

August, D. \& Snow, C. (2007). Developing vocabulary in English-language learners. In B.M. Taylor \& J. E. Ysseldyke (Eds.) Effective interventions for struggling readers, K-6 (pp. 84-108). New York: Teachers College, Columbia University.

Babbie, E. R. (1990). Survey research methods (2nd ed.). Belmont, CA: Wadsworth, Inc.

Bai, H. \& Ertmer, P.A. (2008). Teacher educators' beliefs and technology uses as predictors of preservice teachers' beliefs and technology attitudes. Journal of Technology and Teacher Education,16 (1), 93-112.

Baker, C. (2000). The care and education of young bilinguals: An introduction for professionals. Clevedon, England: Multilingual Matters.

Ballantyne, K.G., Sanderman, A.R., \& Levy, J. (2008). Educating English language learners: Building teacher capacity. Washington, DC: National Clearinghouse for English Language Acquisition. Retrieved Sept. 5, 2010 from http://www.ncela.gwu.edu/practice/mainstream_teachers.htm

Batt, E.G. (2008). Teachers’ perceptions of ELL education: Potential solutions to overcome the greatest challenges. Multicultural Education, Spring, 39-43.

Bialystok, E. (1997). Effects of bilingualism and biliteracy on children's emerging concepts of print. Developmental Psychology, 33(3), 429-440. 
Boyle, A., Taylor, J., Hurlburt, S. \& Soga, K. (2010). Title III Accountability: Behind the numbers. ESEA Evaluation Brief. American Institutes for Research (AIR). Retrieved July 16, 2010 from http://www2.ed.gov/rschstat/eval/title-iii/behindnumbers.pdf

Brisk, M.E. (1998). Bilingual education: From compensatory to quality schooling. Mahwah, NJ: Erlbaum.

Brown, M. (2007). Educating all students: Creating culturally responsive teachers, classrooms and schools. Intervention in School and Clinic, 43 (1), 57-62.

Buddin, R., \& Zamarro, G. (2009). Teacher qualifications and student achievement in urban elementary schools. Journal of Urban Economics, 66, 103-115.

Bustos Flores, B., \& Smith, H.L. (2008). Teachers' characteristics and attitudinal beliefs about linguistic and cultural diversity. Bilingual Research Journal, 31, (1), 323358.

Byrnes, D., Kiger, G., \& Manning, M.L. (1997). Teachers’ attitudes about language diversity. Teaching and Teacher Education, 13 (6), 637-644.

Cadiero-Kaplan, K. \& Rodriguez, J.L. (2008). The preparation of highly qualified teachers for English language learners: Educational responsiveness for unmet needs. Equity \& Excellence in Education, 41 (3), 372-387. doi: $10.1080 / 10665680802179444$

Campanelli, P. (2008). Testing survey questions. In E. D. de Leeuw, J. J. Hox, \& D. A. Dillman (Eds.) International handbook of survey methodology (pp. 176-200). New York: Lawrence Erlbaum Associates. 
Capps, R., Fix, M., Murray, J., Ost, J., Passel, J.S. \& Herwantoro, S.(2005). The new demography of America's schools: Immigration and the No Child Left Behind Act. Washington, D.C.: The Urban Institute. Retrieved July 28, 2010 from http://www.urban.org/UploadedPDF/311230_new_demography.pdf

Cartledge, G. \& Kourea, L. (2008). Culturally responsive classrooms for culturally diverse students with and at risk for disabilities. Exceptional Children, 74 (3), 351-371.

Cataldi, E.F., Laird, J., \& KewalRamani, A. (2009). High School dropout and completion rates in the United States: 2007. (NCES 2009-064). National Center for Education Statistics, Institute of Education Sciences, U.S. Department of Education. Washington, DC. Retrieved October 9, 2010 from http://nces.ed.gov/pubsearch/pubsinfo.asp?pubid=2009064

Chan, D. (2009). So why ask me? Are self-report data really that bad? In C.E. Vance \& R.J. Vandenberg (Eds.) Statistical and methodological myths and urban legends: Doctrine, verity and fable in the organizational and social sciences (pp. 309-332). New York, New York: Routledge.

Cirino, P.T., Pollard-Durodola, S.D., Foorman, B. R., Carlson, C. D. \& Francis, D. J. (2007). Teacher characteristics, classroom instruction, and student literacy and language Outcomes in bilingual kindergartners. The Elementary School Journal, 107 (4), 342-364.

Clewell, B.C., de Cohen, C.C., \& Murray, J. (2007). Promise or peril?: NCLB and the education of ELL students. Program for Evaluation and Equity Research, The Urban Institute, Washington DC. 
Clotfelter, C.T., Ladd, H.F., \& Vigdor, J.L. (2007). How and why do teacher credentials matter for student achievement? (NBER Working Paper No. 12828). Cambridge, MA: National Bureau of Economic Research. Retrieved January 21, 2011 from http://www.nber.org/tmp/71287-w12828.pdf

Cochran-Smith, M., Davis, D., \& Fries, K. (2004). Multicultural teacher education:

Research, practice, and policy. In J. Banks \& C. Banks (eds.), Handbook of research on multicultural education (2nd ed), pp. 931-975. San Francisco, CA: Jossey Bass.

Constantine, M. G., \& Ladany, N. (2000). Self-report multicultural counseling competence scales: Their relation to social desirability attitudes and multicultural case conceptualization ability. Journal of Counseling Psychology, 47 (2),155-164.

Cook, C., Heath, F. \& Thompson, R. L. (2000). A meta-analysis of response rates in webor internet-based surveys. Educational and Psychological Measurement, 60 (6), 821-836.

Cook, T.D. \& Campbell, D.T. (1979). Quasi-experimentation: Design and analysis for field settings. Chicago, Illinois: Rand McNally.

Council of Chief State School Officers (1992). Recommendations for improving the assessment and monitoring of students with limited English proficiency. Alexandria, VA: Council of Chief State School Officers, Weber Design. Crawford, J. (2004). Educating English Learners: Language diversity in the classroom. Los Angeles, CA : Bilingual Educational Services, Inc.

Crawford, J. \& Krashen, S. (2007). English Learners in American classrooms: 101 questions, 101 answers. New York: Scholastic. 
Cummins, J. (1981) Age on arrival and immigrant second language learning in Canada. A reassessment. Applied Linguistics,2, 132-149.

Cummins, J. (1986).Empowering language minority students. Harvard Educational Review, 56, 18-36.

Cummins, J. (1991). Empowering culturally and linguistically diverse students with learning problems. ERIC Digest [Online]. Available: http://www.eric.ed.gov/contentdelivery/servlet/ERICServlet?accno=ED333622

Cummins, J. (2001) Empowering minority students: A framework for intervention. Harvard Educational Review, 71 (4), 656-676.

Curran, M. E. (2003). Linguistic diversity and classroom management. Theory Into Practice, 42 (4), 334-340.

Czaja, R. \& Blair, J. (2005). Designing surveys: A guide to decisions and procedures, $2^{\text {nd }}$ edition. Thousand Oaks, CA: Pine Forge Press

Darling-Hammond, L. (2000). Teacher quality and student achievement: A review of state policy evidence. Education Policy Analysis Archives, 8 (1), Retrieved October 10, 2010 from: http://epaa.asu.edu/ojs/article/viewFile/392/515.

Darling-Hammond, L. (2007). Race, inequality and educational accountability: the irony of 'No Child Left Behind'. Race, Ethnicity and Education, 10 (3), 245-260.

Darling-Hammond, L., \& McLaughlin, M. (1995). Policies that support professional development in an era of reform. Phi Delta Kappan, 76 (8), 597-604.

Darling-Hammond, L., \& Youngs, P. (2002). Defining “highly qualified teacher”: What does “scientifically-based research” actually tell us? Educational Researcher, 31(9), 13-25. 
DeCarlo, L.T. (1997). On the meaning and use of kurtosis. Psychological Methods, 2 (3), 292-307.

Dee, J. R., \& Henkin, A.B. (2002). Assessing dispositions toward cultural diversity among pre-service teachers. Urban Education, 37 (1), 22-40.

de Jong, E. J. \& Harper, C.A. (2005). Preparing mainstream teachers for Englishlanguage learners: Is being a good teacher good enough? Teacher Education Quarterly 32 (2), 101-24.

de Leeuw, E.D., \& de Heer, W. (2002). Trends in household survey nonresponse: A longitudinal and international comparison. In R. M. Groves, D.A. Dillman, J.E. Eltinge, \& R. J. A. Little (Eds.), Survey Nonresponse (pp. 41-54). New York: John Wiley.

de Leeuw, E.D. \& Hox, J.J. (2008). Self-administered questionnaires: mail surveys and other applications. In E. D. de Leeuw. J.J. Hox \& D. A. Dillman (Eds.). International handbook of survey methodology. (pp. 239-263). New York: Lawrence Erlbaum Associates.

de Leeuw, E.D., Hox, J.J. \& Dillman, A.A. (2008). The cornerstones of survey research. In E. D. de Leeuw. J.J. Hox \& D. A. Dillman (Eds.). International handbook of survey methodology. (pp. 1-17). New York: Lawrence Erlbaum Associates.

Delpit, L.D. (1988). The silenced dialogue: Power and pedagogy in educating other people’s children. Harvard Educational Review, 58 (3), 280-298.

Deussen, T., Autio, E., Miller, B., Turnbaugh-Lockwood, A., \& Stewart, V. (2008). What teachers should know about instruction for English language learners: A report to Washington State. Portland, Oregon: Northwest Regional Educational 
Laboratory. Retrieved June 8, 2010 from

http://www.k12.wa.us/migrantbilingual/pubdocs/NWREL-Report-

ELLInstruction-Nov2008.pdf

Dillman, D.A. (2000). Mail and internet surveys: The tailored design method. New York: Wiley.

Dillman, D. A. (2007). Mail and internet surveys: The tailored design method. Hoboken, New Jersey: John Wiley \& Sons, Inc.

Doherty, R.W., Hilberg, R.S., Pinal, A. \& Tharp, R.G. (2003). Five standards and student achievement. NABE Journal of Research Practices, 1(1), 1-24.

Durden, T. (2008). Do your homework! Investigating the role of culturally relevant pedagogy in comprehensive school reform models serving diverse student populations. Urban Review, 40(5), 403-419.

Escamilla, K., Chávez, L., \& Vigil, P. (2005). Rethinking the “Gap”. Journal of Teacher Education, 56 (2), 132-144.

Field, A. (2009). Discovering statistics using SPSS ( $3^{\text {rd }}$. ed.). Los Angeles: Sage.

Fielding, C. (2004). Low performance on high-stakes test drives special education referrals: A Texas survey. The Educational Forum, 68, 126-132.

Fillmore, L. W. (2000). Loss of family languages: Should educators be concerned? Theory Into Practice, 39 (4), 203-210.

Fillmore, L.W., \& Snow, C. (2000). What teachers need to know about language. McHenry, IL, and Washington, DC: Delta Systems and Center for Applied Linguistics. 
Fleischman, H.L., \& Hopstock, P.J. (1993). Descriptive study of services to limited English proficient students, Volume 1. summary of findings and conclusions. Arlington, VA: Development Associates. Retrieved March 25, 2011 from http://www.eric.ed.gov/ERICWebPortal/search/detailmini.jsp?_nfpb=true\&_\&ER ICExtSearch_SearchValue_0=ED420167\&ERICExtSearch_SearchType_0=no\&a ccno=ED420167

Flynn, K. \& Hill, J. (2005) English language learners: A growing population [policy brief]. Aurora, CO: Mid-continent Research for Education and Learning.

Fowler, F. J. (2009). Survey research methods ( $4^{\text {th }}$ ed.). Washington DC: Sage. Gaiser, T.J. \& Schreiner, A.E. (2009). A guide to conducting on-line research. Los Angeles: Sage.

Gallavan, N.P. (2005). Helping teachers unpack their "invisible knapsacks". Multicultural Education, 13 (1), 36-39.

Gandara, P. C., \& Maxwell-Jolly, J. (2000). Preparing teachers for diversity: A dilemma of quality and quantity. Santa Cruz, CA: The Center for the Future of Teaching and Learning.

Gándara, P., Maxwell-Jolly, J., \& Driscoll, A. (2005). Listening to teachers of English learners. Santa Cruz, CA: Center for the Future of Teaching and Learning.

Gandara, P., \& Rumberger, R. (2006). Resource needs for California's English language learners. Paper prepared for: Getting down to facts: A research project to inform solutions to California's education problems. Los Angeles: University of California Linguistic Minority Research Institute. Retrieved January 31, 2011 
from http://irepp.stanford.edu/documents/GDF/STUDIES/22-GandaraRumberger/22-Gandara-Rumberger(3-07).pdf

Garcia, E. (1991). Education of linguistically and culturally diverse students: effective instructional practices. Educational practice report: 1. Santacruz, CA: National Center for Research on Cultural Diversity and Second Language Learning. Retrieved October 1, 2010 from http://www.eric.ed.gov/PDFS/ED338099.pdf

Garcia, E., Arias, M.B., Murri, N.J.H., \& Serna, C. (2010). Developing responsive teachers: A challenge for a demographic reality. Journal of Teacher Education, $61(1-2) 132-142$.

Garcia, E.E., Jensen, B.T., \& Scribner, K.P. (2009). The demographic imperative: Educating English language learners. Educational Leadership, 66 (7), 9-13.

Garcia, P. (2009). Connecting research about English language learners to practice: An introductory guide for educators. Learning Point Associates.

Garcia, S. B., \& Guerra, P.L. (2004). Deconstructing deficit thinking: Working with educators to create more equitable learning environments. Education and Urban Society, 36 (2), 150-168.

Gardiner, M., Canfield-Davis, K., \& Anderson, K. (2009). Urban School Principals and the ‘No Child Left Behind’ Act. Urban Review, 41(2), 141-160. doi: $10.1007 / \mathrm{s} 11256-008-0102-1$

Gay, G. (2000). Culturally responsive teaching. New York: Teachers College Press.

Gay, G. (2002). Preparing for culturally responsive teaching. Journal of Teacher Education, 53 (2), 106-116. doi: 10.1177/0022487102053002003 
Gelman, J.A., Pullen, P.L., \& Kauffman, J.M. (2004). The meaning of highly qualified and a clear road map to accomplishment. Exceptionality,12 (4), 195-207.

Genesee, F., Lindholm-Leary, K., Saunders, W., \& Christian, D. (2006). Educating English language learners. New York: Cambridge University Press.

Gersten, R. \& Baker, S.K. (2006) English-language learners with LD. In H.L. Swanson, K.R. Harris \& S. Graham (Eds.) Handbook of learning disabilities (pp. 94-109). New York: The Guilford Press.

Gersten, R., Baker, S. K., Shanahan, T., Linan-Thompson, S., Collins, P., \& Scarcella, R. (2007). Effective literacy and English language instruction for English learners in elementary grades: A practice guide (NCEE 2007-4011). Washington, DC: U.S. Department of Education, Institute of Education Sciences, National Center for Education Evaluation and Regional Assistance. Available at http://ies.ed.gov/ncee Goldenberg, C. (2008). Teaching English Language Learners what the research doesand does not—say. American Education, 8-44.

Goldhaber, D. (2002). The mystery of good teaching. Education Next (Spring, 2002). Retrieved January 21, 2011 from http://educationnext.org/files/ednext20021_50.pdf

Goldhaber, D. \& Anthony, E.. (2005) Can teacher quality be effectively assessed? National Board Certification as a signal of effective teaching. University of Washington and Urban Institute Working Paper. Retrieved January 21, 2011 from http://www.urban.org/UploadedPDF/411271_teacher_quality.pdf 
Goldhaber, D.D., \& Brewer, D.J. (2000). Does teacher certification matter? High school teacher certification status and student achievement. Educational Evaluation and Policy Analysis, 22 (2), 129-145.

Gollnick, D. M., \& Chinn, P. C. (2002). Multicultural education in a pluralistic society (6th ed.). New York: Merrill.

Gonzalez, N. C., Moll, L. C., \& Amanti, C. (2005). Funds of knowledge: Theorizing practices in households, communities, and classrooms. Mahwah, NJ: Lawrence Erlbaum Associates, Inc.

Graves, A. W., Gersten, R., \& Haager, D. (2004). Literacy instruction in multiplelanguage first-grade classrooms: Linking student outcomes to observed instructional practice. Learning Disabilities Research and Practice,19 (4), 262272.

Griffiths, C. (2007). Language learning strategies: students’ and teachers’ perceptions. ELT Journal, 61(2), 91-99.

Groves, R.M. (2006). Nonresponse rates and nonresponse bias in household surveys. Public Opinion Quarterly, 70 (5), 641-675.

Guggino, P.C., \& Brint, S. (2010). Does the No Child Left Behind Act help or hinder K12 education? Policy Matters, 3 (3), 1-8.

Hamayan, E., Marler, B., Sanchez-Lopez, C., \& Damico, J. (2007) Special education considerations for English language learners: Delivering a continuum of services. Philadelphia: Caslon Publishing.

Hanushek, E., (1971). Teacher characteristics and gains in student achievement: Estimations using micro data. Paper and proceedings of the eighty-third annual 
meeting of the American Economic Association. The American Economic Review, 61(2), 280-288.

Harper, C. \& de Jong, E. (2004). Misconceptions about teaching English language learners. Journal of Adolescent and Adult Literacy, 48 (2), 152-162.

Harry, B., \& Klingner, J. K. (2006). Why are so many minority students in special education? Understanding race \& disability in schools. New York: Teachers College Press.

Hill, J. D., \& Flynn, K. M. (2006). Classroom instruction that works with English language learners. Alexandria, VA: Association for Supervision and Curriculum Development.

Howard, T.C. (2001). Powerful pedagogy for African American students: A case of four teachers. Urban Education, 36 (2), 179-202. doi: 10.1177/0042085901362003

Howard, T. C.(2003). Culturally relevant pedagogy: Ingredients for critical teacher reflection. Theory Into Practice, 42(3), 195-202.

Iddings, A.C.D., \& Katz, L. (2007). Identities of recent-immigrant Hispanic English language learners through classroom practices. Journal of Language, Identity, and Education, 6 (4), 299-314.

Jacob, B., \& Lefgren, L. (2008). Can principals identify effective teachers? Evidence on subjective performance evaluation in education. Journal of Labor Economics 26 (1), 101-136.

Jepsen, C. (2005). Teacher characteristics and student achievement: evidence from teacher surveys. Journal of Urban Economics, 57 (2), 302 -319. 
Kane, T.J., Rockoff, J.E., \& Staiger, D.O. (2006). What does certification tell us about teacher effectiveness? Evidence from New York City. (NBER Working Paper No. 12155). Cambridge, MA: National Bureau of Economic Research. Retrieved January 21, 2011 from http://www.nber.org/tmp/24929-w12155.pdf

Kaplowitz, M.D., Hadlock, T.D., \& Levine, R. (2004). A comparison of web and mail survey response rates. Public Opinion Quarterly, 68 (1), 94-101.

Karabenick, S.A., \& Noda, P.C. (2004). Professional development implications of teachers' beliefs and attitudes toward English language learners. Bilingual Research Journal, 28 (1), 55-75.

Kindler, A. L. (2002). Survey of the states' limited English proficient students and available educational programs and services: 2000-2001 summary report. Washington, DC: National Clearinghouse for English Language Acquisition and Language Instruction Educational Programs. Retrieved July 10, 2010 from http://www.ncela.gwu.edu/files/rcd/BE021853/Survey_of_the_States.pdf

Klingner, J. K., Artiles, A. J., \& Barletta, L. M (2006). English language learners who struggle with reading: Language acquisition or LD? Journal of Learning Disabilities, 39 (2), 108-128.

Klingner, J. K., de Schonwise, E. A., de Onis, C., \& Barletta, L.M. (2008). Misconceptions about the second language acquisition process. In J. K. Klingner, J. J. Hoover and L.M. Baca (Eds.) Why do English language learners struggle with reading? (pp. 17-35). Thousand Oaks, CA: Corwin Press. 
Klingner, J. K. \& Edwards, P. A. (2006). Cultural considerations with response to intervention models. Reading Research Quarterly, 41 (1), 108-117. doi: 10.1598/rrq.41.1.6

Klingner, J. K., \& Harry, B. (2006). The special education referral and decision-making process for English language learners: Child study team meetings and placement conferences. Teachers College Record, 108(11), 2247-2281.

Kohler, V.R. (1988). Teacher beliefs about at-risk students. Paper presented at the Annual Meeting of the American Educational Research Association. New Orleans, LA.

Kohnert, K., Yim, D., Nett, K., Kan, P.F., \& Duran, L. (2005). Intervention with linguistically diverse preschool children: A focus on developing home language(s). Language, Speech and Hearing Services in Schools, 36 (3), 251-263.

Krashen, S. D. (1981). Principles and practice in second language acquisition. English Language Teaching Series. London: Prentice-Hall International (UK) Ltd.

Krashen, S. D., \& Terrell, T. (1983). The natural approach: language acquisition in the classroom. Oxford: Pergamon.

Ladson-Billings, G. (1994). The dreamkeepers. San Francisco: Jossey-Bass.

Layton, C.A. \& Lock, R.H. (2002). Sensitizing teachers to English language learner evaluation procedures for students with learning disabilities. Teacher Education and Special Education, 25 (4), 362-267. doi: 10.1177/088840640202500405

Lee, O. (2003) Equity for linguistically and culturally diverse students in science education: A research agenda. Teachers College Record, 105 (3), 465-489. 
Lesaux, N. K. (2006). Building consensus: Future directions for research on English language learners at risk for learning difficulties. Teachers College Record, 108 (11), 2406-38.

Lewis, L., Parsad, B., Carey, N., Bartfai, N., Farris, E., \& Smerdon, B. (1999). Teacher quality: A report on the preparation and qualifications of public school teachers. Washington, DC: U. S. Department of Education, Institute of Education Sciences, National Center for Education Statistics.

Lightbown, P.M. \& Spada, N. (2006). How languages are learned. New York: Oxford University Press.

Manfreda, K. L., Bosnjak, M., Berzelak, J., Haas, I., \& Vehovar, V. (2008). Web surveys versus other survey modes: A meta-analysis comparing response rates. International Journal of Market Research, 50(1), 79-104.

Manfreda, K.L., \& Vehovar, V. (2008). Internet surveys. In E. D. de Leeuw. J.J. Hox \& D. A. Dillman (Eds.). International handbook of survey methodology. (pp. 264284). New York: Lawrence Erlbaum Associates.

McCray, A.D., \& Garcia, S.B. (2002). The stories we must tell: developing a research agenda for multicultural and bilingual special education. Qualitative Studies in Education, 15 (6), 599-612.

McLaughlin, B. (1992). Myths and misconceptions about second language learning. ERIC Digest [Online]. Retrieved August 3, 2010 from http://www.eric.ed.gov/contentdelivery/servlet/ERICServlet?accno=ED350885 
McLaughlin, B. (1995). Fostering second language development in young children. ERIC Digest [Online]. Retrieved August 3, 2010 from http://www.cal.org/ericcll/digest/ncrcds04.html

Menken, K. \& Kleyn, T. (2010). The long-term impact of subtractive schooling in the educational experiences of secondary English language learners. International Journal of Bilingual Education and Bilingualism, 13 (4), 399-417.

Miller, M., Strosnider, R., \& Dooley, E. (2002). States’ diversity requirements for teachers. Teacher Education and Special education: The Journal of the Teacher Education Division of the Council for Exceptional Children, 25 (1), 32-40.

Mississippi Department of Education (2011). Mississippi guidelines for English language learners. Author.

Missouri Department of Elementary and Secondary Education (DESE) (2006). Educating linguistically diverse learners. Author.

Missouri Department of Elementary and Secondary Education (2010). Recruitment and retention of teachers in Missouri public schools. A report to the Missouri general assembly. Author.

Moll, L.C. (1992). Bilingual classroom studies and community analysis: Some recent trends. Educational Researcher, 21 (2), 20-24.

Moll, L.C., Amanti, C., Neff, D. \& Gonzalez, N. (1992). Funds of knowledge for teaching: using a qualitative approach to connect homes and classrooms. Theory into Practice, 31(1), 132-41.

Moll, L.C., Ibanez-Velez, C., Greenberg, J. \& Rivera, C. (1990). Community knowledge and classroom practice: Combining resources for literacy instruction. Technical 
Report. (ERIC Document Reproduction Service No. ED341968) Retrieved November 23, 2008, from the ERIC database.

Montgomery, W. (2001). Creating culturally responsive, inclusive classrooms. Teaching Exceptional Children, 33 (4), 4-9.

Morrison, K.A., Robbins, H.H., \& Rose, D.G. (2008). Operationalizing culturally relevant pedagogy: A synthesis of classroom-based research. Equity \& Excellence in Education, 41 (4), 433-452.

Murphy, M. T. (2008). Teaching in the context of NCLB: A qualitative study of the impact of Teachers' work, morale, and professional support. Doctoral Dissertation. University of Southern California: Rossier School of Education.

National Center for Education Statistics. (2002). 1999-2000 Schools and staffing survey: Overview of the data for public, private, public charter and bureau of Indian affairs elementary and secondary schools. Washington, DC: U.S. Department of Education, Office of Educational Research and Improvement.

National Center for Education Statistics. (2009). The nation's report card: Reading 2009 (NCES 2010-458). Institute of Education Sciences, U.S. Department of Education, Washington, D.C.

National Institute of Child Health and Human Development. (2000). Report of the National Reading Panel. Teaching children to read: An evidence-based assessment of the scientific research literature on reading and its implications for reading instruction (NIH Publication No. 00-4769). Washington, DC: U.S. Government Printing Office. 
National Staff Development Council (NSDC) (n.d). Proposal to amend: Elementary and Secondary Education Act of 1965 (ESEA). Title IX. Section 9101 (34). Retrieved May 10, 2011 from

http://www.aypf.org/documents/62609NSDCDefinitionofProfessionalDevelopme nt908.pdf.

Nias, J (1996). Thinking about feeling: The emotions in teaching. Cambridge Journal of Education, 26 (3), 293-306.

Nieto, S. (2000). Placing equity front and center: Some thoughts on transforming teacher education for a new century. Journal of Teacher Education, 51 (3), 180-187. doi : $10.1177 / 0022487100051003004$

No Child Left Behind Act of 2001, 20 U.S.C. $70 \S 6301$ et seq. Available at http://www2.ed.gov/policy/elsec/leg/esea02/107-110.pdf

Noel, J. (2008). Developing multicultural educators. Long Grove, Illinois: Waveland Press.

Ortiz, A.A., \& Garcia, S. B. (1995). Serving Hispanic students with learning disabilities: recommended policies and practices. Urban Education, 29 (4), 471-481.

Paradis., J., Genesee, F., \& Crago., M. B. (2010). Dual language development and disorders: A handbook on bilingualism and second language learning. Baltimore: Paul H. Brookes.

Phuntsog, N. (2001).Culturally responsive teaching: what do selected United States elementary school teachers think? Intercultural Education, 12 (1),51-64. doi: $10.1080 / 14675980120033966$

Ponterotto, J.G., Mendelsohn, J., \& Belizaire, L. (2003). Assessing teacher multicultural 
competence: Self-report instruments, observer-report evaluations, and a portfolio assessment. In D. P. Pope-Davis, H. L. K. Coleman, R. Toporek, \& W. Liu (Eds.), Handbook of multicultural competencies in counseling and psychology (pp. 191210). Thousand Oaks, CA: Sage.

Ponterotto, J. G., Potere, J. C., \& Johansen, S. A. (2002). The Quick Discrimination Index: Normative data and user guidelines for counseling researchers. Journal of Multicultural Counseling and Development, 30, 192-207.

Pope-Davis, D. B., \& Dings, J. G. (1994). An empirical comparison of two self-report multicultural counseling competency inventories. Measurement and Evaluation in Counseling and Development,27, 93-102.

Razavi, T. (2001). Self-report measures: An overview of concerns and limitations of questionnaire use in occupational stress research. Discussion Papers in Accounting and Management Sciences, School of Management, University of Southampton.

Reeves, J. R. (2006). Secondary teacher attitudes toward including English-language learners in mainstream classrooms. The Journal of Educational Research, 99 (3), 131-142.

Rhodes, R.L., Ochoa, S.H., \& Ortiz, S.O. (2005). Assessing culturally and linguistically diverse students: A practical guide. New York: Guilford Press.

Richards, H.V., Brown, A. F., \& Forde, T.B. (2006). Addressing diversity in schools: Culturally responsive pedagogy. NCCrest: Practitioner brief.

Rivkin, S.G., Hanushek, E.A., \& Kain, J.F. (2005). Teachers, schools and academic achievement. Econometrica, 73 (2), 417-458. 
Roseberry-McKibbin, C. (2008). Multicultural students with special education needs: Practical strategies for assessment and intervention. Oceanside, CA: Academic Communication Associates, Inc.

Ruiz, R. (1984). Orientations in language planning. NABE: The Journal for the National Association for Bilingual Education, 8 (2), 15-34.

Rumberger, R.W. \& Gándara, P. (2004). Seeking equity in the education of California's English learners. Teachers College Record, 106 (10), 2032-2056.

Sanchez, W., Li, C., \& Nuttall, E.V. (1995). Working with diverse learners and school staff in a multicultural society. ERIC Digest [Online]. Available: http://www.eric.ed.gov/contentdelivery/servlet/ERICServlet?accno=ED390018

Saunders, W. M., Foorman, B. R., \& Carlson, C. D. (2006). Is a separate block of time for oral English language development in programs for English learners needed? The Elementary School Journal, 107 (2), 181-198.

Scott, K.A. \& Mumford, V.E. (2007). Critical thoughts: Reexamining teacher training, cultural awareness, and school reform. Multicultural Perspectives, 9(4), 54-58.

Singer, E. (2002). The use of incentives to reduce nonresponse in household surveys. In R. M. Groves, D. A. Dillman, J. L. Eltinge, \& R. J.A. Little (Eds.) Survey Nonresponse (pp. 163-177). New York: John Wiley \& Sons.

Slavin, R.E., \& Cheung, A. (2003).Effective Reading programs for English language learners: A best-evidence synthesis. Retrieved June 4, 2009 from http://www.csos.jhu.edu/crespar/techReports/Report66.pdf

Snow, C. (2001) Disability is natural: Revolutionary common sense for raising successful children with disabilities. Woodland Park, CO: Braveheart Press. 
Spanierman, L. B., Oh, E., Heppner, P. P., Neville, H. A., Mobley, M., Wright, C. V., Dillon, F. R., \& Navarro, R. (2010). The multicultural teaching competencies scale (MTCS): Development and initial validation. Urban Education. Advance online publication.

Spinelli, C.G. (2008). Addressing the issue of cultural and linguistic diversity and assessment: Informal evaluation measures for English language learners. Reading \& Writing Quarterly, 24, 101-118. doi: 10.1080/10573560701753195

Tellez, K. \& Waxman, H. C. (2005). Quality teachers for English language learners: A review of the research. Temple University Center for Research in Human Development and Education: The Laboratory for Student Success.

U.S. Department of Education, National Center for Education Statistics (2001). Teacher Preparation and Professional Development: 2000, NCES 2001-088, by Basmat Parsad, Laurie Lewis, and Elizabeth Farris. Project Officer: Bernard Greene. Washington, DC.

U.S. Department of Education (2009). State and local implementation of the No Child Left Behind Act, Volume VIII-Teacher quality: Final report. By Beatrice Birman, Andrea Boyle, Kerstin Carlson Le Floch, Amy Elledge, Deborah Holtzman, Mengli Song, Kerri Thomsen, Kirk Walters, and Kwang-Suk Yoon. Washington, D.C.: U.S. Department of Education, Office of Planning, Evaluation, and Policy Development, Policy and Program Studies Service.

Vandevoort, L. G., Amrein-Beardsley, A. \& Berliner, D. C. (2004). National board certified teachers and their students’ achievement. Education Policy Analysis 
Archives, 12 (46). Retrieved January 21, 2011 from

http://epaa.asu.edu/epaa/v12n46/.

Vehovar, V., Batagelji, Z., Manfreda, K.L., \& Zalatel, M. (2002). Nonresponse in web surveys. In R. M. Groves, D. A. Dillman, J. L. Eltinge, \& R. J.A. Little (Eds.) Survey Nonresponse (pp. 229-242). New York: John Wiley \& Sons.

Villar, A., Fletcher, S. \& Strong, M. (2007). Examining the relation between comprehensive mentoring for beginning teachers and student achievement in English language arts and math. Paper presented at the National Commission on Teaching and America's Future Conference on the Induction of Science and Mathematics Teachers into Professional Learning Communities, Wingspread Conference Center, Racine, WI.

Villegas, A.M. (1991). Culturally responsive pedagogy for the 1990s and beyond (Trends and Issues Paper No. 6) Washington DC: ERIC Clearinghouse on Teacher Education.

Villegas, A. M., \& Lucas, T. (2002). Preparing culturally responsive teachers: Rethinking the curriculum. Journal of Teacher Education, 53 (1), 20-32.

Wayne, A. J., \& Youngs, P. (2003). Teacher characteristics and student academic achievement: A review. Review of Educational Research, 73(1), 89-122.

Wenglinsky, H., (2002). How schools matter: The link between teacher classroom practices and student academic performance. Education Policy Analysis Archives, 10(12). Retrieved October 20, 2010 from http://epaa.asu.edu/epaa/v10n12/.

Wilde, J. (2010). Guidelines for professional development: An overview. In C.J. Casteel \& K.G. Ballantyne, K.G. (Eds.). Professional Development in Action: Improving 
Teaching for English Learners (Pp. 5-12). Washington, DC: National Clearinghouse for English Language Acquisition. Available at http://www.ncela.gwu.edu/files/uploads/3/PD_in_Action.pdf

Wink, J. (2005). Critical pedagogy: Notes from the real world. New York: Pearson Education, Inc.

Youngs, C.S., \& Youngs, G.A. (2001). Predictors of mainstream teachers' attitudes toward ESL students. TESOL Quarterly, 35 (1), 97-120.

Zehler, A.M., Fleischman, H.L., Hopstock, P.J., Pendzick, M.L., Stephenson, T.G. \& Sapru, S. (2003). Descriptive study of services to LEP Students and LEP students with disabilities. Policy report: Summary of findings related to LEP and SpEdLEP students. Arlington VA: Development Associates, Inc. 


\section{VITA}

Sushama Nagarkar is a certified school psychologist. She has worked in school districts in South-East Louisiana and more recently in Columbia, Missouri. She obtained an undergraduate degree in Psychology and a graduate degree in Clinical Psychology from the University of Bombay. She then received her Specialists degree in School Psychology from Nichols State University, Thibodaux, LA. Her professional experiences have primarily focused on data-based decision making and collaborative problem-solving within school systems. 
APPENDIX A

Survey 


\section{Informed Consent}

\section{Introduction}

The purpose of this study is to explore whether specific teacher characteristics are related to the perceived importance and reported implementation of culturally responsive practices within classrooms. It also seeks to explore the relationship between implementation of culturally responsive teaching practices and their perceived importance as reported by teachers.

Procedures. You are being asked to respond to a survey consisting of four sections. The first section requires you to indicate the degree of perceived importance of culturally responsive practices within the classroom and the frequency of your use of these practices. The second section explores your attitudes towards and beliefs about English language learners. The third section examines your knowledge of second language acquisition and the fourth section asks you for demographic information. The entire questionnaire is on-line and should take approximately 20 to 25 minutes to complete.

Risks/Discomforts. There are no risks to this study. You will not be asked for your name. All answers will be kept confidential and will only be examined by the researcher.

Benefits. There are no direct benefits to participants. It is hoped that through your participation, this researcher will learn more about how educators equip themselves to teach an increasingly diverse student body.

Confidentiality. All data obtained from participants will be kept confidential and will only be reported in an aggregated format (only reporting combined results and never reporting individual results). All questionnaires will be concealed, and no one other than the primary investigator and faculty advisor will have access. The data collected will be stored in a secure database until it has been deleted by the primary investigator.

Compensation. There is no direct compensation for participating in the study. However, if you wish to participate in a drawing for one of ten \$20.00 gift cards to Amazon.com, you may submit your email address to the researcher at the end of the survey. Your email address will not be tied to your responses in any way.

Participation. Participation in this research study is completely voluntary. You have the right to refuse to participate entirely. If you desire to withdraw during the survey, you would close your internet browser and if you chose to, you would inform the principal investigator at the email address listed below.

Questions about the Research. If you have questions regarding this study, you may contact Ms. Sushama Nagarkar, the principal investigator at 573-445-6390 or at sn33d@mail.missouri.edu. If you have questions that you do not feel comfortable asking the researcher, you may contact Dr. Erica Lembke, the faculty advisor at lembkee@missouri.edu or by phone at 573-882-0434. 
Questions about Rights as Research Participants. If you have questions regarding your rights as a research participant, the email address for the University of Missouri Campus Institutional Review Board is umcresearchcirb@missouri.edu. The phone number is 573 882-9585.

I have read, and understood the above consent form and desire of my own free will to participate in this study.
$\mathrm{O}$ Yes
O No 


\section{Section A}

This section consists of statements reflecting teaching practices that teachers may utilize in their classrooms. Please indicate how important you believe it is to use these practices and how often you use them.

1. I modify my instruction so that diverse students such as English language learners will have an equal opportunity to learn.

$\begin{array}{ll}\text { O } & \text { Extremely Unimportant } \\ 0 & \text { Very Unimportant } \\ 0 & \text { Somewhat Unimportant } \\ 0 & \text { Somewhat Important } \\ 0 & \text { Very Important } \\ 0 & \text { Extremely Important } \\ & \\ 0 & \text { Never } \\ 0 & \text { Less than Once a Month } \\ 0 & \text { Once a Month } \\ 0 & \text { 2-3 Times a Month } \\ 0 & \text { Once a Week } \\ 0 & \text { 2-3 Times a Week } \\ 0 & \text { Daily }\end{array}$

2. I utilize instructional materials that reflect cultural elements of diverse groups such as English language learners.

$\begin{array}{ll}\text { O } & \text { Extremely Unimportant } \\ \text { O } & \text { Very Unimportant } \\ \text { O } & \text { Somewhat Unimportant } \\ \text { O } & \text { Somewhat Important } \\ 0 & \text { Very Important } \\ 0 & \text { Extremely Important } \\ & \\ 0 & \text { Never } \\ 0 & \text { Less than Once a Month } \\ 0 & \text { Once a Month } \\ 0 & \text { 2-3 Times a Month } \\ 0 & \text { Once a Week } \\ 0 & \text { 2-3 Times a Week } \\ 0 & \text { Daily }\end{array}$


3. I encourage English language learners and other culturally and linguistically diverse students not to raise their hands during classroom discussion (DISTRACTER)

$\begin{array}{ll}\text { O } & \text { Extremely Unimportant } \\ \text { O } & \text { Very Unimportant } \\ 0 & \text { Somewhat Unimportant } \\ 0 & \text { Somewhat Important } \\ 0 & \text { Very Important } \\ 0 & \text { Extremely Important } \\ & \\ 0 & \text { Never } \\ 0 & \text { Less than Once a Month } \\ 0 & \text { Once a Month } \\ 0 & \text { 2-3 Times a Month } \\ 0 & \text { Once a Week } \\ 0 & \text { 2-3 Times a Week } \\ 0 & \text { Daily }\end{array}$

4. I relate content and instructional strategies to the cultural background of my students.
O Extremely Unimportant
O Very Unimportant
O Somewhat Unimportant
O Somewhat Important
O Very Important
Extremely Important
O Never
Less than Once a Month
O Once a Month
O 2-3 Times a Month
O Once a Week
O 2-3 Times a Week
O Daily 
5. I utilize information from several sources, including families, to assess student achievement.

$\begin{array}{ll}\text { O } & \text { Extremely Unimportant } \\ 0 & \text { Very Unimportant } \\ 0 & \text { Somewhat Unimportant } \\ 0 & \text { Somewhat Important } \\ 0 & \text { Very Important } \\ 0 & \text { Extremely Important } \\ & \\ 0 & \text { Never } \\ 0 & \text { Less than Once a Month } \\ 0 & \text { Once a Month } \\ 0 & \text { 2-3 Times a Month } \\ 0 & \text { Once a Week } \\ 0 & \text { 2-3 Times a Week } \\ 0 & \text { Daily }\end{array}$

6. I use a variety of teaching strategies to assist my students who are from diverse ethnic, racial, cultural, and language backgrounds in meeting State standards and other mandated requirements such as NCLB.

$\begin{array}{ll}\text { O } & \text { Extremely Unimportant } \\ \text { O } & \text { Very Unimportant } \\ 0 & \text { Somewhat Unimportant } \\ 0 & \text { Somewhat Important } \\ 0 & \text { Very Important } \\ 0 & \text { Extremely Important } \\ & \\ 0 & \text { Never } \\ 0 & \text { Less than Once a Month } \\ 0 & \text { Once a Month } \\ 0 & \text { 2-3 Times a Month } \\ 0 & \text { Once a Week } \\ 0 & \text { 2-3 Times a Week } \\ 0 & \text { Daily }\end{array}$


7. I establish strong, supportive relationships with linguistically diverse minority parents.
Extremely Unimportant
O Very Unimportant
O Somewhat Unimportant
O Somewhat Important
O Very Important
O Extremely Important
O Never
Less than Once a Month
O Once a Month
O 2-3 Times a Month
O Once a Week
O 2-3 Times a Week
O Daily

8. I correct the written language of English language learners and other culturally and linguistically diverse students, with a red pen to draw their attention to their mistakes (DISTRACTER)

$\begin{array}{ll}\text { O } & \text { Extremely Unimportant } \\ \text { O } & \text { Very Unimportant } \\ \text { O } & \text { Somewhat Unimportant } \\ 0 & \text { Somewhat Important } \\ 0 & \text { Very Important } \\ 0 & \text { Extremely Important } \\ & \\ 0 & \text { Never } \\ 0 & \text { Less than Once a Month } \\ 0 & \text { Once a Month } \\ 0 & \text { 2-3 Times a Month } \\ 0 & \text { Once a Week } \\ 0 & \text { 2-3 Times a Week } \\ 0 & \text { Daily }\end{array}$


9. My instructional activities include a discussion of what the students, including English language learners, already know from the home, community and school.

$\begin{array}{ll}\mathrm{O} & \text { Extremely Unimportant } \\ \mathrm{O} & \text { Very Unimportant } \\ \mathrm{O} & \text { Somewhat Unimportant } \\ \mathrm{O} & \text { Somewhat Important } \\ \mathrm{O} & \text { Very Important } \\ & \text { Extremely Important } \\ \mathrm{O} & \text { Never } \\ \mathrm{O} & \text { Less than Once a Month } \\ \mathrm{O} & \text { Once a Month } \\ \mathrm{O} & \text { 2-3 Times a Month } \\ \mathrm{O} & \text { Once a Week } \\ \mathrm{O} & \text { 2-3 Times a Week } \\ \mathrm{O} & \text { Daily }\end{array}$

10. I plan activities to celebrate diverse cultural practices in my classroom.

$\begin{array}{ll}\text { O } & \text { Extremely Unimportant } \\ 0 & \text { Very Unimportant } \\ 0 & \text { Somewhat Unimportant } \\ 0 & \text { Somewhat Important } \\ 0 & \text { Very Important } \\ 0 & \text { Extremely Important } \\ & \\ 0 & \text { Never } \\ 0 & \text { Less than Once a Month } \\ 0 & \text { Once a Month } \\ 0 & \text { 2-3 Times a Month } \\ 0 & \text { Once a Week } \\ 0 & \text { 2-3 Times a Week } \\ 0 & \text { Daily }\end{array}$


11. For the English language learners or other diverse learners in my class, I make time to preview the upcoming lesson.

$\begin{array}{ll}\text { O } & \text { Extremely Unimportant } \\ 0 & \text { Very Unimportant } \\ 0 & \text { Somewhat Unimportant } \\ 0 & \text { Somewhat Important } \\ 0 & \text { Very Important } \\ 0 & \text { Extremely Important } \\ & \\ 0 & \text { Never } \\ 0 & \text { Less than Once a Month } \\ 0 & \text { Once a Month } \\ 0 & \text { 2-3 Times a Month } \\ 0 & \text { Once a Week } \\ 0 & \text { 2-3 Times a Week } \\ 0 & \text { Daily }\end{array}$

12. I help all students to connect and apply what they have learned to the home and the community.

$\begin{array}{ll}\text { O } & \text { Extremely Unimportant } \\ 0 & \text { Very Unimportant } \\ 0 & \text { Somewhat Unimportant } \\ \mathrm{O} & \text { Somewhat Important } \\ \mathrm{O} & \text { Very Important } \\ \mathrm{O} & \text { Extremely Important } \\ & \\ \mathrm{O} & \text { Never } \\ \mathrm{O} & \text { Less than Once a Month } \\ \mathrm{O} & \text { Once a Month } \\ \mathrm{O} & \text { 2-3 Times a Month } \\ \mathrm{O} & \text { Once a Week } \\ \mathrm{O} & \text { Daily Times a Week }\end{array}$


13. I provide extensive opportunities for parents and families of my diverse learners to participate in classroom instructional activities.

$\begin{array}{ll}\mathrm{O} & \text { Extremely Unimportant } \\ \mathrm{O} & \text { Very Unimportant } \\ \mathrm{O} & \text { Somewhat Unimportant } \\ \mathrm{O} & \text { Somewhat Important } \\ \mathrm{O} & \text { Very Important } \\ & \\ \mathrm{O} & \text { Never } \\ \mathrm{O} & \text { Less than Once a Month } \\ \mathrm{O} & \text { Once a Month } \\ \mathrm{O} & \text { 2-3 Times a Month } \\ \mathrm{O} & \text { Once a Week } \\ \mathrm{O} & \text { 2-3 Times a Week } \\ \mathrm{O} & \text { Daily }\end{array}$

14. I encourage linguistically diverse families to make every effort to maintain their home language.

$\begin{array}{ll}\mathrm{O} & \text { Extremely Unimportant } \\ \mathrm{O} & \text { Very Unimportant } \\ \mathrm{O} & \text { Somewhat Unimportant } \\ \mathrm{O} & \text { Somewhat Important } \\ \mathrm{O} & \text { Very Important } \\ & \text { Extremely Important } \\ \mathrm{O} & \text { Never } \\ \mathrm{O} & \text { Less than Once a Month } \\ \mathrm{O} & \text { Once a Month } \\ \mathrm{O} & \text { 2-3 Times a Month } \\ \mathrm{O} & \text { Once a Week } \\ \mathrm{O} & \text { 2-3 Times a Week } \\ \mathrm{O} & \text { Daily }\end{array}$




\section{Section B}

This section explores your attitudes towards and beliefs about English language learners. For each statement, using the 6-point scale, please select one of the choices provided, depending on your level of agreement or disagreement with the statement.

1. As school populations become more linguistically diverse, teachers' jobs become increasingly rewarding.

$\begin{array}{ll}\mathrm{O} & \text { Strongly Disagree } \\ \mathrm{O} & \text { Disagree } \\ \mathrm{O} & \text { Somewhat Disagree } \\ \mathrm{O} & \text { Somewhat Agree } \\ \mathrm{O} & \text { Agree } \\ \mathrm{O} & \text { Strongly Agree }\end{array}$

2. Having English language learners in my class would be socially challenging for many students.

$\begin{array}{ll}\mathrm{O} & \text { Strongly Disagree } \\ \mathrm{O} & \text { Disagree } \\ \mathrm{O} & \text { Somewhat Disagree } \\ \mathrm{O} & \text { Somewhat Agree } \\ \mathrm{O} & \text { Agree } \\ \mathrm{O} & \text { Strongly Agree }\end{array}$

3. Having English language learners in my class would enrich the educational experiences of all students in the class.

$\begin{array}{ll}\mathrm{O} & \text { Strongly Disagree } \\ \mathrm{O} & \text { Disagree } \\ \mathrm{O} & \text { Somewhat Disagree } \\ \mathrm{O} & \text { Somewhat Agree } \\ \mathrm{O} & \text { Agree } \\ \mathrm{O} & \text { Strongly Agree }\end{array}$

4. Adapting classroom instruction for English language learners is difficult.

$\begin{array}{ll}\mathrm{O} & \text { Strongly Disagree } \\ \mathrm{O} & \text { Disagree } \\ \mathrm{O} & \text { Somewhat Disagree } \\ \mathrm{O} & \text { Somewhat Agree } \\ \mathrm{O} & \text { Agree } \\ \mathrm{O} & \text { Strongly Agree }\end{array}$


5. Parents of English language learners are a valuable resource for school activities.
O Strongly Disagree
O Disagree
S Somewhat Disagree
O Somewhat Agree
O Agree
O Strongly Agree

6. English language learners should not be included in my class unless they attain a minimum level of English proficiency.
Strongly Disagree
O Disagree
O Somewhat Disagree
O Somewhat Agree
O Agree
S Strongly Agree

7. I believe that English language learners should be encouraged to use their native language as often as possible.

$\begin{array}{ll}\text { O } & \text { Strongly Disagree } \\ \bigcirc & \text { Disagree } \\ 0 & \text { Somewhat Disagree } \\ 0 & \text { Somewhat Agree } \\ 0 & \text { Agree } \\ 0 & \text { Strongly Agree }\end{array}$

8. English language learners would be a welcome addition to my classroom.

$\begin{array}{ll}0 & \text { Strongly Disagree } \\ \bigcirc & \text { Disagree } \\ \bigcirc & \text { Somewhat Disagree } \\ 0 & \text { Somewhat Agree } \\ 0 & \text { Agree } \\ 0 & \text { Strongly Agree }\end{array}$


9. It is unreasonable to expect a regular classroom teacher to teach a child who is not fluent in English.

$\begin{array}{ll}\mathrm{O} & \text { Strongly Disagree } \\ \mathrm{O} & \text { Disagree } \\ \mathrm{O} & \text { Somewhat Disagree } \\ \mathrm{O} & \text { Somewhat Agree } \\ \mathrm{O} & \text { Agree } \\ \mathrm{O} & \text { Strongly Agree }\end{array}$

10. English language learners should avoid using their native language while at school.
O Strongly Disagree
O Disagree
O Somewhat Disagree
Somewhat Agree
$\mathrm{O}$ Agree
Strongly Agree 


\section{Section C}

When English language learners (ELLs) enroll in school, they are required by law to become proficient in the use of the English language. This section seeks information on your knowledge of the processes of second language acquisition as they apply to elementary age students. Listed below are a series of questions. Please select the best answer from the choices listed below each question.

1. An English language learner's native language can best be described as which of the following?
$\mathrm{O}$ A. The first language learned
$\mathrm{O}$ B. The language in which the speaker has greater proficiency
$\mathrm{O} \quad \mathrm{C}$. The language that the speaker prefers to use
$\mathrm{O}$ D. None of the above

2. Code-switching, described as a switch among languages during conversation, occurs at which of the following levels?
O A. Word level
O B. Sentence level
C. Blocks of speech
$\mathrm{O}$ D. All of the above

3. Which of the following is not true about errors in second language learning?
A . Errors are a positive sign that the student is making progress
B. Errors are a necessary aspect of second language acquisition
C. Errors provide clues about a student's interlanguage (developing
O D. Errors are problematic and should be avoided second language knowledge)

4. Which of the following is not true about ELLs who demonstrate fluent conversational English?

setting

A. They are able to talk informally with teachers and others in the school

B. They frequently develop native-like conversational skills within two

years

$\mathrm{O}$ C. They no longer require language instruction

$\mathrm{O}$ D. Both B and C

5. Students who do not know enough English to hold a conversation are often able to demonstrate which of the following?
A. Knowledge of phonological awareness
$\mathrm{O}$ B. Decoding ability in English
O C. Neither A nor B
$\mathrm{O}$ D. Both $\mathrm{A}$ and $\mathrm{B}$ 
6. According to current research, the best method for English language learners to acquire all aspects of English in the same way they acquire their first language, is which of the following?
A. Exposure
B. Explicit instruction
C. Interaction with native speakers
O D. A and C

7. Which of the following would most likely help ELLs to read and write in English?
A. Frequent use of their first language
O B. Conversational ability in their first language
$\mathrm{O}$ C. Literacy in their first language
$\mathrm{O}$ D. Both A and B

8. When a parent declines their child's participation in a program designed for providing language support for ELLs, the district retains a responsibility for which of the following?

O A. To ensure that the student has an equal opportunity to have his or her English language needs met

O B. To ensure that the student has an equal opportunity to have his or her academic needs met
C. To ensure that a referral for special education is made
$\mathrm{O}$ D. Both A and B

9. In the education of English language learners, which of the following aspects of instruction is most important to ensure effective outcomes?
$O$ A. Language of instruction
B . Duration of instruction
O C. Quality of instruction
$\mathrm{O}$ D. Frequency of instruction

10. Comprehensive literacy programs for ELLs need to have components of which of the following?
A. Appropriate modifications to instruction
B $\quad$ B. Focus on oral English development
C. High quality literacy instruction
O D. All of the above

11. In the assessment of ELLs, accommodations may be provided to which of the following?
A . The presentation of the assessment
O B. Method of response
$\mathrm{O}$ C. Setting in which assessments are conducted
$\mathrm{O}$ D. All of the above 


\section{Section D: Demographic Data}

Please indicate your current position:

\begin{tabular}{ll}
$\bigcirc$ & Classroom teacher \\
$\bigcirc$ & Special educator \\
$\mathrm{O}$ & Other, please specify \\
\hline
\end{tabular}

Please indicate the grade(s) that you are currently teaching

\begin{tabular}{ll}
\hline & Kinderga \\
$\square$ & Grade 1 \\
$\square$ & Grade 2 \\
$\square$ & Grade 3 \\
$\square$ & Grade 4 \\
$\square$ & Grade 5
\end{tabular}

Approximately how many years have you been teaching full-time?

$\begin{array}{ll}O & 1-5 \text { years } \\ 0 & 6 \text { to } 10 \text { years } \\ 0 & 11 \text { to } 15 \text { years } \\ 0 & 16 \text { and more years }\end{array}$

Please indicate the highest college degree that you currently hold:

$\begin{array}{ll}\mathrm{O} & \text { Bachelors degree } \\ \mathrm{O} & \text { Bachelors degree }+ \text { hours } \\ \mathrm{O} & \text { Masters degree } \\ \mathrm{O} & \text { Masters degree }+ \text { hours } \\ \mathrm{O} & \text { Specialist degree } \\ \mathrm{O} & \text { Doctoral degree }\end{array}$

Would you describe yourself as being a Highly Qualified Teacher (HQT) according to the requirements of NCLB (college degree, full state certification or license, subject matter competence)?

$\begin{array}{ll}\text { O } & \text { Yes } \\ \mathrm{O} & \text { No }\end{array}$

Please check whichever applies to you:

․ Full State certification as a teacher

License to teach in the State

a Taken the Praxis II in subject matter being taught

口 Other (please specify) 
How many extra hours of training specific to ELLs have you had?

口 Building or district inservices

$\square \quad$ Training offered by professional organizations such as the National

Association of Bilingual Education (NABE)

$\square \quad$ Undergraduate university level coursework

$\square \quad$ Graduate university level coursework

During the current school year, approximately what percentage of your students are ELLs?
$0 \%$
O $1 \%$ to $5 \%$
O $6 \%$ to $10 \%$
O $11 \%$ to $15 \%$
O $16 \%$ to $20 \%$
O over $20 \%$

During the previous school year, approximately what percentage of your students were ELLs?

$\begin{array}{ll}0 & 0 \% \\ 0 & 1 \% \text { to } 5 \% \\ 0 & 6 \% \text { to } 10 \% \\ 0 & 11 \% \text { to } 15 \% \\ 0 & 16 \% \text { to } 20 \% \\ 0 & \text { over } 20 \%\end{array}$

While you were in school, what percentage of your fellow students were from diverse cultural and/or linguistic backgrounds?

\begin{tabular}{|c|c|c|c|}
\hline & school & $\begin{array}{l}\text { Secondary } \\
\text { school }\end{array}$ & $\begin{array}{c}\text { Post- } \\
\text { secondary School }\end{array}$ \\
\hline Less than $25 \%$ & $\square$ & $\square$ & $\square$ \\
\hline$\% \quad 26 \%$ to 50 & $\square$ & $\square$ & $\square$ \\
\hline \% $\quad 51 \%$ to 75 & $\square$ & $\square$ & $\square$ \\
\hline$\% \quad 76 \%$ to 100 & $\square$ & $\square$ & $\square$ \\
\hline
\end{tabular}

Please indicate your gender:

$\begin{array}{ll}\bigcirc & \text { Male } \\ \bigcirc & \text { Female }\end{array}$

Please indicate your ethnicity? 


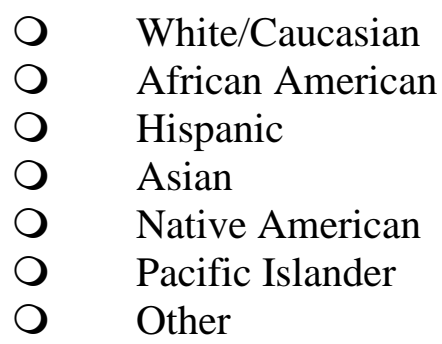

Do you fluently speak a language other than English?

$\begin{array}{ll}\mathrm{O} & \text { Yes } \\ \mathrm{O} & \text { No }\end{array}$

Thank you for your time!

If you would like to enroll your name in a drawing for a \$20.00 gift card to Amazon.com, please email Sushama Nagarkar, the principal investigator, at snagarkar@centurytel.net. The drawing will be held during the week of March 14, 2011 and if you win a gift card, you will be notified shortly thereafter. 
APPENDIX B

Pilot Survey 


\section{Informed Consent}

\section{Introduction}

The purpose of this study is to explore whether specific teacher characteristics are related to the perceived importance and reported implementation of culturally responsive practices within classrooms. It also seeks to explore the relationship between implementation of culturally responsive teaching practices and their perceived importance as reported by teachers.

Procedures. You are being asked to respond to a survey consisting of four sections. The first section requires you to indicate the degree of perceived importance of culturally responsive practices within the classroom and the frequency of your use of these practices. The second section explores your attitudes towards and beliefs about English language learners. The third section examines your knowledge of second language acquisition and the fourth section asks you for demographic information. The entire questionnaire is on-line and should take approximately 20 to 25 minutes to complete.

Risks/Discomforts. There are no risks to this study. You will not be asked for your name. All answers will be kept confidential and will only be examined by the researcher.

Benefits. There are no direct benefits to participants. It is hoped that through your participation, this researcher will learn more about how educators equip themselves to teach an increasingly diverse student body.

Confidentiality. All data obtained from participants will be kept confidential and will only be reported in an aggregated format (only reporting combined results and never reporting individual results). All questionnaires will be concealed, and no one other than the primary investigator and faculty advisor will have access. The data collected will be stored in a secure database until it has been deleted by the primary investigator.

Compensation. There is no direct compensation for participating in the study. However, if you wish to participate in a drawing for one of ten \$20.00 gift cards to Amazon.com, you may submit your email address to the researcher at the end of the survey. Your email address will not be tied to your responses in any way.

Participation. Participation in this research study is completely voluntary. You have the right to refuse to participate entirely. If you desire to withdraw during the survey, you would close your internet browser and if you chose to, you would inform the principal investigator at the email address listed below.

Questions about the Research. If you have questions regarding this study, you may contact Ms. Sushama Nagarkar, the principal investigator at 573-445-6390 or at sn33d@mail.missouri.edu. If you have questions that you do not feel comfortable asking the researcher, you may contact Dr. Erica Lembke, the faculty advisor at lembkee@missouri.edu or by phone at 573-882-0434. 
Questions about Rights as Research Participants. If you have questions regarding your rights as a research participant, the email address for the University of Missouri Campus Institutional Review Board is umcresearchcirb@missouri.edu. The phone number is 573 882-9585.

I have read, and understood the above consent form and desire of my own free will to participate in this study.

$\begin{array}{ll}\mathrm{O} & \text { Yes } \\ \mathrm{O} & \text { No }\end{array}$ 


\section{Section A}

When English language learners (ELLs) enroll in school, they are required by law to become proficient in the use of the English language. This section seeks information on your knowledge of the processes of second language acquisition as they apply to elementary age students. Listed below are a series of questions. Please select the best answer from the choices listed below each question.

1. An English language learner's native language can best be described as which of the following?
$\mathrm{O} \quad$ A. The first language learned
$\mathrm{O}$ B. The language in which the speaker has greater proficiency
$\mathrm{O}$ C. The language that the speaker prefers to use
$\mathrm{O}$ D. None of the above

2. Code-switching, described as a switch among languages during conversation, occurs at which of the following levels?
O A. Word level
O B. Sentence level
C. Blocks of speech
$\mathrm{O}$ D. All of the above

3. Which of the following is not true about errors in second language learning?
A . Errors are a positive sign that the student is making progress
$\mathrm{O} \quad$ B. Errors are a necessary aspect of second language acquisition
C. Errors provide clues about a student's interlanguage (developing second language knowledge)
D. Errors are problematic and should be avoided

4. Which of the following is not true about ELLs who demonstrate fluent conversational English?
O A. They are able to talk informally with teachers and others in the school setting
B B. They frequently develop native-like conversational skills within two years
$\mathrm{O} \quad \mathrm{C}$. They no longer require language instruction
$\mathrm{O}$ D. Both B and C

5. Students who do not know enough English to hold a conversation are often able to demonstrate which of the following?
A $\quad$ Anowledge of phonological awareness
B. Decoding ability in English
C. Neither A nor B
$\mathrm{O} \quad$ D. Both $\mathrm{A}$ and $\mathrm{B}$ 
6. According to current research, the best method for English language learners to acquire all aspects of English in the same way they acquire their first language, is which of the following?
O A. Exposure
B. Explicit instruction
C. Interaction with native speakers
$\mathrm{O} \quad \mathrm{D}$. A and $\mathrm{C}$

7. Which of the following would most likely help ELLs to read and write in English?
A. Frequent use of their first language
B. Conversational ability in their first language
C. Literacy in their first language
$\mathrm{O}$ D. Both A and B

8. When a parent declines their child's participation in a program designed for providing language support for ELLs, the district retains a responsibility for which of the following?

A. To ensure that the student has an equal opportunity to have his or her English language needs met

O B. To ensure that the student has an equal opportunity to have his or her academic needs met
O C. To ensure that a referral for special education is made
$\mathrm{O}$ D. Both A and B

9. In the education of English language learners, which of the following aspects of instruction is most important to ensure effective outcomes?
A. Language of instruction
B. Duration of instruction
C C. Quality of instruction
D. Frequency of instruction

10. Comprehensive literacy programs for ELLs need to have components of which of the following?
A. Appropriate modifications to instruction
B . Focus on oral English development
C. High quality literacy instruction
O D. All of the above

11. In the assessment of ELLs, accommodations may be provided to which of the following?
A. The presentation of the assessment
B. Method of response
C. Setting in which assessments are conducted
D. All of the above 
When English language learners (ELLs) enroll in school, they are required by law to become proficient in the use of the English language. This section seeks information on your knowledge of the processes of second language acquisition as they apply to elementary age students. Please select either true or false for each statement.

1. An English language learner's native language can best be described as the language that the student prefers to use.

$\begin{array}{ll} & \text { True } \\ \mathrm{O} & \text { False }\end{array}$

2. During conversation, code-switching, described as a switch among languages during conversation, may occur at the level of the word, the sentence or for blocks of speech.

O True

O False

3. Errors during second language acquisition are problematic and should be avoided.
O True
O False

4. ELLs who demonstrate fluent conversational English no longer require language instruction from a teacher for English language learners.
O True
O False

5. Students who may not know enough English to hold a conversation are often able to demonstrate decoding ability in English.

$\begin{array}{ll}\bigcirc & \text { True } \\ \text { O } & \text { False }\end{array}$

6. According to current research, the best method for English language learners to acquire all aspects of English in the same way they acquire their first language, is frequent interaction with their peers.
O True
False

7. Literacy in their first language would most likely help English language learners to read and write in English.
O True
O False 
8. When parents decline their child's participation in a program designed for providing language support for ELLs, the district retains the responsibility to ensure that English language learners have equal opportunities to have both their English language and academic needs met.

$\begin{array}{ll}0 & \text { True } \\ 0 & \text { False }\end{array}$

9. In the education of English language learners, language of instruction is the most important aspect that will ensure effective outcomes.

$\begin{array}{ll}0 & \text { True } \\ 0 & \text { False }\end{array}$

10. Comprehensive literacy programs for ELLs need to include a focus on oral English development.

True

O False

11. In the assessment of ELLs, accommodations may be provided to the method of response.

$\begin{array}{ll}\mathrm{O} & \text { True } \\ \mathrm{O} & \text { False }\end{array}$ 


\section{Section B}

This section uses a 6-point scale. For each statement, please select one of the choices provided, depending on your level of agreement or disagreement with the statement.

1. As school populations becomes more linguistically diverse, teachers' jobs becomes increasingly rewarding.

O Strongly Disagree

O Disagree

O Somewhat Disagree

O Somewhat Agree

O Agree

O Strongly Agree

2. Having English language learners in my class would be socially challenging for many students.
O Strongly Disagree
O Disagree
O Somewhat Disagree
O Somewhat Agree
O Agree
O Strongly Agree

3. Having English language learners in my class would enrich the educational experiences of all students in the class.
$\mathrm{O}$ Strongly Disagree
O Disagree
O Somewhat Disagree
O Somewhat Agree
$\mathrm{O}$ Agree
O Strongly Agree

4. Adapting classroom instruction for English language learners is difficult.
O Strongly Disagree
$\mathrm{O}$ Disagree
O Somewhat Disagree
O Somewhat Agree
O Agree
O Strongly Agree 
5. Parents of English language learners are a valuable resource for school activities.
O Strongly Disagree
O Disagree
Somewhat Disagree
Somewhat Agree
O Agree
Strongly Agree

6. English language learners should not be included in my class unless they attain a minimum level of English proficiency.
O Strongly Disagree
O Disagree
Somewhat Disagree
Somewhat Agree
O Agree
O Strongly Agree

7. I believe that English language learners should be encouraged to use their native language as often as possible.

$\begin{array}{ll}\mathrm{O} & \text { Strongly Disagree } \\ \mathrm{O} & \text { Disagree } \\ \mathrm{O} & \text { Somewhat Disagree } \\ \mathrm{O} & \text { Somewhat Agree } \\ \mathrm{O} & \text { Agree } \\ \mathrm{O} & \text { Strongly Agree }\end{array}$

8. English language learners would be a welcome addition to my classroom.
Strongly Disagree
O Disagree
O Somewhat Disagree
O Somewhat Agree
O Agree
O Strongly Agree

9. It is unreasonable to expect a regular classroom teacher to teach a child who is not fluent in English.
O Strongly Disagree
Disagree
Somewhat Disagree
O Somewhat Agree
O Agree
Strongly Agree 
10. English language learners should avoid using their native language while at school.

O Strongly Disagree

O Disagree

O Somewhat Disagree

O Somewhat Agree

O Agree

Strongly Agree 


\section{Section C}

This section consists of statements reflecting teaching practices that teachers may utilize in their classrooms. Please indicate how often you use these practices and how important you believe it is to use them.

1. I modify my instruction so that diverse students such as English language learners will have an equal opportunity to learn.

$\begin{array}{ll}\text { O } & \text { Extremely Unimportant } \\ 0 & \text { Very Unimportant } \\ 0 & \text { Somewhat Unimportant } \\ 0 & \text { Somewhat Important } \\ 0 & \text { Very Important } \\ 0 & \text { Extremely Important } \\ & \\ 0 & \text { Never } \\ 0 & \text { Less than Once a Month } \\ 0 & \text { Once a Month } \\ 0 & \text { 2-3 Times a Month } \\ 0 & \text { Once a Week } \\ 0 & \text { 2-3 Times a Week } \\ 0 & \text { Daily }\end{array}$

2. I utilize instructional materials that reflect cultural elements of diverse groups such as English language learners.

$\begin{array}{ll}\text { O } & \text { Extremely Unimportant } \\ 0 & \text { Very Unimportant } \\ 0 & \text { Somewhat Unimportant } \\ 0 & \text { Somewhat Important } \\ 0 & \text { Very Important } \\ 0 & \text { Extremely Important } \\ & \\ 0 & \text { Never } \\ 0 & \text { Less than Once a Month } \\ 0 & \text { Once a Month } \\ 0 & \text { 2-3 Times a Month } \\ 0 & \text { Once a Week } \\ 0 & \text { 2-3 Times a Week } \\ 0 & \text { Daily }\end{array}$


3. I encourage English language learners and other culturally and linguistically diverse students not to raise their hands during classroom discussion (DISTRACTER)
O Extremely Unimportant
O Very Unimportant
O Somewhat Unimportant
O Somewhat Important
O Very Important
O Extremely Important
O Never
Less than Once a Month
O Once a Month
O 2-3 Times a Month
O Once a Week
O 2-3 Times a Week
O Daily

4. I relate content and instructional strategies to the cultural background of my students.
O Extremely Unimportant
O Very Unimportant
O Somewhat Unimportant
O Somewhat Important
O Very Important
O Extremely Important
O Never
O Less than Once a Month
O Once a Month
O 2-3 Times a Month
Once a Week
O 2-3 Times a Week
O Daily 
5. I utilize information from several sources, including families, to assess student achievement.
O Extremely Unimportant
O Very Unimportant
O Somewhat Unimportant
O Somewhat Important
O Very Important
O Extremely Important

$\begin{array}{ll}\text { O } & \text { Never } \\ \text { O } & \text { Less than Once a Month } \\ \text { O } & \text { Once a Month } \\ \text { O } & \text { 2-3 Times a Month } \\ \text { O } & \text { Once a Week } \\ \text { O } & \text { 2-3 Times a Week } \\ \text { O } & \text { Daily }\end{array}$

6. I use a variety of teaching strategies to assist my students who are from diverse ethnic, racial, cultural, and language backgrounds in meeting State standards and other mandated requirements such as NCLB.
O Extremely Unimportant
O Very Unimportant
O Somewhat Unimportant
O Somewhat Important
O Very Important
O Extremely Important

$\begin{array}{ll}\text { O } & \text { Never } \\ \text { O } & \text { Less than Once a Month } \\ \text { O } & \text { Once a Month } \\ \text { O } & \text { 2-3 Times a Month } \\ \text { O } & \text { Once a Week } \\ \text { O } & \text { 2-3 Times a Week } \\ \text { O } & \text { Daily }\end{array}$


7. I establish strong, supportive relationships with linguistically diverse minority parents.

O Extremely Unimportant

O Very Unimportant

O Somewhat Unimportant

O Somewhat Important

O Very Important

O Extremely Important

O Never

O Less than Once a Month

O Once a Month

O 2-3 Times a Month

O Once a Week

O 2-3 Times a Week

O Daily

8. I correct the written language of English language learners and other culturally and linguistically diverse students, with a red pen to draw their attention to their mistakes (DISTRACTER)

O Extremely Unimportant

O Very Unimportant

O Somewhat Unimportant

O Somewhat Important

O Very Important

O Extremely Important

O Never

Less than Once a Month

O Once a Month

O 2-3 Times a Month

O Once a Week

O 2-3 Times a Week

O Daily 
9. My instructional activities include a discussion of what the students, including English language learners, already know from the home, community and school.

$\begin{array}{ll}\text { O } & \text { Extremely Unimportant } \\ 0 & \text { Very Unimportant } \\ 0 & \text { Somewhat Unimportant } \\ 0 & \text { Somewhat Important } \\ 0 & \text { Very Important } \\ 0 & \text { Extremely Important } \\ & \\ 0 & \text { Never } \\ 0 & \text { Less than Once a Month } \\ 0 & \text { Once a Month } \\ 0 & \text { 2-3 Times a Month } \\ 0 & \text { Once a Week } \\ 0 & \text { 2-3 Times a Week } \\ 0 & \text { Daily }\end{array}$

10. I plan activities to celebrate diverse cultural practices in my classroom.

O Extremely Unimportant

O Very Unimportant

O Somewhat Unimportant

O Somewhat Important

O Very Important

Extremely Important

O Never

O Less than Once a Month

Once a Month

O 2-3 Times a Month

O Once a Week

O 2-3 Times a Week

O Daily 
11. For the English language learners or other diverse learners in my class, I make time to preview the upcoming lesson.
O Extremely Unimportant
O Very Unimportant
O Somewhat Unimportant
O Somewhat Important
O Very Important
O Extremely Important
O Never
O Less than Once a Month
O Once a Month
O 2-3 Times a Month
O Once a Week
O 2-3 Times a Week
$\bigcirc \quad$ Daily

12. I help all students to connect and apply what they have learned to the home and the community.

$\begin{array}{ll}\text { O } & \text { Extremely Unimportant } \\ 0 & \text { Very Unimportant } \\ 0 & \text { Somewhat Unimportant } \\ 0 & \text { Somewhat Important } \\ 0 & \text { Very Important } \\ 0 & \text { Extremely Important } \\ & \\ 0 & \text { Never } \\ 0 & \text { Less than Once a Month } \\ \bigcirc & \text { Once a Month } \\ 0 & \text { 2-3 Times a Month } \\ 0 & \text { Once a Week } \\ 0 & \text { Daily }\end{array}$


13. I provide extensive opportunities for parents and families of my diverse learners to participate in classroom instructional activities.
O Extremely Unimportant
O Very Unimportant
O Somewhat Unimportant
O Somewhat Important
O Very Important
O Extremely Important

$\begin{array}{ll}\mathrm{O} & \text { Never } \\ \mathrm{O} & \text { Less than Once a Month } \\ \mathrm{O} & \text { Once a Month } \\ \mathrm{O} & \text { 2-3 Times a Month } \\ \mathrm{O} & \text { Once a Week } \\ \mathrm{O} & \text { Daily }\end{array}$

14. I encourage linguistically diverse families to make every effort to maintain their home language.

$\begin{array}{ll}\text { O } & \text { Extremely Unimportant } \\ 0 & \text { Very Unimportant } \\ 0 & \text { Somewhat Unimportant } \\ 0 & \text { Somewhat Important } \\ 0 & \text { Very Important } \\ 0 & \text { Extremely Important } \\ & \\ 0 & \text { Never } \\ 0 & \text { Less than Once a Month } \\ 0 & \text { Once a Month } \\ 0 & \text { 2-3 Times a Month } \\ 0 & \text { Once a Week } \\ 0 & \text { 2-3 Times a Week } \\ 0 & \text { Daily }\end{array}$




\section{Section D}

\section{Demographic Data}

Please indicate your gender:

$\begin{array}{ll}\bigcirc & \text { Male } \\ \bigcirc & \text { Female }\end{array}$

Please indicate your ethnicity?

O White/Caucasian

O African American

O Hispanic

O Asian

O Native American

Pacific Islander

O Other

Please indicate the highest college degree that you currently hold:
O Bachelors degree
O Bachelors degree + hours
O Masters degree
O Masters degree + hours
Specialist degree
O Doctoral degree

Please indicate your current position:
O Classroom teacher
O Special educator
Other, please specify

Would you describe yourself as being a Highly Qualified Teacher (HQT) according to the requirements of NCLB (college degree, full state certification or license, subject matter competence)?
$\mathrm{O}$ Yes
O No

Please check whichever applies to you:

$\begin{array}{ll}\square & \text { Full State certification as a teacher } \\ \square & \text { License to teach in the State } \\ \square & \text { Taken the Praxis II in subject matter being taught } \\ \square & \text { Other (please specify) }\end{array}$


Please indicate the grade(s) that you are currently teaching.

$\begin{array}{ll}\square & \text { Kinderga } \\ \square & \text { Grade 1 } \\ \square & \text { Grade 2 } \\ \square & \text { Grade 3 } \\ \square & \text { Grade 4 } \\ \square & \text { Grade 5 }\end{array}$

How would you describe the community in which your school district is located?

O City -- a territory inside an urbanized area and inside a principal city

O Suburban - a territory outside a principal city and inside an urbanized area

O Town - a territory inside an urban cluster

Approximately how many years have you been teaching full-time?
O 1 -5 years
O 6 to 10 years
O 11 to 15 years
O 16 and more years

Have you had any extra training specific to teaching ELLs?

O None

Building or district inservice. How many hours?

O Training offered by professional organizations such as the National Association of Bilingual Education (NABE). Describe.

O Undergraduate university level coursework. How many hours?

O Graduate university level coursework. How many hours?

During the current school year approximately what percentage of your students are ELLs?

During the previous school year approximately what percentage of your students were ELLs?

While you were in elementary school, what percentage of your fellow students were from diverse cultural and/or linguistic backgrounds?
O Less than $25 \%$
O $26 \%$ to $50 \%$
○ $51 \%$ to $75 \%$
○ $\quad 76 \%$ to $100 \%$ 
While you were in middle school, what percentage of your fellow students were from diverse cultural and/or linguistic backgrounds?
O Less than $25 \%$
O $26 \%$ to $50 \%$
O $51 \%$ to $75 \%$
○ $76 \%$ to $100 \%$

While you were in secondary school, what percentage of your fellow students were from diverse cultural and/or linguistic backgrounds?
O Less than $25 \%$
O $26 \%$ to $50 \%$
○ $\quad 51 \%$ to $75 \%$
○ $76 \%$ to $100 \%$

While you were in post-secondary school, what percentage of your fellow students were from diverse cultural and/or linguistic backgrounds?
O Less than $25 \%$
O $26 \%$ to $50 \%$
○ $\quad 51 \%$ to $75 \%$
○ $76 \%$ to $100 \%$

Please answer the following questions so that the survey may be refined as needed.

Thank you!

Of the two sections that assess teacher knowledge of second language acquisition, which format (multiple choice or true/false) do you think would more comprehensively measure this (teacher knowledge of second language acquisition) variable?

$\begin{array}{ll}\mathrm{O} & \text { Multiple Choice } \\ \mathrm{O} & \text { True/ False Responses }\end{array}$

Which items on the survey were unclear or ambiguous? Please explain.

Which questions, if any, did you find difficult to answer? Please explain.

Thank you very much for your participation. If you have further suggestions, please email Ms. Sushama Nagarkar, the principal investigator, at sn33d@mail.missouri.edu. 


\section{APPENDIX C}

Pre-notification Email 
Dr./Ms./......

My name is Sushama Nagarkar and I am currently doing my doctoral dissertation at the University of Missouri under the advisement of Dr. Erica Lembke. I have been given permission by .... school district administration to conduct a research study and I am writing to you at this time to explain the importance of the research and the methodology I will be using.

Regardless of whether teachers currently have English language learners enrolled in their classroom, with increasing numbers of such students who come from backgrounds where English is not the primary language spoken, it becomes imperative for researchers to explore teacher characteristics as they pertain to the education of these students.

The purpose of my study is to explore such teacher characteristics as knowledge of second language acquisition, attitudes towards English language learners, culturally responsive practices and skills in teaching this population and to that end I have developed an anonymous on-line survey for teachers to complete.

Participation in the study is entirely voluntary and it should take a teacher about 20 mins. to complete the survey. In a few days I will send the electronic link for this survey to you and I would greatly appreciate it if you would then forward it to your faculty.

Thank you in advance. If you have any questions please feel free to email me at sn33d@mail.missouri.edu or call me at 5734456390.

Ms. Sushama Nagarkar 
APPENDIX D

Survey link 
Dr./Ms./......

A few days ago I had emailed you detailing my research study exploring teacher characteristics as they relate to the education of English language learners. At this time, I am writing to you seeking the participation of all elementary educators in your building. While participation is completely voluntary, I hope many of your staff will be willing to participate!

Please send this link...... out to the teachers in your building so that they can access this survey conveniently and complete it on their own time.

After the teachers have completed the survey, there is an option for them to email me if they would like to have their names enrolled in a drawing for ten, $\$ 20$ gift cards to Amazon.com. The drawing will be held after the data collection phase and winners will be informed via email.

I am hopeful that many of your staff will participate. The greater number of teacher respondents there are, the more important and useful the results will be.

Thank you in advance for sending this out! If you have any questions please feel free to email me at sn33d@mail.missouri.edu or call me at 573445 6390. In addition, you could also contact my advisor, Dr. Erica Lembke at lembkee@missouri.edu.

Thank you for your time.

Ms. Sushama Nagarkar 
APPENDIX E

$1^{\mathrm{ST}}$ FOLLOW-UP 
Dr./Ms./......

This is a follow-up on an email that I had sent you on February 8, 2011 about a research study I am conducting as a doctoral student at the University of Missouri in Columbia under the advisement of Dr. Erica Lembke. This study requests elementary educators in your building to take an approximately 20-minute anonymous on-line survey. The link to the survey which has been designed to explore whether certain teacher characteristics are related to implementing culturally responsive practices in classroom, is as follows:.....

Findings from this research would have the potential to better serve our linguistically and culturally diverse populations.

As I had mentioned in the previous email, teacher participation is entirely voluntary. However after completing the survey, teachers may enroll their names in a drawing for one of ten $\$ 20$ gift cards to Amazon.com. The drawing will be held after the data collection phase and winners will be informed via email.

If you have any questions please feel free to email me at sn33d@mail.missouri.edu or call me at 5734456390.

Thank you for your time.

Ms. Sushama Nagarkar 


\section{APPENDIX F}

$2^{\text {ND }}$ FOLLOW-UP 
Dr./Ms./......

Thank you very much for supporting my doctoral research.

In case the teachers who want to complete what they have started wish to do so, or if there are still others who wish to participate in the study, please forward this survey link to your faculty: ...

Teachers may enroll their names in a drawing for one of ten $\$ 20$ gift cards to Amazon.com after completion.

Again, thank you for your time and support of this endeavor.

Sushama Nagarkar 
APPENDIX G

$3^{\mathrm{RD}}$ FOLLOW-UP 
Dr./Ms./......

I appreciate your support of my research endeavor!

The survey will be closed out a week from today and this will be my final

reminder. In case some of your teachers want to complete their surveys or others still

want to take it, the link is as follows:

The drawing for the ten \$20 Amazon gift cards will take place next week as well and winners will be informed via email.

Again thanks very much for your time and support.

Sushama Nagarkar 


\section{APPENDIX H}

Internal Consistency of Subscales Items Tables 
Table H.i

Perceived importance of culturally responsive practices, item analysis if item deleted

Scale Mean if Scale Variance Corrected Item- Cronbach Alpha

Item Deleted if Item Deleted Total Correlation if Item Deleted

\begin{tabular}{|c|c|c|c|c|}
\hline $\begin{array}{l}\text { I modify my } \\
\text { instruction so that ... }\end{array}$ & 53.47 & 122.468 & .364 & .836 \\
\hline $\begin{array}{l}\text { I utilize instructional } \\
\text { materials ... }\end{array}$ & 54.47 & 114.294 & .618 & .818 \\
\hline $\begin{array}{l}\text { I relate content and } \\
\text { instructional ... }\end{array}$ & 54.03 & 118.279 & .562 & .823 \\
\hline $\begin{array}{l}\text { I utilize information } \\
\text { from several ... }\end{array}$ & 54.67 & 116.832 & .500 & .827 \\
\hline $\begin{array}{l}\text { I use a variety of } \\
\text { teaching strategies ... }\end{array}$ & 53.27 & 122.540 & .523 & .827 \\
\hline $\begin{array}{l}\text { I establish strong, } \\
\text { supportive... . . . }\end{array}$ & 55.19 & 112.205 & .601 & .818 \\
\hline $\begin{array}{l}\text { My instructional } \\
\text { activities include ... }\end{array}$ & 53.59 & 121.414 & .463 & .829 \\
\hline $\begin{array}{l}\text { I plan activities to } \\
\text { celebrate diverse ... }\end{array}$ & 56.35 & 117.408 & .517 & .825 \\
\hline $\begin{array}{l}\text { For the English } \\
\text { language learners ... }\end{array}$ & 54.17 & 117.088 & .451 & .831 \\
\hline $\begin{array}{l}\text { I help all students to } \\
\text { connect and apply ... }\end{array}$ & 53.20 & 124.018 & .527 & .828 \\
\hline $\begin{array}{l}\text { I provide extensive } \\
\text { opportunities for ... }\end{array}$ & 56.34 & 112.803 & .530 & .824 \\
\hline I encourage & 56.33 & 110.369 & .483 & .831 \\
\hline linguistically ... & & & & \\
\hline
\end{tabular}


Table H. ii

Reported use of culturally responsive practices, item analysis if item deleted

Scale Mean if Scale Variance Corrected Item- Cronbach Alpha Item Deleted if Item Deleted Total Correlation if Item Deleted

\begin{tabular}{|c|c|c|c|c|}
\hline I modify my & 55.84 & 42.823 & .456 & .884 \\
\hline \multicolumn{5}{|l|}{ instruction so that ... } \\
\hline I utilize instructional & 56.07 & 42.760 & .589 & .874 \\
\hline \multicolumn{5}{|l|}{ materials ... } \\
\hline I relate content and & 55.96 & 43.505 & .582 & .874 \\
\hline \multicolumn{5}{|l|}{ instructional ... } \\
\hline I utilize information & 55.92 & 42.492 & .631 & .871 \\
\hline \multicolumn{5}{|l|}{ from several ... } \\
\hline I use a variety of & 55.54 & 43.988 & .657 & .872 \\
\hline \multicolumn{5}{|l|}{ teaching strategies ... } \\
\hline I establish strong, & 55.77 & 42.493 & .707 & .868 \\
\hline \multicolumn{5}{|l|}{ supportive... ... } \\
\hline My instructional & 55.63 & 43.988 & .650 & .872 \\
\hline \multicolumn{5}{|l|}{ activities include ... } \\
\hline I plan activities to & 56.21 & 42.576 & .587 & .874 \\
\hline \multicolumn{5}{|l|}{ celebrate diverse ... } \\
\hline For the English & 55.94 & 42.892 & .603 & .873 \\
\hline \multicolumn{5}{|l|}{ language learners ... } \\
\hline I help all students to & 55.51 & 44.094 & .625 & .873 \\
\hline \multicolumn{5}{|l|}{ connect and apply ... } \\
\hline I provide extensive & 56.32 & 41.669 & .627 & .872 \\
\hline \multicolumn{5}{|l|}{ opportunities for ... } \\
\hline I encourage & 56.23 & 43.036 & .449 & .884 \\
\hline linguistically ... & & & & \\
\hline
\end{tabular}


Table H.iii

Attitudes towards and perceptions of ELLs, item analysis if item deleted

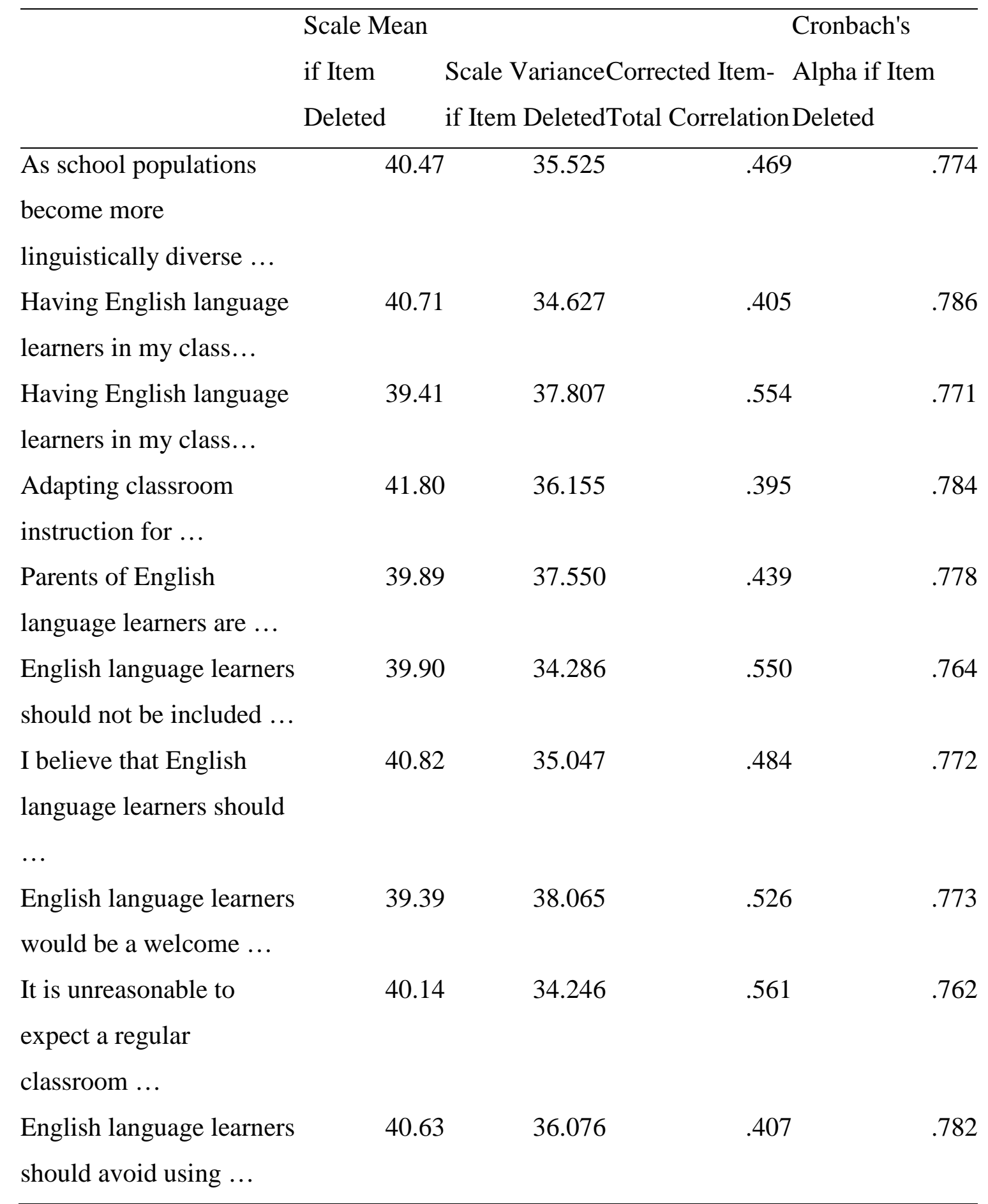




\section{APPENDIX I}

Verification of the Assumptions of the Linear Regression Model 
Figure I.i

Dependent variable: Perceived importance, histogram

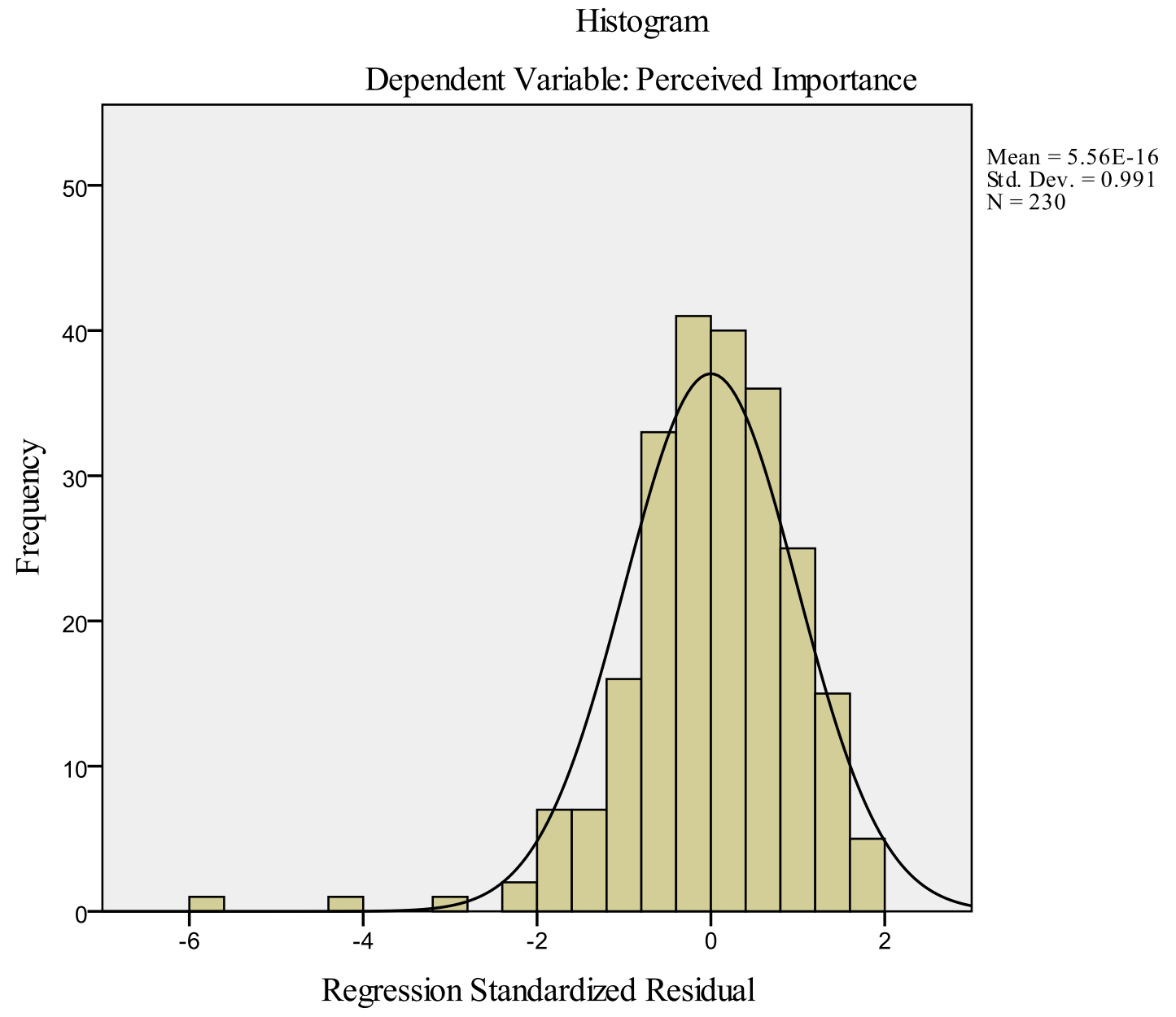


Figure I.ii

Dependent variable: Perceived importance, normal P-P plot of regression standardized residual

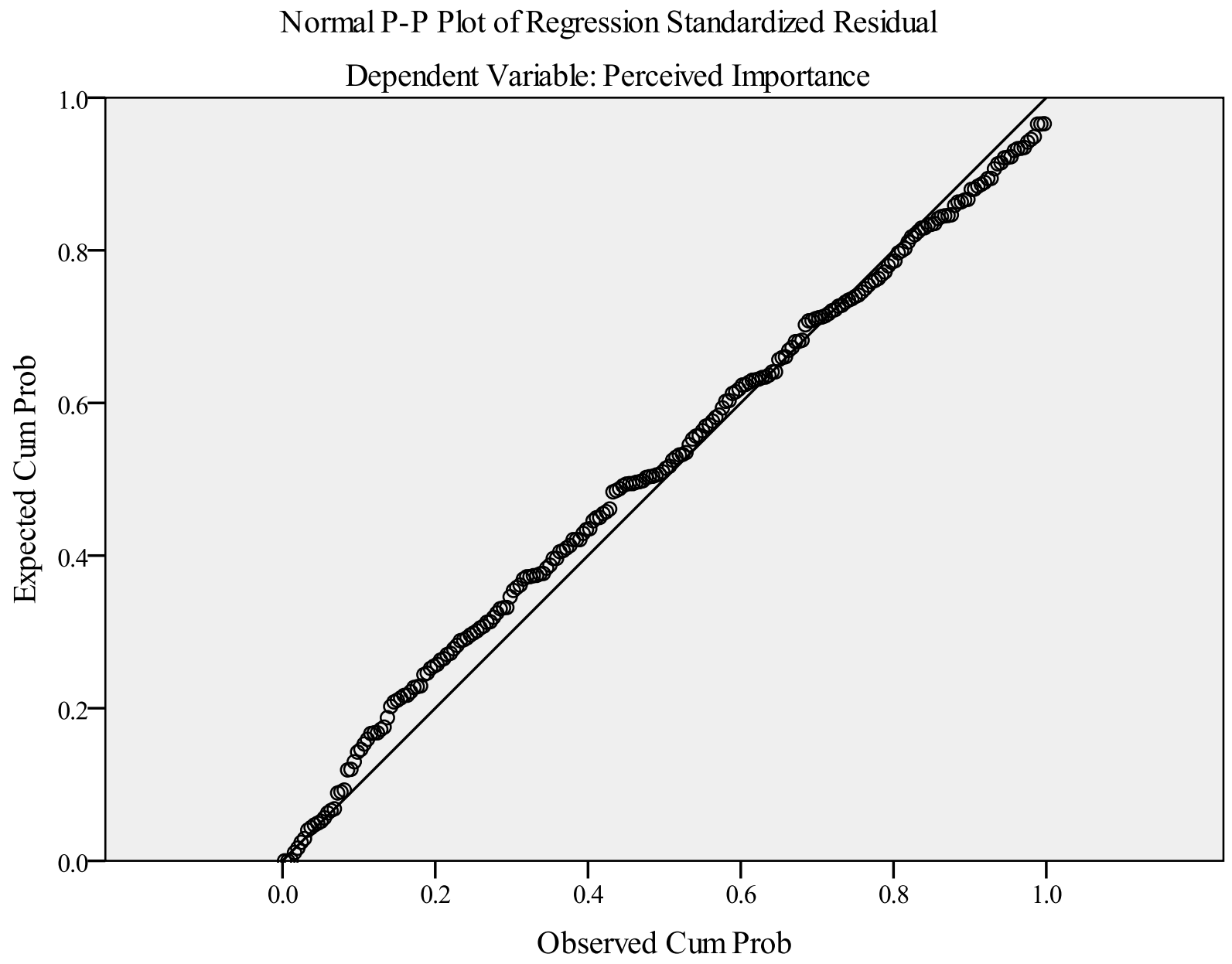


Figure I.iii

Dependent variable: Perceived importance, scatterplot

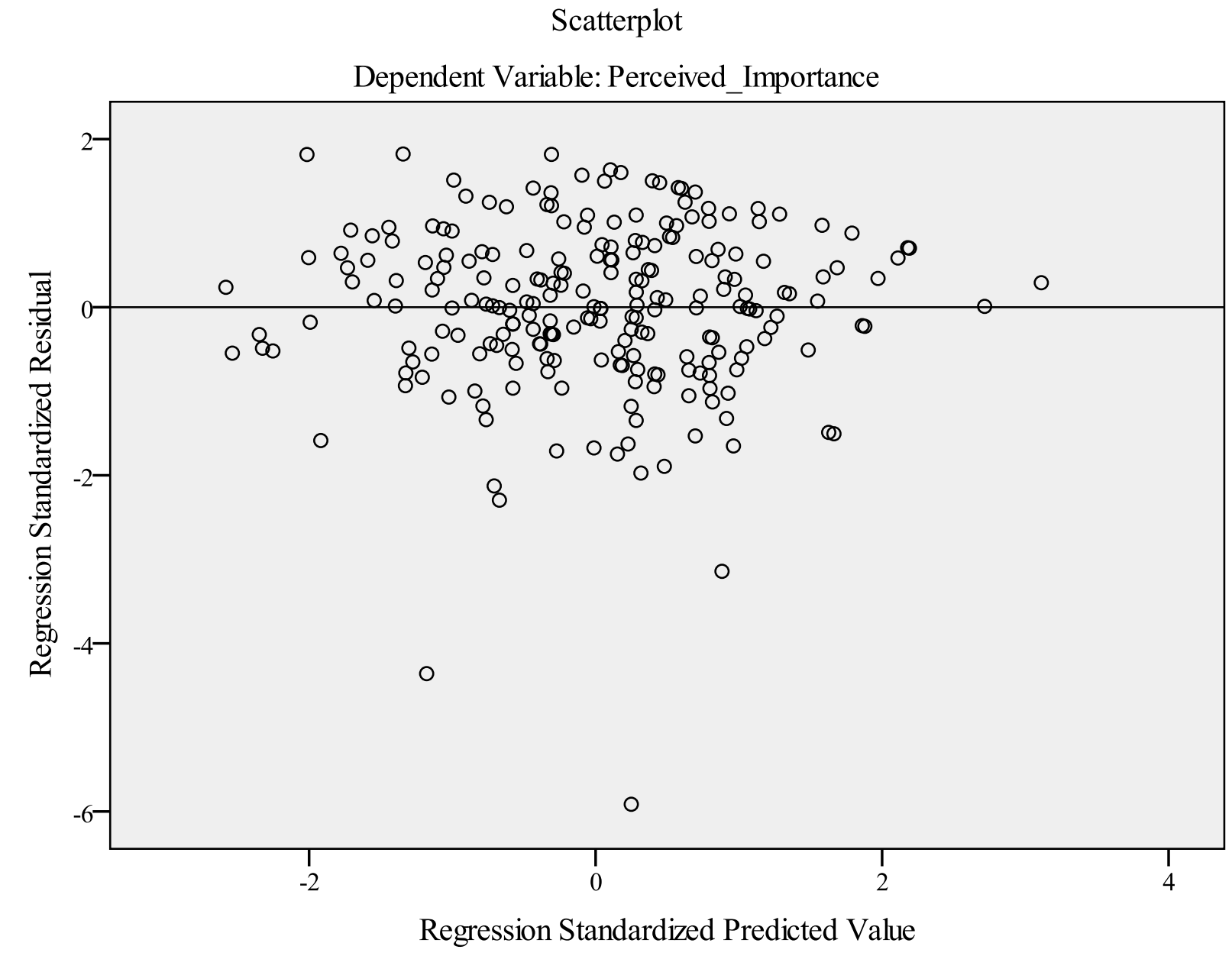


Table I.i

Dependent variable: Perceived importance, collinearity statistics

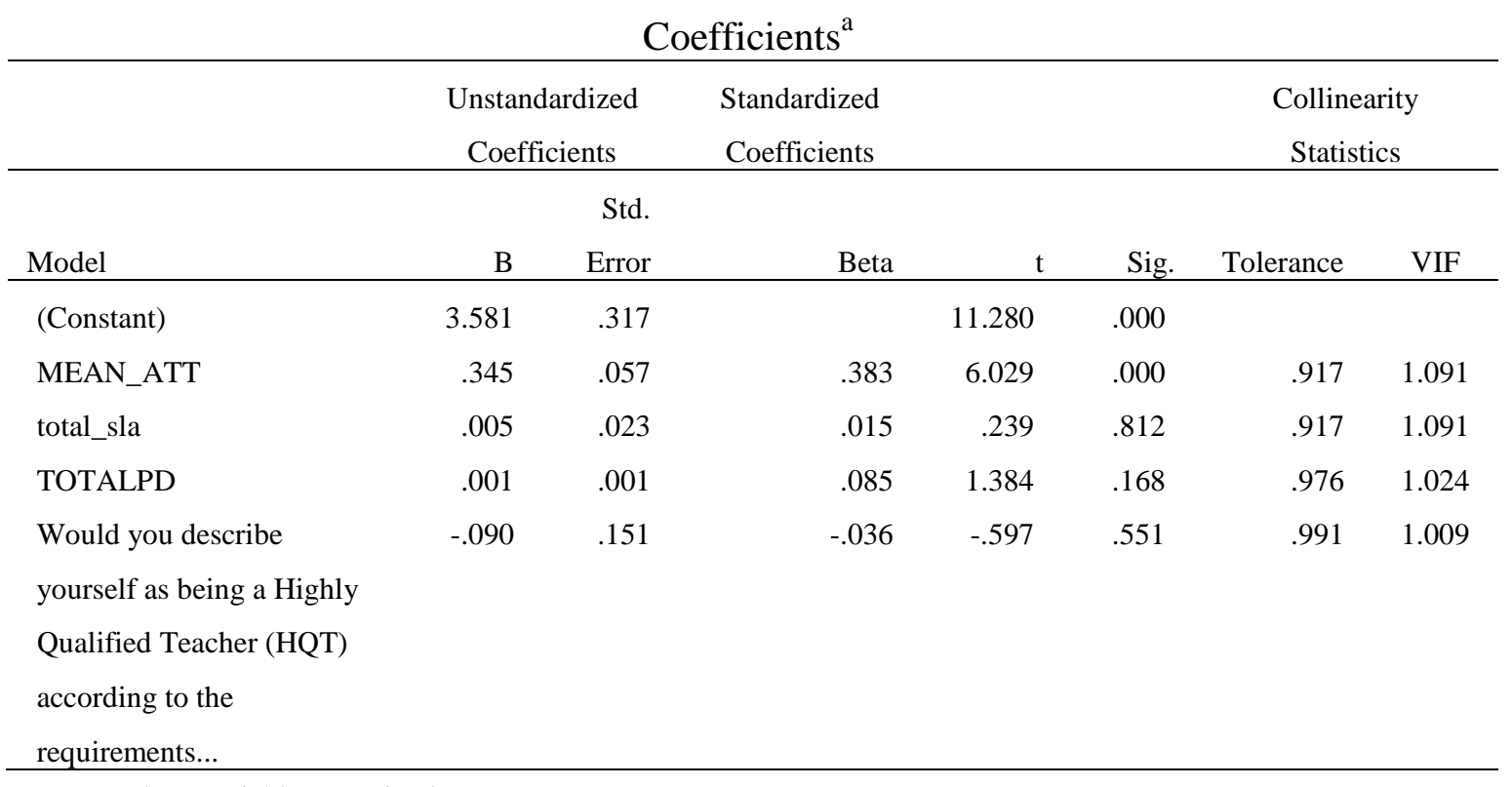

a. Dependent Variable: Perceived Importance 
Figure I.iv

Dependent variable: Reported use, histogram

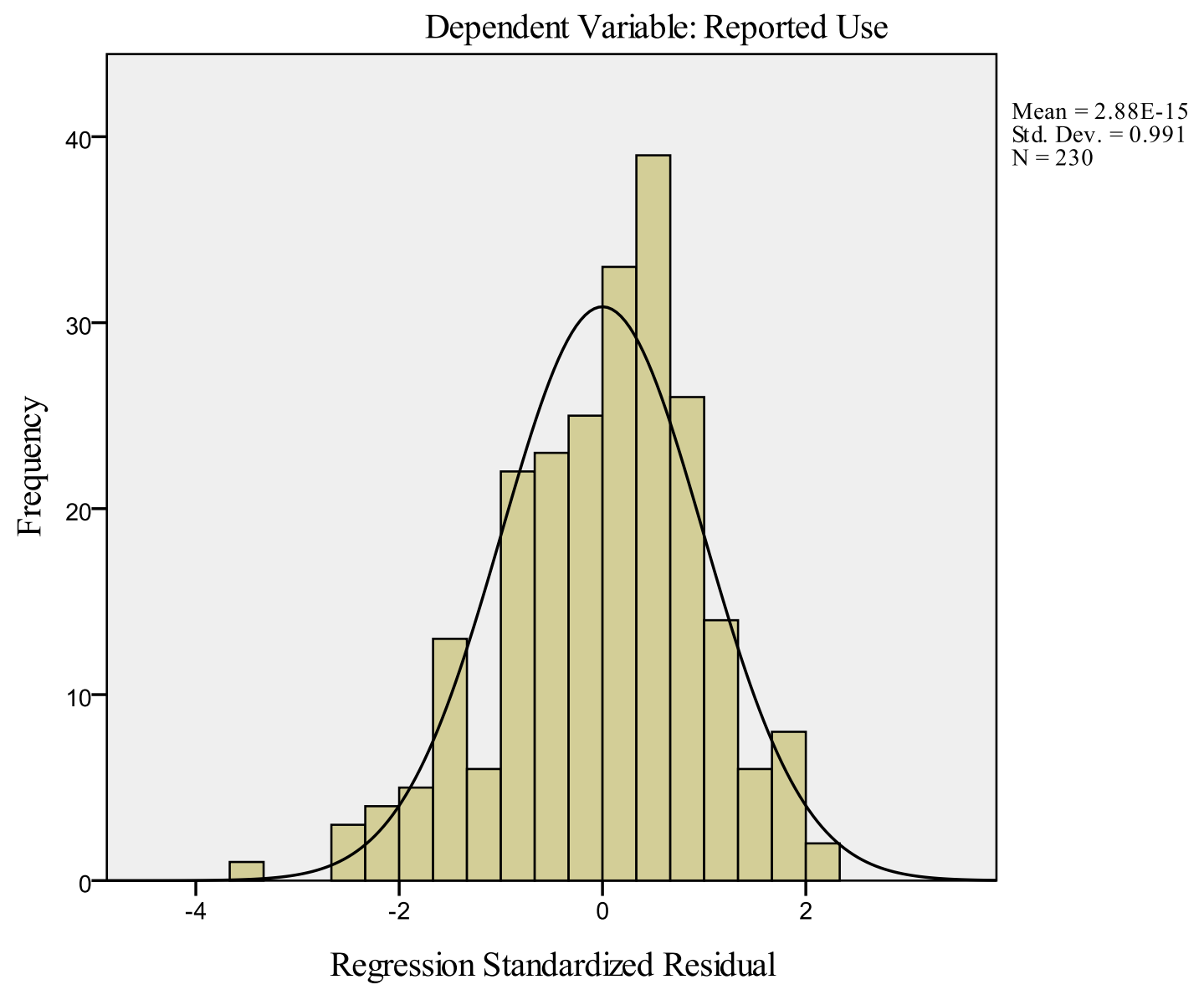


Figure I.v

Dependent variable: Reported use, normal P-P plot of regression standardized residual

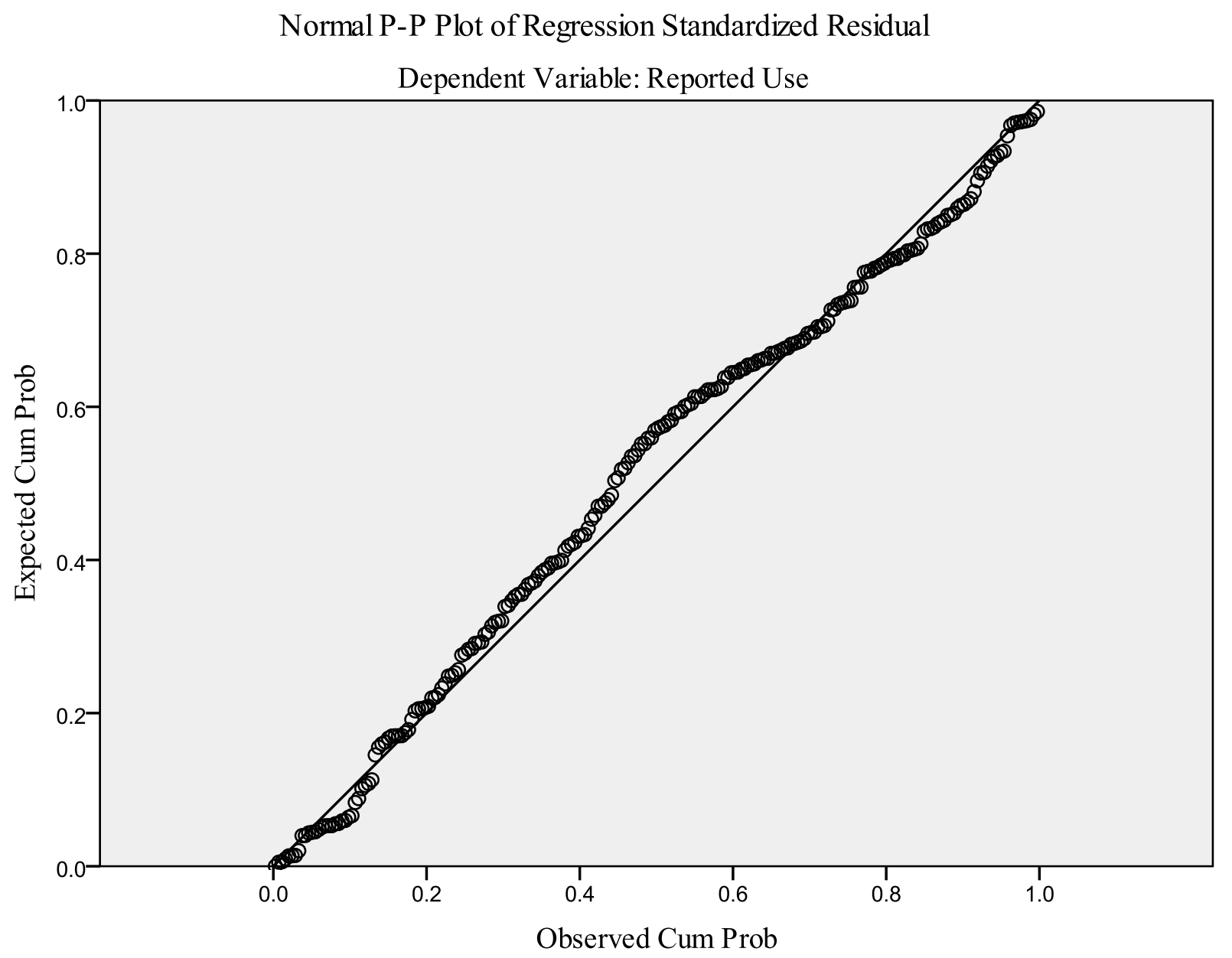


Figure I.vi

Dependent variable: Reported use, scatterplot

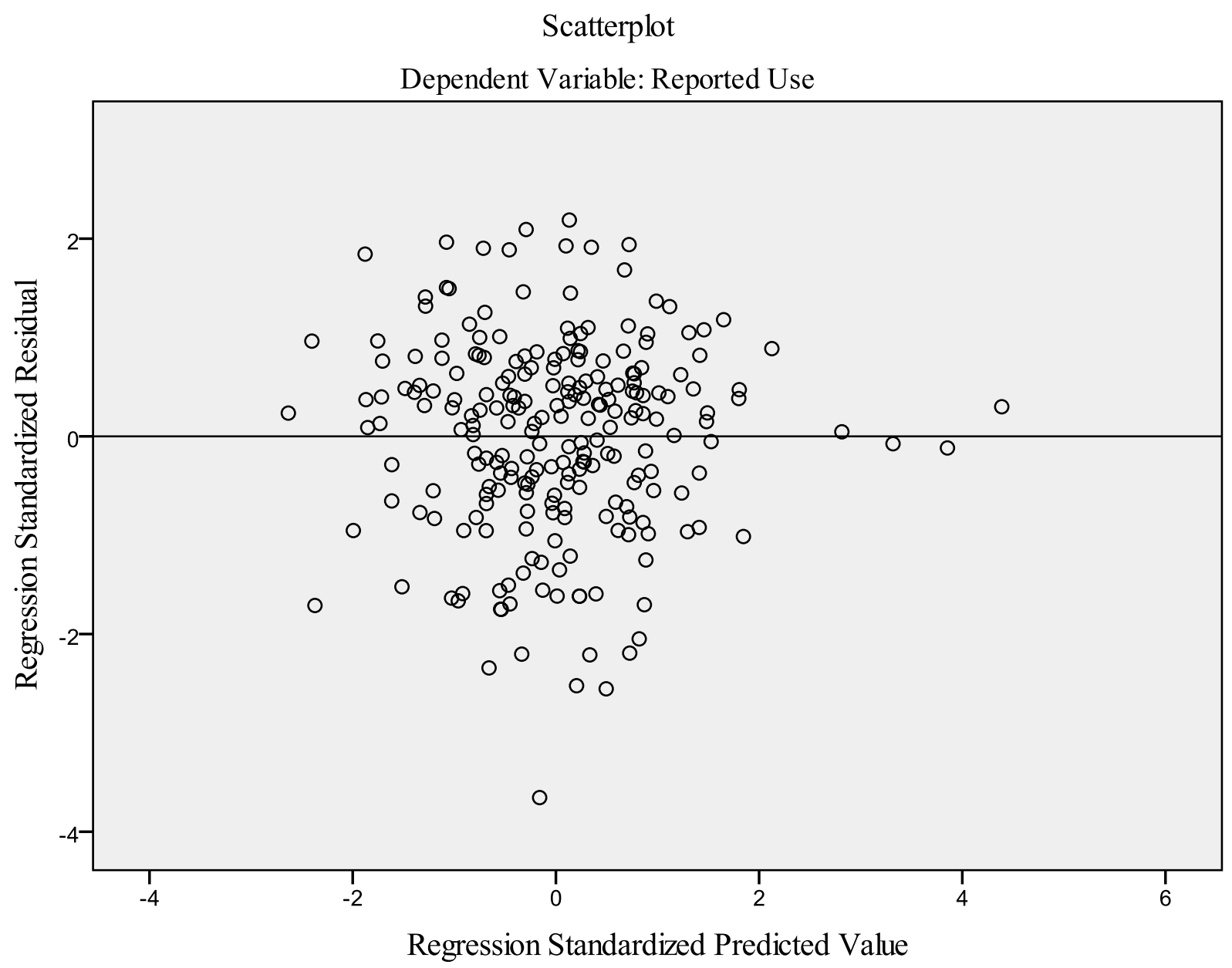


Table I.ii

Dependent variable: Reported use, collinearity statistics

\begin{tabular}{|c|c|c|c|c|c|c|c|}
\hline \multicolumn{8}{|c|}{ Coefficients $^{\mathrm{a}}$} \\
\hline & \multirow{2}{*}{\multicolumn{2}{|c|}{$\begin{array}{c}\text { Unstandardized } \\
\text { Coefficients } \\
\end{array}$}} & \multirow{2}{*}{$\begin{array}{l}\text { Standardized } \\
\text { Coefficients }\end{array}$} & & & \multirow{2}{*}{\multicolumn{2}{|c|}{$\begin{array}{c}\text { Collinearity } \\
\text { Statistics } \\
\end{array}$}} \\
\hline & & & & & & & \\
\hline \multirow[b]{2}{*}{ Model } & & Std. & & & & & \\
\hline & $\mathrm{B}$ & Error & Beta & $\mathrm{t}$ & Sig. & Tolerance & VIF \\
\hline (Constant) & 3.070 & .528 & & 5.813 & .000 & & \\
\hline MEAN_ATT & .502 & .095 & .338 & 5.277 & .000 & .917 & 1.091 \\
\hline \multirow[t]{2}{*}{ total_sla } & -.044 & .038 & -.075 & - & .246 & .917 & 1.091 \\
\hline & & & & 1.163 & & & \\
\hline TOTALPD & .005 & .002 & .180 & 2.901 & .004 & .976 & 1.024 \\
\hline Would you describe & -.118 & .252 & -.029 & -.467 & .641 & .991 & 1.009 \\
\hline \multicolumn{8}{|l|}{ yourself as being a Highly } \\
\hline \multicolumn{8}{|l|}{ Qualified Teacher (HQT) } \\
\hline \multicolumn{8}{|l|}{ according to the } \\
\hline requirements... & & & & & & & \\
\hline
\end{tabular}

a. Dependent Variable: Reported Use 